UCRL-ID-128409

\title{
Criticality Experiments with Mixed Plutonium and Uranium Nitrate Solution at a Plutonium Fraction of 0.4 in Slab Geometry
}

Bertram A. Pohl

Stewart C. Keeton

September 1997

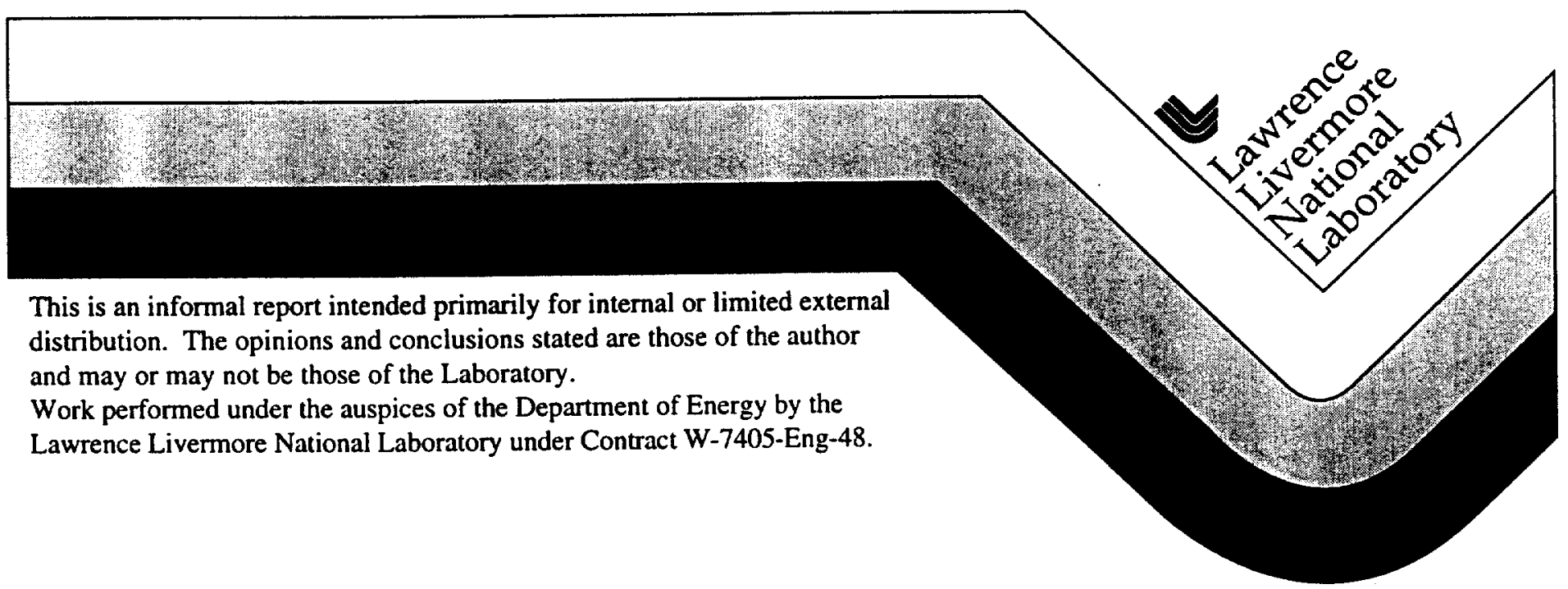




\section{DISCLAIMER}

This docurnent was prepared as an account of work sponsored by an agency of the United States Government. Neither the United States Government nor the University of California nor any of their employees, makes any warranty, express or implied, or assumes any legal liability or responsibility for the accuracy, completeness, or usefulness of any information, apparanus, product, or process disclosed, or represents that its use would not infringe privately owned rights. Reference herein to any specific commercial product, process, or service by trade name, trademark, manufacturer, or otherwise, does not necessarily constitute or imply its endorsement, recommendation, or favoring by the United States Government or the University of Califomia. The views and opinions of authors expressed herein do not necessarily state or reflect those of the United States Government or the University of Califomia, and shall not be used for advertising or product endorsement purposes.

This report has been reproduced directly from the best available copy.

Available to DOE and DOE contractors from the Office of Scientific and Technical Information P.O. Box 62, Oak Ridge, TN 37831

Prices available from (615) 576-8401, FTS 626-8401

Available to the public from the

National Technical Information Service

U.S. Department of Commerce

5285 Port Royal Rd.

Springfield, VA 22161 


\title{
MIX-SOL-THERM-005
}

\section{Criticality Experiments with Mixed Plutonium and Uranium Nitrate Solution at a Plutonium Fraction of 0.4 in Slab Geometry}

\author{
Evaluator \\ Bertram A. Pohl \\ Stewart C. Keeton \\ Lawrence Livermore National Laboratory \\ Internal Reviewer \\ Stewart C. Keeton \\ Bertram A. Pohl \\ Lawrence Livermore National Laboratory
}

Independent Reviewer

Virginia Dean

Consultant, Idaho National Engineering Laboratory 
The authors wish to thank Gary Smolen, currently with Parallax Inc., for his continuing assistance throughout this series of evaluations. His firsthand knowledge of the project and his willingness to share his insights with us, served to clarify many of the details of the PNL experiments. 


\section{CRITICALITY EXPERIMENTS WITH MIXED PLUTONIUM AND URANIUM NITRATE SOLUTION AT A PLUTONIUM FRACTION OF O.4 IN SLAB GEOMETRY}

\section{IDENTIFICATION NUMBER: MIX-SOL-THERM-005}

KEY WORDS: acceptable, bare, critical experiment, homogeneous solution, slab, moderated, plutonium, plutonium nitrate, solution, thermal, water-reflected, uranium, uranyl nitrate

\subsection{DETAILED DESCRIPTION}

\subsection{Overview of Experiment}

R. C. Lloyd of PNL has completed and published a series of critical experiments with mixed plutoniumuranium nitrate solutions (Reference 1). This series of critical experiments was part of an extensive program jointly sponsored by the U. S. Department of Energy (DOE) and the Power Reactor and Nuclear Fuel Development Corporation (PNC) of Japan and was carried out in the mid-1980's. The experiments evaluated here (published as Report PNL-6327) were performed with mixed plutoniumuranium nitrate solution in a variable thickness slab tank with two $106.7 \mathrm{~cm}$ square sides and a width that could be varied from 7.6 to $22.8 \mathrm{~cm}$. The objective of these experiments was to obtain experimental data to permit the validation of computer codes for criticality calculations and of crosssection data to minimize the uncertainties inherent therein, so that facility safety, efficiency, and reliability could be enhanced. The concentrations of the solution were about 105, 293, and 435 $\mathrm{g}(\mathrm{Pu}+\mathrm{U}) /$ /iter with a ratio of plutonium to total heavy metal (plutonium plus uranium) of about 0.40 for all eight experiments. Four measurements were made with a water reflector, and four with no reflector.

Following the publication of the initial PNL reports, considerable effort was devoted to an extensive reevaluation of this series of experiments by a collaboration of researchers from ORNL, PNL, and PNC (Reference 2). Their work resulted in a more accurate description of the "as built" hardware configuration and the materials specifications. For the evaluations in this report, the data published in Reference 2 by Smolen et al. is selected to supersede the original PNL report.

Eight experiments have been evaluated and seven $(063,064,071,072,074,075$, and 076) provide benchmark criticality data. Experiment 073 could not achieve criticality within vessel height limitations. 


\subsection{Description of the Experimental Configuration}

1.2.1 Room - The solution system is located in the critical assembly room at PNL, which is 10.67 meters square and has a ceiling height of 6.4 meters. Three side walls are composed of 1.52 metersthick-concrete; the south wall is 0.91 -meters-thick. Both the concrete ceiling and floor are 0.61 meters thick.

1.2.2 Bellows Assembly - The all stainless steel (Type 304L) slab tank holding the fissile solution is composed of two square sides each connected to four accordion-like sides joined to each other through a $2.54 \mathrm{~cm}$ spacer. (The spacer in the middle of the expandable side can be seen in Figure 3.) Because of these expandable sides, the width of the solution tank can be continuously varied from 7.6 to $22.8 \mathrm{~cm}$ in the north-south direction. The average height and width of the square faces of the slab solution tank were $106.7 \mathrm{~cm}$, measured from halfway between the peaks and troughs of the pleats in the expandable sides. Each of the four corners of the square faces was rounded on a $14.4 \mathrm{~cm}$ radius. A photograph of the bellows assembly is shown in Figure 1. The thickness of the steel forming the pleats is $0.079 \mathrm{~cm}$; the distance from a pleat trough to a pleat peak is $5.08 \mathrm{~cm}$ for a slab thickness of $15.2 \mathrm{~cm}$. Each expandable side bellows assembly contains a total of 10 peaks and 8 troughs; the peaks and troughs correspond to the outermost and innermost extent of the bellows, respectively. The square end plates of the bellows are $0.159 \mathrm{~cm}$ thick and are prevented from bulging by an attached egg-crate style support grid. The open grid has a square pitch spacing of $10.6 \mathrm{~cm}$, a depth of $11.43 \mathrm{~cm}$, and is constructed of $0.3175 \mathrm{~cm}$ stainless steel plates. The support grid maintains the position of the side to within a tolerance of 0.025 $\mathrm{cm}$ as the tank is filled. Schematic diagrams of this vessel system are shown in Figures 2 and 3.

1.2.3 Reflector Tank - The bellows assembly was housed in a cuboidal 304L stainless steel tank that could be filled to form a water reflector. The inside dimensions of the tank are $68.6 \mathrm{~cm}$ in the northsouth direction, $142.2 \mathrm{~cm}$ in the east-west direction and $143.5 \mathrm{~cm}$ high. The plates on the north and south sides are $0.635 \mathrm{~cm}$ thick; the others, including the bottom, are $0.476 \mathrm{~cm}$ thick. The bellows is raised $18.4 \mathrm{~cm}$ from the bottom of the reflector tank (measured from the midpoint of the bellows pleat). There is an equal space of $17.75 \mathrm{~cm}$ between the bellows and both the east and west sides of the reflector tank (measured from the midpoint of the bellows pleat). The north-south spacing of the bellows within the reflector tank is variable, depending on the particular experiment, from $25.6 \mathrm{~cm}$ to $33.2 \mathrm{~cm}$ on the south side, and $20.2 \mathrm{~cm}$ to $27.8 \mathrm{~cm}$ on the north side, for slab thicknesses of $22.8 \mathrm{~cm}$ (maximum extent) to $7.6 \mathrm{~cm}$ (minimum extent), respectively. The bottom of the reflector tank is situated $100.6 \mathrm{~cm}$ above the concrete floor. 
1.2.4 Containment Hood - The bellows and reflector tank system is additionally enclosed in a containment hood composed of $0.635-\mathrm{cm}$-thick stainless steel plates and 0.95 -cm-thick Plexiglas viewing windows. The east-west extent of the hood is $278.522 \mathrm{~cm}$, the north-south extent of the hood is $243.84 \mathrm{~cm}$. The north-west comer of the hood is located $183 \mathrm{~cm}$ from the north wall of the room and $152 \mathrm{~cm}$ from the west wall. Within the hood the broad faces of the reflector tank are situated $34.3 \mathrm{~cm}$ from the south hood wall and $138.4 \mathrm{~cm}$ from the north hood wall. The narrow faces of the reflector tank are situated $24.6 \mathrm{~cm}$ from the west hood wall and $109.5 \mathrm{~cm}$ from the east hood wall. The hood extends from the floor to $\sim 100 \mathrm{~cm}$ below the ceiling ${ }^{(a)}$. A photograph of the containment hood is shown in Figure 4. A $2.5 \mathrm{~cm}$ thick open steel grate catwalk placed $230 \mathrm{~cm}$ above the floor was mounted on the inside perimeter of the hood. The grate did not cover the slab tank and was predominately open space.

\footnotetext{
(a) No specification was listed for the height of the containment hood. The estimated height used in this model was based on the photograph in Figure 4.
} 


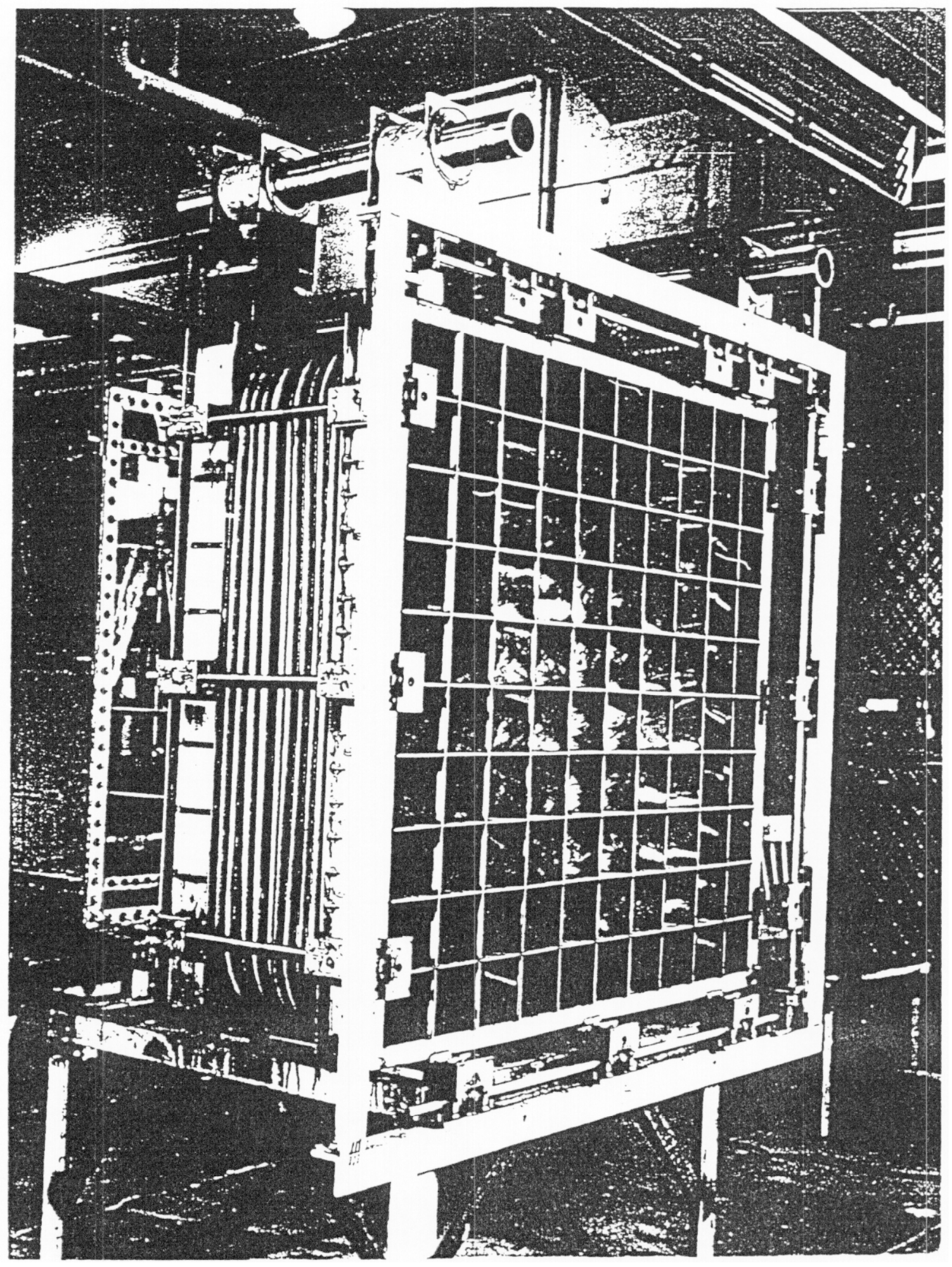

Figure 1. Photograph of the Slab Tank System (Reference 1, p. 2.11) 


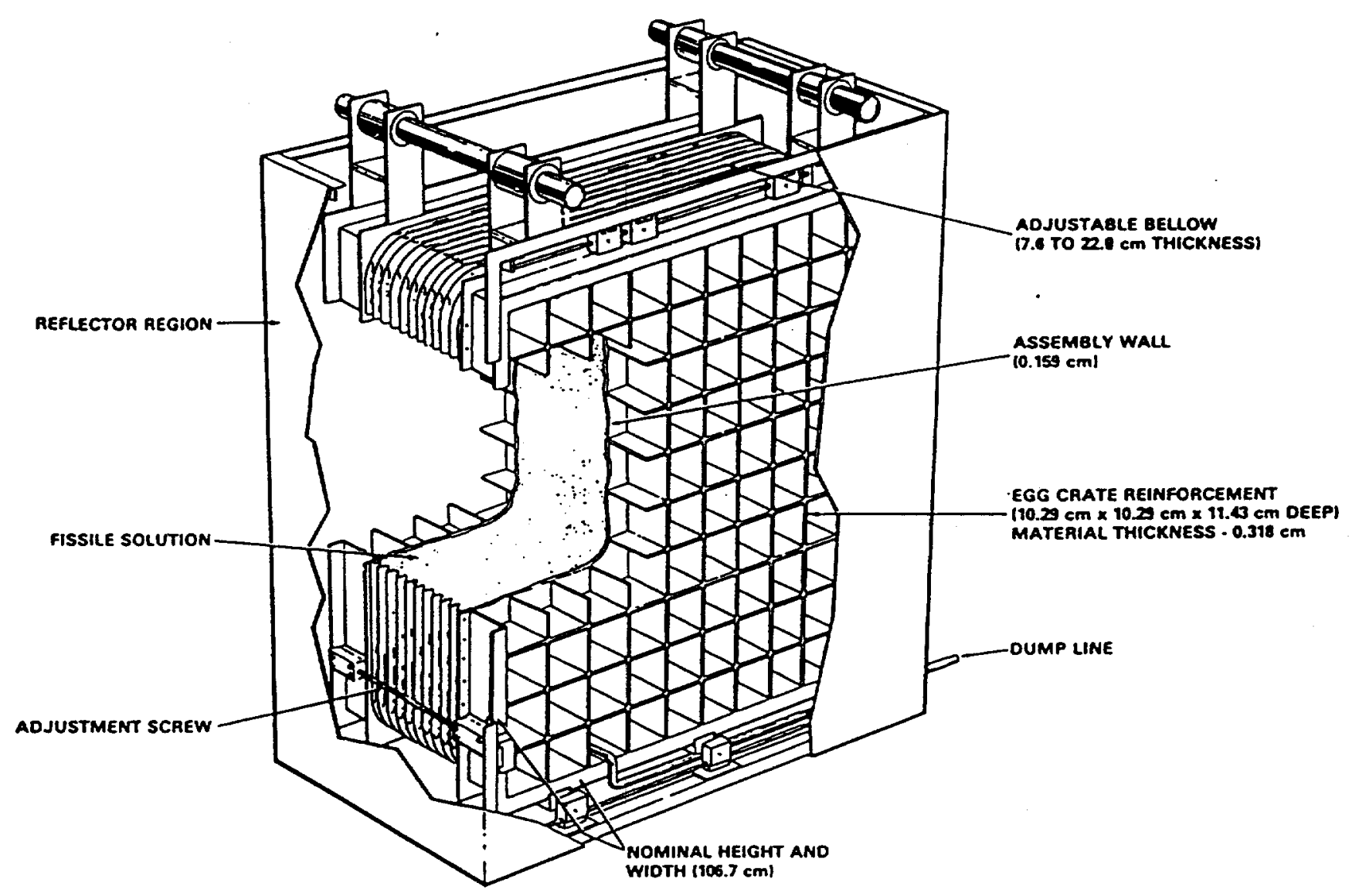

Figure 2. Schematic of Variable Thickness Slab Tank (Reference 2, p. 309). 


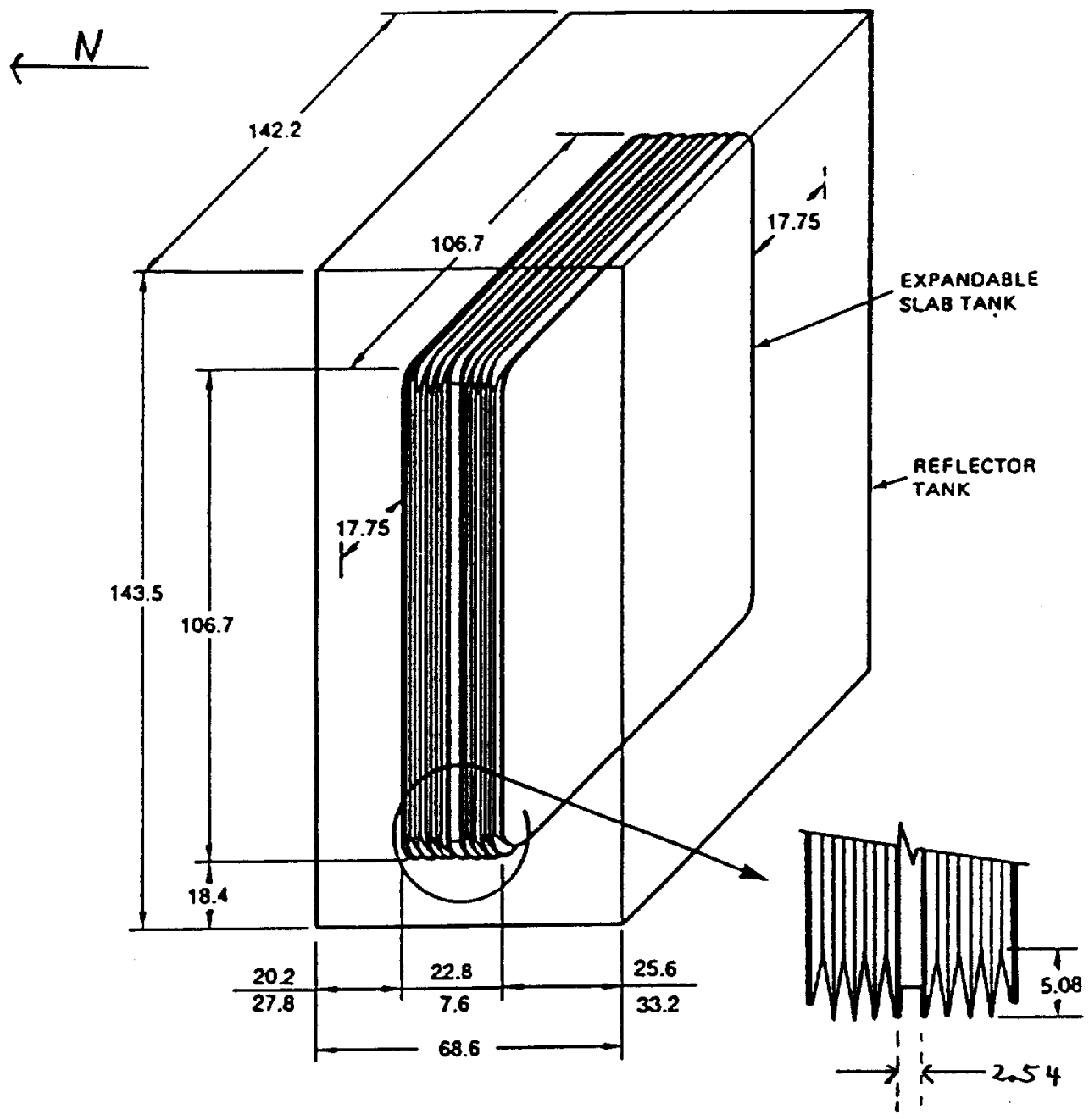

Figure 3. Schematic of the Slab Tank Inside of the Reflector Tank (Reference 2, p. 311). (dimensions in centimeters) 


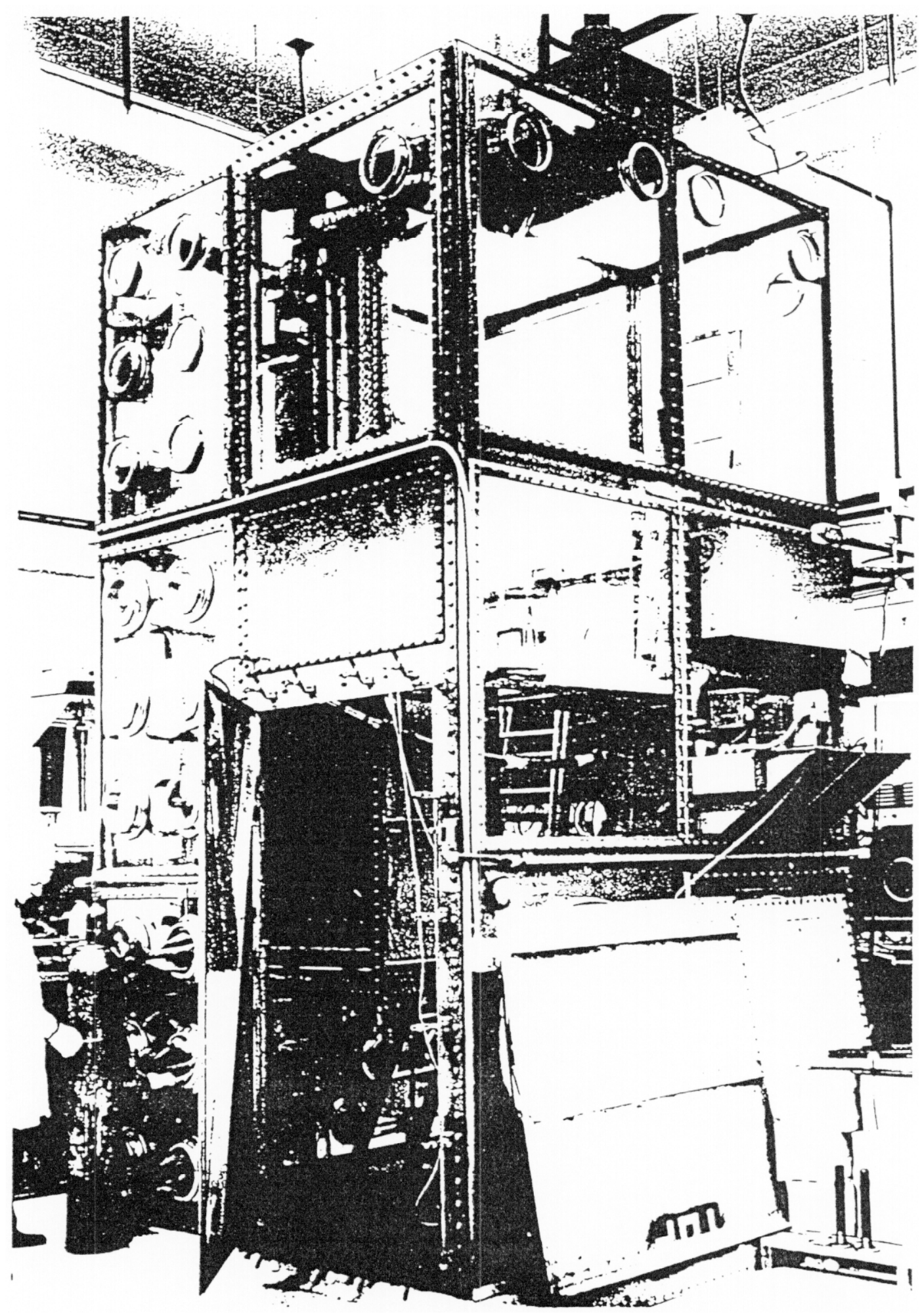

Figure 4. Photograph of the Containment Hood (Reference 2, p. 310) 
MIX-SOL-THERM-005

1.2.5 Critical Measurements - The critical heights for the experiments in this evaluation were determined using the critical approach method (Reference 3). Neutron flux measurements were made with three independent boron-lined proportional counters located at separate positions as the height of the solution was incrementally increased. A plot of solution height over count rate plotted as a function of solution height produces a straight line that extrapolates to zero at delayed critical. The uncertainty in the critical height was estimated to be $\pm 1.6 \mathrm{~mm}$.

The solution slab thickness for each experiment, the measured critical heights, and the temperatures of the reflector water, where applicable, are listed in Table 1. For the water-reflected experiments, the water level was even with the top of the slab tank (the midpoint of the upper bellows pleat). The empty reflector tank remained in place during the bare experiments.

Table 1. Slab Thickness and Critical Heights.

\begin{tabular}{|c|c|c|c|}
\hline $\begin{array}{c}\text { Experiment ID } \\
\text { number }\end{array}$ & $\begin{array}{c}\text { Reflector } \\
\left(\text { Temperature }^{\circ} \mathrm{C}\right)\end{array}$ & $\begin{array}{c}\text { Slab } \\
\text { Thickness (cm) }\end{array}$ & $\begin{array}{c}\text { Critical Height } \\
(\mathrm{cm})^{(\mathbf{a})}\end{array}$ \\
\hline \hline 063 & bare & 19.81 & 54.70 \\
\hline 064 & water $^{(\mathrm{b})}(17.3)$ & 13.97 & 80.14 \\
\hline 071 & water $^{(\mathrm{b})}(22.1)$ & 13.97 & 47.44 \\
\hline 072 & water $^{(\mathrm{b})}(22.7)$ & 12.70 & 67.16 \\
\hline 074 & bare & 18.03 & 70.13 \\
\hline 075 & bare & 19.05 & 85.38 \\
\hline 076 & water $^{(\mathrm{b})}(21.7)$ & 13.46 & 74.19 \\
\hline
\end{tabular}

(a) measured from the midpoint of the bottom pleats

(b) Water height is $106.7 \mathrm{~cm}$, measured from the midpoint of the bottom pleats of the slab tank.

\subsection{Description of the Material Data}

The solution was characterized by measuring the concentration of plutonium and uranium, the density of the solution, and the molarity of the free nitric acid. No data exists for the temperature of the fissile solution during the actual experiments, although temperatures for the fissile solution storage tank and the containment hood were reported. The estimated temperature range was from about $17^{\circ} \mathrm{C}$ to 30 ${ }^{\circ} \mathrm{C}$. The values of the solution parameters are given in Table 2 . 
MIX-SOL-THERM-005

Table 2. Solution Parameters. ${ }^{\text {(a) }}$

\begin{tabular}{||c|c|c|c|c||}
\hline $\begin{array}{c}\text { Experiment } \\
\text { Number }\end{array}$ & $\begin{array}{c}\text { Plutonium } \\
\text { Concentration } \\
{[\mathrm{g} / \mathrm{l}]}\end{array}$ & $\begin{array}{c}\text { Uranium } \\
\text { Concentration } \\
{[\mathrm{g} / \mathrm{l}]}\end{array}$ & $\begin{array}{c}\text { Solution } \\
\text { Density } \\
{[\mathrm{g} / \mathrm{ml}]}\end{array}$ & $\begin{array}{c}\text { Free } \\
\text { Nitric Acid } \\
{[\mathrm{M}]}\end{array}$ \\
\hline \hline 063 & 41.06 & 62.89 & 1.1725 & 0.61 \\
\hline 064 & 41.90 & 63.36 & 1.1752 & 0.61 \\
\hline 071 & 118.87 & 173.48 & 1.4633 & 1.03 \\
\hline 072 & 118.87 & 173.48 & 1.4633 & 1.03 \\
\hline 074 & 119.04 & 174.01 & 1.4637 & 1.04 \\
\hline 075 & 172.77 & 262.81 & 1.6703 & 1.24 \\
\hline 076 & 172.68 & 262.94 & 1.6699 & 1.24 \\
\hline
\end{tabular}

(a) The PNL-estimated uncertainties were: plutonium or uranium concentration $\pm 0.2 \%$, solution density $\pm 0.0003 \mathrm{~g} / \mathrm{cm}^{3}$, and free nitric acid $\pm 0.04 \mathrm{M}$.

(b) Measured at $23^{\circ} \mathrm{C}$.

The ${ }^{241}$ Am concentration was measured in 30 chemical analyses spaced over a four year period. Since the ${ }^{241} \mathrm{Am}$ concentration depends on the radioactive decay of ${ }^{241} \mathrm{Pu}$, the ${ }^{241} \mathrm{Am}$ concentration should be a smooth time-dependent function. Smolen, et al. (Reference 2, p.310) performed a linear regression analysis on the concentration data and developed an analytic expression for the relative ${ }^{241}$ Am concentration as a function of time for all of the experiments studied here. The relative concentration is given in terms of $\mathrm{mg}^{241} \mathrm{Am}$ per $\mathrm{g} \mathrm{Pu}$ and is given by:

$$
{ }^{241} \mathrm{Am}=4.950+5.921 \times 10^{-4} \times t
$$

where $t$ is the time in days from January 1, 1985 that the experiment in question was run, and this is listed in Table 3. The predicted ${ }^{241}$ Am concentrations in $\mu \mathrm{g}^{241} \mathrm{Am}$ per $\mathrm{ml}$ for all experiments dealt with in this report are also given in Table 3.

Table 3. Run Dates for Experiments and Corresponding Time in Days from January 1, 1985, and Concentration Values for Americium-241.

\begin{tabular}{|c|c|c|c|c||}
\hline $\begin{array}{c}\text { Experiment } \\
\text { Number }\end{array}$ & $\begin{array}{c}\text { Sample } \\
\text { Number }\end{array}$ & Run Date & $\begin{array}{c}t \\
(\text { days })\end{array}$ & $\begin{array}{c}{ }^{241} \mathrm{Am}^{(\mathrm{s})} \\
(\mu \mathrm{g} / \mathrm{ml})\end{array}$ \\
\hline \hline 063 & 1153 & $2-04-86$ & 399 & 212.95 \\
\hline 064 & 1154 & $2-10-86$ & 405 & 217.45 \\
\hline 071 & 1166 & $3-13-86$ & 436 & 619.09 \\
\hline 072 & 1166 & $3-14-86$ & 437 & 619.16 \\
\hline 074 & 1167 & $3-18-86$ & 441 & 620.33 \\
\hline 075 & 1170 & $4-22-86$ & 476 & 903.90 \\
\hline 076 & 1171 & $4-23-86$ & 477 & 903.54 \\
\hline
\end{tabular}

(a) The concentration values are given to five significant figures to avoid roundoff problems when attempting to reproduce the number densities for ${ }^{241} \mathrm{Am}$ in Tables 16-22. 
The data for the isotopic values for the plutonium and uranium of the experiments were reevaluated by Smolen, et al. (Reference 2, p. 310 and Table V, p. 313). Using their results, the isotopic composition for Pu and $\mathrm{U}$ is shown in Tables 4 and 5 in wt.\%. All experiments evaluated in this report have the same isotopic values.

Table 4. Isotopic Analyses Values of Pu for All Experiments.

\begin{tabular}{||c|c|c|c|r|}
\hline $\begin{array}{c}238 \mathrm{Pu} \\
\mathrm{Wt} . \%\end{array}$ & $\begin{array}{c}{ }^{239} \mathrm{Pu} \\
\mathrm{Wt} . \%\end{array}$ & $\begin{array}{c}240 \mathrm{Pu} \\
\mathrm{Wt} . \%\end{array}$ & $\begin{array}{c}{ }^{241} \mathrm{Pu} \\
\mathrm{Wt} . \%\end{array}$ & $\begin{array}{l}{ }^{242} \mathrm{Pu} \\
\mathrm{Wt} . \%\end{array}$ \\
\hline \hline $0.029 \pm 0.001$ & $91.118 \pm 0.02$ & $8.310 \pm 0.02$ & $0.450 \pm 0.004$ & $0.093 \pm 0.002$ \\
\hline
\end{tabular}

Table 5. Isotopic Analyses Values of U for All Experiments.

\begin{tabular}{|c|c|c|c|}
\hline \hline $\begin{array}{c}238 \mathrm{U} \\
\mathrm{Wt} . \%\end{array}$ & ${ }^{236} \mathrm{U}$ & ${ }^{235} \mathrm{U}$ & ${ }^{234} \mathrm{U}$ \\
\hline $\mathrm{Wt} . \%$ & $\mathrm{Wt} . \%$ & Wt.\% \\
\hline \hline $99.406 \pm 0.004$ & $0.023 \pm 0.001$ & $0.564 \pm 0.005$ & $0.007 \pm 0.001$ \\
\hline
\end{tabular}




\section{MIX-SOL-THERM-005}

Selected data of impurity concentrations were also reevaluated and averaged for experiments coming from the same parent solution by Smolen, et al. (Reference 2, Table VII). By averaging the appropriate impurity measurements obtained from the Inductively Coupled Plasma (ICP) Atomic Emission Spectroscopy method the uncertainty in impurity concentration can be reduced to \pm 25 percent. The averaged impurity concentrations, in $\mu \mathrm{g}$ impurity per $\mathrm{g} \mathrm{Pu}$, for all impurities measured are listed in Table 6. Impurities were measured by Spark Source Mass Spectroscopy, with an estimated factor-of-3 uncertainty, unless otherwise noted in Table 6.

Table 6. Analysis of Impurities.

\begin{tabular}{||c|c||c|c||c|c||}
\hline Element & $\begin{array}{c}\text { Impurity } \\
\text { Concentration } \\
(\mu \mathrm{g} / \mathrm{g} \mathrm{Pu})\end{array}$ & Element & $\begin{array}{c}\text { Impurity } \\
\text { Concentration } \\
(\mu \mathrm{g} / \mathrm{g} \mathrm{Pu})\end{array}$ & Element & $\begin{array}{c}\text { Impurity } \\
\text { Concentration } \\
(\mu \mathrm{g} / \mathrm{g} \mathrm{Pu})\end{array}$ \\
\hline \hline $\mathrm{Al}$ & $950^{(\mathrm{a})}$ & $\mathrm{Fe}$ & $2935^{(\mathrm{a})}$ & $\mathrm{Nd}$ & 20 \\
\hline $\mathrm{B}$ & $49^{(\mathrm{b})}$ & $\mathrm{Gd}$ & 11 & $\mathrm{Ni}$ & $542^{(\mathrm{a})}$ \\
\hline $\mathrm{Ba}$ & 46 & $\mathrm{~K}$ & 94 & $\mathrm{Rh}$ & 75 \\
\hline $\mathrm{Ca}$ & $598^{(\mathrm{a})}$ & $\mathrm{La}$ & 5 & $\mathrm{Ru}$ & 27 \\
\hline $\mathrm{Cd}$ & $57^{(\mathrm{a})}$ & $\mathrm{Li}$ & 3 & $\mathrm{Si}$ & 556 \\
\hline $\mathrm{Ce}$ & 46 & $\mathrm{Mg}$ & 154 & $\mathrm{Sr}$ & 2 \\
\hline $\mathrm{Cr}$ & $746^{(2)}$ & $\mathrm{Mn}$ & $148^{(2)}$ & $\mathrm{Ti}$ & $225^{(\mathrm{a})}$ \\
\hline $\mathrm{Cu}$ & 163 & $\mathrm{Mo}$ & 10 & $\mathrm{Zn}$ & 48 \\
\hline $\mathrm{Dy}$ & 7 & $\mathrm{Na}$ & 470 & $\mathrm{Zr}$ & 45 \\
\hline
\end{tabular}

(a) $\pm 25 \%$; measured by ICP method (Reference 2)

(b) $\pm 70 \%$ (Reference 2)

The density and composition of stainless steel $304 \mathrm{~L}$ is given in Table 7.

Table 7. Density(a) and Composition(b) for Stainless Steel 304L.

\begin{tabular}{||c|c|}
\hline Element & Wt.\% \\
\hline \hline Stainless Steel 304L & (density $=8.02 \mathrm{~g} / \mathrm{ml}$ ) \\
\hline $\mathrm{C}$ & $0.03 \mathrm{Max}$ \\
\hline $\mathrm{Mn}$ & $2.0 \mathrm{Max}$ \\
\hline $\mathrm{P}$ & $0.045 \mathrm{Max}$ \\
\hline $\mathrm{S}$ & $0.03 \mathrm{Max}$ \\
\hline $\mathrm{Si}$ & $1.00 \mathrm{Max}$ \\
\hline $\mathrm{Cr}$ & $18.00-20.00$ \\
\hline $\mathrm{Ni}$ & $8.00-10.00$ \\
\hline $\mathrm{Fe}$ & $66.895-74.00$ \\
\hline
\end{tabular}

(a) R.C. Weast, et al., page D-186, Handbook of Chemistrv and Physics; 70th Edition, CRC Press, Inc. (1989)

(b) Ibid., page F-135. The minimum Fe value results from subtracting the maximum composition of all other elements from $100 \%$, and the maximum Fe value results from subtracting the minimum composition (or zero) of all other elements. 


\subsection{EVALUATION OF PUBLISHED DATA}

The experiments are documented in extreme detail and are presented in a well organized format. All relevant data are included in the report (Reference 1). Engineering drawings were provided in PNL5768 (Lloyd 1986) (Reference 4) for the slab tank system. These drawings contain design dimensions used for fabrication of the hardware; they agree quite well with those actually measured by Smolen et al. (References 2 and 5).

The density and composition of the concrete chosen for the models of the walls, floor and ceiling are listed in Table 8. No actual description of the structural room concrete composition was supplied in the PNL report. The composition chosen is the same concrete composition and density specified in Reference 1 for a companion experiment in which an annular concrete collar was used to shroud a small cylindrical reaction vessel (MIX-SOL-THERM-004).

Table 8. Density(a) and Composition ${ }^{(b)}$ for Concrete.

\begin{tabular}{||c|c|}
\hline \multicolumn{1}{||c|}{ Element } & Wt.\% \\
\hline \hline Concrete & (density $=2.33 \mathrm{~g} / \mathrm{ml}$ ) \\
\hline $\mathrm{O}$ & 51.91 \\
\hline $\mathrm{Si}$ & 23.10 \\
\hline $\mathrm{Ca}$ & 12.00 \\
\hline $\mathrm{Al}$ & 4.79 \\
\hline $\mathrm{Fe}$ & 3.37 \\
\hline $\mathrm{Na}$ & 1.43 \\
\hline $\mathrm{H}$ & 1.05 \\
\hline $\mathrm{Mg}$ & 0.92 \\
\hline $\mathrm{K}$ & 0.72 \\
\hline $\mathrm{S}$ & 0.38 \\
\hline $\mathrm{Ti}$ & 0.33 \\
\hline
\end{tabular}

(a) Corrected density as given on page 306 in Reference 2 .

(b) Composition as given in Table F.3, page F.3 in Reference 1.

All of the ONEDANT calculations referred to in this section were performed using SCALE 27-group ENDF/B-IV cross sections, with $\mathrm{S}_{+8}$ angular quadrature, and with inner loop convergence parameter equal to $10^{-6}$. 


\subsection{Measurement Uncertainties}

The PNL documentation (Reference 1) and Smolen, et. al. (Reference 2) identify seven sources of experimental uncertainty accompanied by estimated magnitudes. They are listed in Tables 9 and 10 .

Table 9. Effects on $\mathrm{k}_{\text {eff }}$ Due to Some PNL-Estimated Experimental Uncertainties (Reference 1)

\begin{tabular}{|c|c|c|c|c|}
\hline $\begin{array}{l}\text { Solution } \\
\text { Parameter Varied }\end{array}$ & PNL-Estimated Uncertainty & $064 \Delta \mathrm{k}_{\text {eff }}$ & $\begin{array}{r}\text { Experiment } \\
071 \Delta \mathrm{k}_{\text {eff }} \\
\end{array}$ & $076 \Delta \mathrm{k}_{\mathrm{eff}}$ \\
\hline Pu concentration & $\pm 0.2 \%$ & 0.0002 & 0.0003 & 0.0005 \\
\hline U concentration & $\pm 0.2 \%$ & 0.0004 & 0.0005 & 0.0006 \\
\hline Density & $\pm 0.0003 \mathrm{~g} / \mathrm{cm}^{3}$ & 0.0003 & 0.0003 & 0.0001 \\
\hline Free Acid & $\pm 0.04 \mathrm{M}$ & 0.0014 & 0.0011 & 0.0013 \\
\hline
\end{tabular}

\begin{tabular}{||l|l|c|c||}
\hline \hline $\begin{array}{l}\text { Geometric } \\
\text { Parameter Varied }\end{array}$ & PNL-Estimated Uncertainty & $\Delta \mathrm{k}_{\text {eff }}^{(\mathrm{a})}$ & $\sigma \Delta \mathrm{k}_{\text {eff }}{ }^{(\mathrm{b})}$ \\
\hline \hline Critical Slab Thickness & $\pm 0.5 \mathrm{~mm}$ & 0.0002 & \pm 0.0001 \\
\hline Critical Slab Height & $\pm 1.6 \mathrm{~mm}$ & 0.0005 & \pm 0.0001 \\
\hline
\end{tabular}

(a) Common for all experiments

(b) The uncertainty in $\Delta \mathrm{k}_{\mathrm{eff}}$ is due to the subtraction of two Monte Carlo $\mathrm{k}_{\mathrm{eff}}$ values each of which is uncertain.

There were essentially three different solution densities used in the experimental investigation; see Table 2. The water-reflected experiments were chosen as reference systems to investigate the effects of each of these uncertainties because they are essentially fully water reflected and so it is not necessary to include external reflector objects. The effect of the experimental uncertainty in the first four parameters was estimated by constructing an analog of experiments 064,071 , and 076 with spherical symmetry and performing ONEDANT calculations.

To estimate the effect of the experimental uncertainty in the critical slab height for these experiments, MCNP calculations were performed with the solution at the measured critical height and at the critical height $\pm 8 \mathrm{~mm}$. To estimate the effect of the experimental uncertainty in the critical slab thickness for these experiments, MCNP calculations were performed with the solution thickness at the measured critical thickness and at the critical thickness $\pm 2.5 \mathrm{~mm}$. The three data points for each experiment were then used to determine the slope of the $k_{\text {eff }}$ versus critical dimension curve. The changes in reactivity for the corresponding six sources of experimental uncertainty are listed in Table 9. 


\section{MIX-SOL-THERM-005}

The experimenters make particular note of the fact that the "free acid" analysis had previously been prone to error. The analyses of the solution data samples used in this experiment were performed using the method developed by J. L. Ryan", and they indicate that this "significantly" reduced the uncertainties in this crucial measurement. The nitrate concentration was not specified, however. It is recognized that an independent measurement of the nitrate concentration would enhance the accuracy of the solution assay.

Errors associated with uncertainties in the concrete composition of the floor, walls, and ceiling of the room are were evaluated by comparisons made using MCNP with two other standard concrete mixtures, "KENO Regular" mix and "Los Alamos MCNP" mix'. The effects are inconsequential.

Table 10. Effects on $\mathrm{k}_{\text {eff }}$ Due to Differing Concrete Mixtures

\begin{tabular}{|l|c|c|}
\hline Concrete Mix Used to Compare Effects & $\Delta \mathrm{k}_{\text {eff }}$ & $\sigma \Delta \mathrm{k}_{\text {eff }}$ \\
\hline \hline KENO Regular & 0.0005 & \pm 0.0011 \\
\hline Los Alamos MCNP & 0.0003 & \pm 0.0011 \\
\hline
\end{tabular}

The effects on $\mathrm{k}_{\mathrm{eff}}$ due to the uncertainties on solution temperature are given in Table 11. Following Smolen, et. al. (Reference 2), the solution temperature was assumed to be $23^{\circ} \mathrm{C}$ for all experiments, the temperature at which density measurements were made. The effect of the experimental uncertainty in the solution temperature was estimated by using the spherical analog of experiments 064,071 , and 076 mentioned above and performing ONEDANT calculations.

The water temperature of the reflector in the water reflected experiments was taken as the value measured during the experiments. The uncertainty in $k_{\text {eff }}$ due to the uncertainty in the water-reflector temperature is expected to be very small, and therefore was not calculated.

Table 11. Temperature Effects on $\mathrm{k}_{\text {eff }}$ Due to Some Estimated Experimental Uncertainties by Smolen, et. al. (Reference 2) on the Water Reflected Experiments.

\begin{tabular}{|c|c|c|c|c|}
\hline Parameter Varied & $\begin{array}{l}\text { Estimated Uncertainty } \\
\text { (Reference 2) }\end{array}$ & $064 \Delta \mathrm{k}_{\mathrm{eff}}$ & $\begin{array}{r}\text { Experiment } \\
071 \Delta \mathrm{k}_{\text {eff }} \\
\end{array}$ & $076 \Delta \mathrm{k}_{\mathrm{eff}}$ \\
\hline Solution Temperature ${ }^{(a)}$ & $\pm 7^{\circ} \mathrm{C}$ & 0.0018 & 0.0018 & 0.0016 \\
\hline
\end{tabular}

(a) Smolen, et. al. determined, based on empirical density data for $\mathrm{Pu}$ and $\mathrm{U}$ solutions, that the $\mathrm{Pu}+\mathrm{U}$ solution concentrations would decrease by $0.34 \%$ due to an increase in solution temperature of $+7^{\circ} \mathrm{C}$. Therefore, the concentration of each solution element was decreased by $0.3+\%$ in determining $\Delta \mathrm{k}_{\text {efr. }}$.

\footnotetext{
"J. L. Ryan et al., Preparation of Acid Standards for and Determination of Free Acid in Concentrated PlutoniumUranium Solutions, Analytical Chemistry. 57:1+23-1427 (1985)

${ }^{b}$ C. D. Harmon,II et al., Criticality Calculations with .MC.MP: A Primer, LA-12827-M Manual, C-4, (1994)
} 
The experimental standard deviations, $\sigma$, of the solution-height zero intercept from the least squares fits to experimental data are given in Table 12 (Reference 1, Figures C-1 through C-14 in Appendix C.). The critical height is also reproduced from Table 1. The value of $\sigma$ for Experiment 075 is about two times larger than the next largest $\sigma$. Nothing was said in the PNL report regarding the increased size of $\sigma$ for this experiment, and there is nothing unusual appearing in the least squares plot shown in Figure C. 13 to suggest an explanation.

Table 12. Standard Deviations of Critical Heights.

\begin{tabular}{||c|c|c||}
\hline $\begin{array}{c}\text { Experiment } \\
\text { ID number }\end{array}$ & $\begin{array}{c}\text { Critical Height } \\
(\mathrm{cm})\end{array}$ & $\begin{array}{c}\sigma \\
(\mathrm{mm})\end{array}$ \\
\hline \hline 063 & 54.70 & 0.26 \\
\hline 064 & 80.14 & 0.24 \\
\hline 071 & 47.44 & 0.22 \\
\hline 072 & 67.16 & 0.49 \\
\hline 074 & 70.13 & 0.50 \\
\hline 075 & 85.38 & 1.23 \\
\hline 076 & 74.19 & 0.19 \\
\hline
\end{tabular}

Table 12 shows that all of the standard deviations from the least squares fits to the experimental data are less than the experimental uncertainty of $\pm 1.6 \mathrm{~mm}$ reported in Table 9 . 
MIX-SOL-THERM-005

\subsection{BENCHMARK SPECIFICATIONS}

\subsection{Description of Model}

The pleated bellows assembly used for the variable-width slab tank is difficult, if not impossible, to accurately model with many common code/cross-section packages. To allow use of less sophisticated geometry capabilities of many modeling codes, a simplification of the bellows assembly was developed. In order to justify the simple model, an exact model of one of the slab tank configurations was prepared for input into MCNP (see Appendix B) and the results were compared to those represented by the simple model. The aim of this exercise was to generate a rectangular cuboid model for the reaction vessel that would neutronically represent the bellows. The largest obstacle was finding an appropriate thickness for the flat surface approximation needed to replace the four non-orthogonally pleated sides of the tank (see Figure 5.). This process was achieved through a sensitivity study described later in this section.

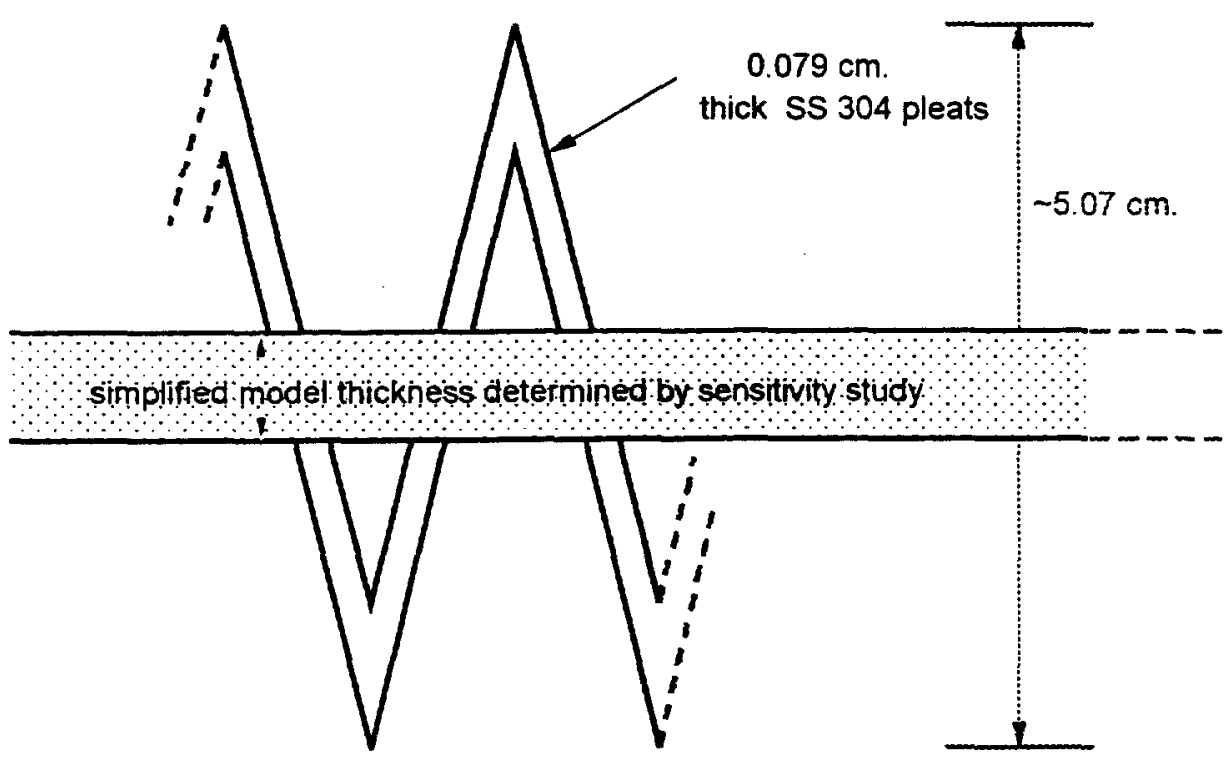

Figure 5. Model Simplification of the Bellows

For water-reflected cases additional simplifications were made to the benchmark model. Previous benchmark evaluations were reported for the small and large cylinders and the annular cylinders using the same solution system in the critical assembly room at PNL (MIX-SOL-THERM-001, MIX-SOLTHERM-002, and MIX-SOL-THERM-004). All three of the previous benchmark calculations involving small and large cylinders as well as annular cylinders indicated that for the water-reflected experiments, simpler benchmark models could be developed from the more complex version of the model of the actual experiment. For these cases, it was not necessary to include the details of the room and equipment in the room outside of the reflector material, since few neutrons escape from the water and return into the fissile material. For this evaluation we were able to eliminate the containment hood, floor and walls from the water reflected cases. 
Two simplified benchmark models were developed for these experiments:

(1) Water reflected cases: Only the cuboidal representation of the slab tank, reinforcing eggcrate support grid, water, and reflector tank faces are included.

(2) Bare cases:

In addition, the containment hood, floor, ceiling, and walls are included.

\section{Reaction Vessel}

The benchmark model for the fuel solution slab consists of a cuboid with square sides $106.7 \mathrm{~cm}$ in height and width. The width of the slab of solution (inner width of the slab tank) varied from one experiment to the other and is listed in Table 13 below. The distances from the solution's square surfaces to the inner reflector tank walls are also given in Table 13.

Table 13. Solution Slab Placement Within the Reflector Tank and Slab Width.

\begin{tabular}{|c|c||c|c|}
\hline $\begin{array}{c}\text { Experiment ID } \\
\text { Number }\end{array}$ & $\begin{array}{c}\text { Distance of Fuel Surface } \\
\text { from Inner North } \\
\text { Reflector-Tank Wall }(\mathrm{cm})\end{array}$ & $\begin{array}{c}\text { Distance of Fuel } \\
\text { Surfacefrom Inner South } \\
\text { Reflector-Tank Wall }(\mathrm{cm})\end{array}$ & $\begin{array}{c}\text { Slab Fuel } \\
\text { Width } \\
(\mathrm{cm})\end{array}$ \\
\hline 063 & 21.695 & 27.095 & 19.81 \\
\hline 064 & 24.615 & 30.015 & 13.97 \\
\hline 071 & 24.615 & 30.015 & 13.97 \\
\hline 072 & 25.250 & 30.650 & 12.70 \\
\hline 074 & 22.585 & 27.985 & 18.03 \\
\hline 075 & 22.075 & 27.475 & 19.05 \\
\hline 076 & 24.870 & 30.270 & 13.46 \\
\hline
\end{tabular}

The benchmark model for the slab tank reaction vessel consists of a stainless steel cuboid with square sides $106.7 \mathrm{~cm}$ in height and width. These square end plates are $0.159 \mathrm{~cm}$ thick. The square faces of the tank are reinforced by an egg-crate style support grid. The grid has a square pitch spacing of $10.6 \mathrm{~cm}$, a depth of $11.43 \mathrm{~cm}$, and is constructed of $0.3175-\mathrm{cm}$ stainless steel. The thickness of the slab tank plates that replace the pleated sides of the bellows assembly (as determined by a sensitivity study) is $0.316 \mathrm{~cm}$. Using this thickness for the replacement plates, the outside height and width of the reaction vessel is $107.332 \mathrm{~cm}$. 


\section{Reflector Tank}

The cuboidal reaction vessel is located inside a cuboidal $304 \mathrm{~L}$ stainless steel reflector tank that contains water to form a water reflector. The inside dimensions of the tank are $68.6 \mathrm{~cm}$ in the north-south direction, $142.2 \mathrm{~cm}$ in the east-west direction and $143.5 \mathrm{~cm}$ high. The north and south sides of the tank are $0.635 \mathrm{~cm}$ thick; the other sides and bottom are $0.476 \mathrm{~cm}$ thick. The outside bottom of the reaction vessel is $18.084 \mathrm{~cm}$ above the inside bottom of the reflector tank and there is a space of $17.434 \mathrm{~cm}$ between the side replacing the bellows and the east and west sides of the reflector tank. The northsouth spacing of the vessel within the reflector tank is variable (see Table 13) depending on the particular experiment. The bottom of the reflector tank is $100.6 \mathrm{~cm}$ above the floor.

Containment Hood (pertains to bare experiments only)

The reaction vessel and reflector tank system is additionally enclosed in a containment hood. In the benchmark model, the hood is composed of 0.635 -cm-thick stainless steel plates. The east-west extent of the hood is $278.522 \mathrm{~cm}$, the north-south extent of the hood is $243.84 \mathrm{~cm}$. The north-west corner of the hood is located $183 \mathrm{~cm}$ from the north wall and $152 \mathrm{~cm}$ from the west wall. Within the hood the broad faces of the reflector tank are situated $34.3 \mathrm{~cm}$ from the south hood wall and $138.4 \mathrm{~cm}$ from the north hood wall. The narrow faces of the reflector tank are situated $24.6 \mathrm{~cm}$ from the west hood wall and $109.5 \mathrm{~cm}$ from the east hood wall. The hood extends from the floor to $100 \mathrm{~cm}$ below the ceiling. (The Plexiglas windows are not included in the benchmark model.)

Room (pertains to bare experiments only)

The solution system is located in a room which is 10.67 meters square and has a ceiling height of 6.4 meters. Three of the side walls are composed of 1.52 -meters-thick concrete; the south wall is 0.91 meters thick. The concrete ceiling and floor are each 0.61 meters thick. Since no description of the structural concrete composition was supplied in the report, the same composition was used for the walls, floor, and ceiling as was provided for the concrete reflectors used in other previous experiments.

Figures 6 through 10 are plan and elevation views of the benchmark geometry, used for both the bare and water-reflected experiments. 


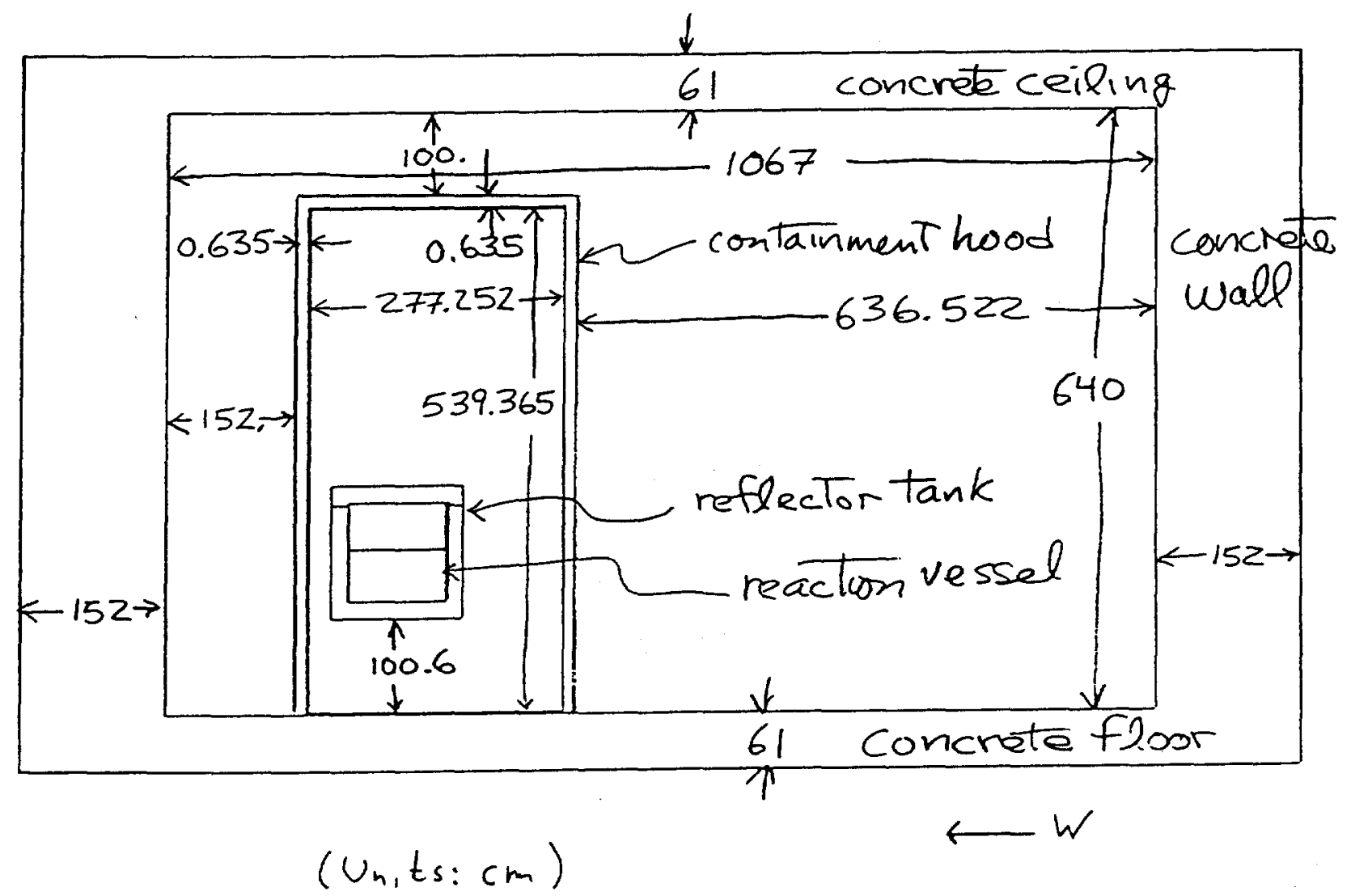

Figure 6. Elevation View of a Bare-Experiment Benchmark Geometry Showing the Room, Containment hood, Reflector Tank, and Reaction Vessel Containing Fissile Solution. 


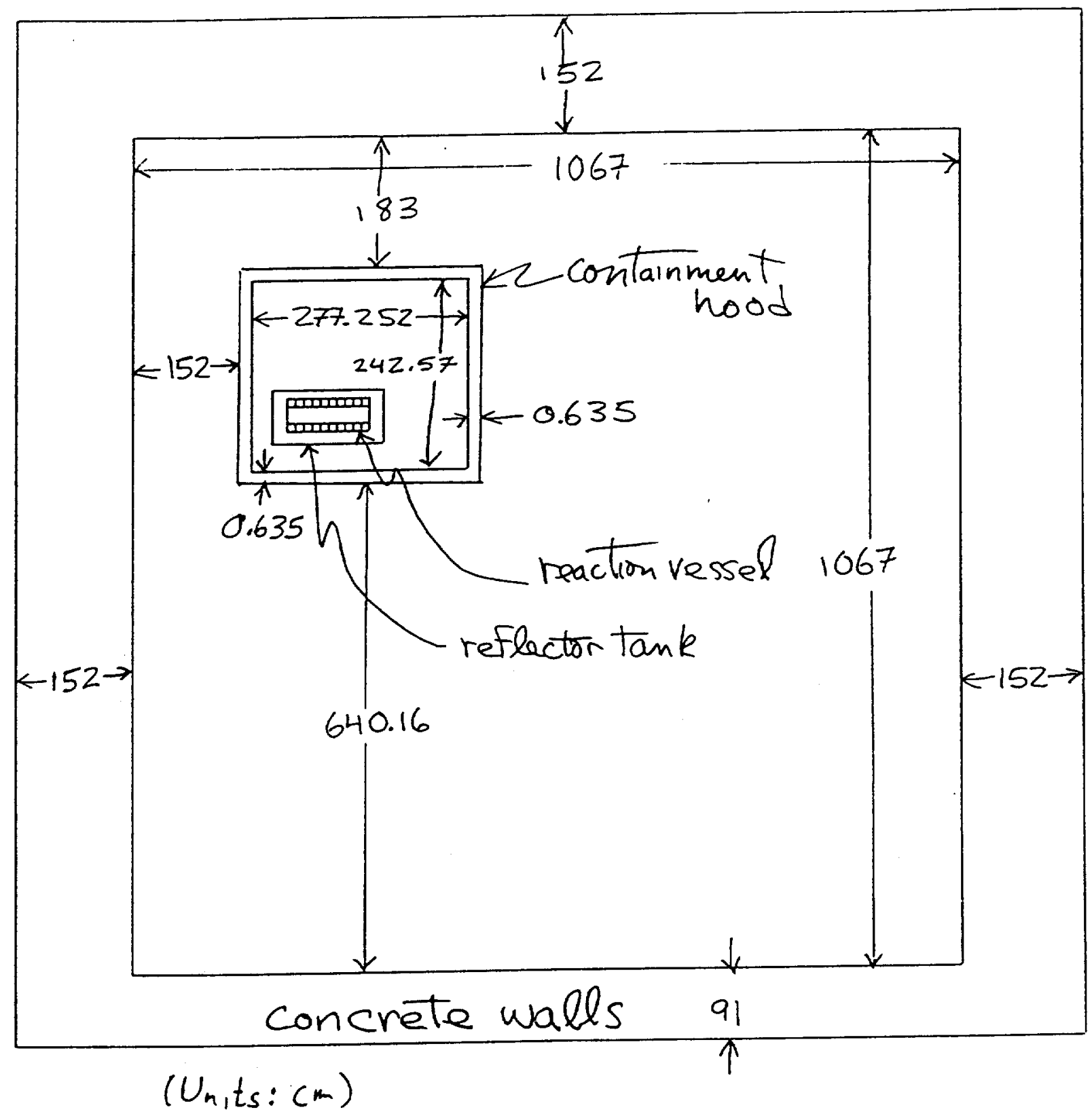

Figure 7. Plan View of a Bare-Experiment Benchmark Geometry Showing the Room, Containment hood, Reflector Tank, Reaction Vessel, and Reinforcing Grid. 


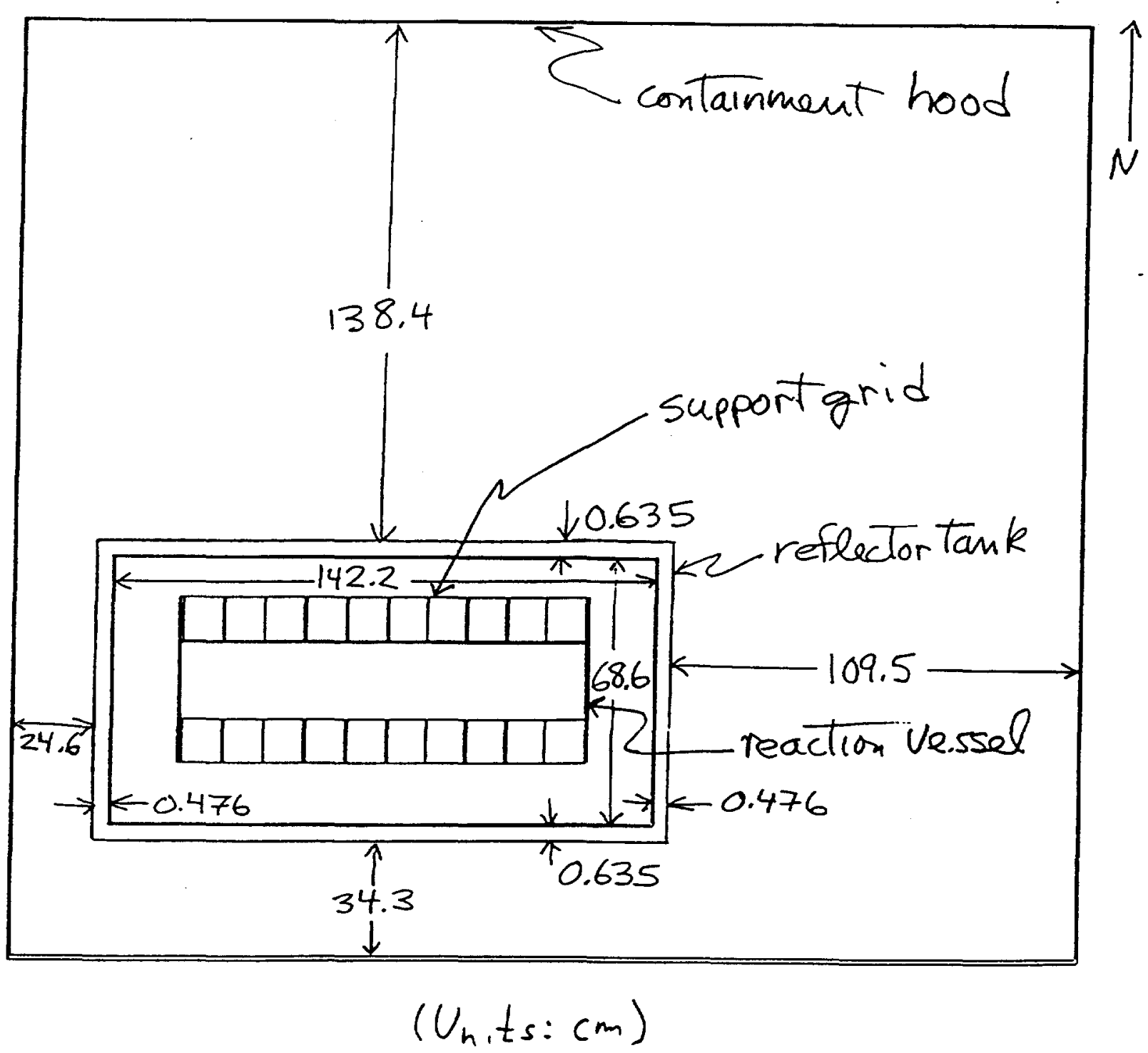

Figure 8. Plan View of a Bare-Experiment Benchmark Geometry Detailing the Containment Hood, Reflector Tank, Reaction Vessel, and Reinforcing Grid. 


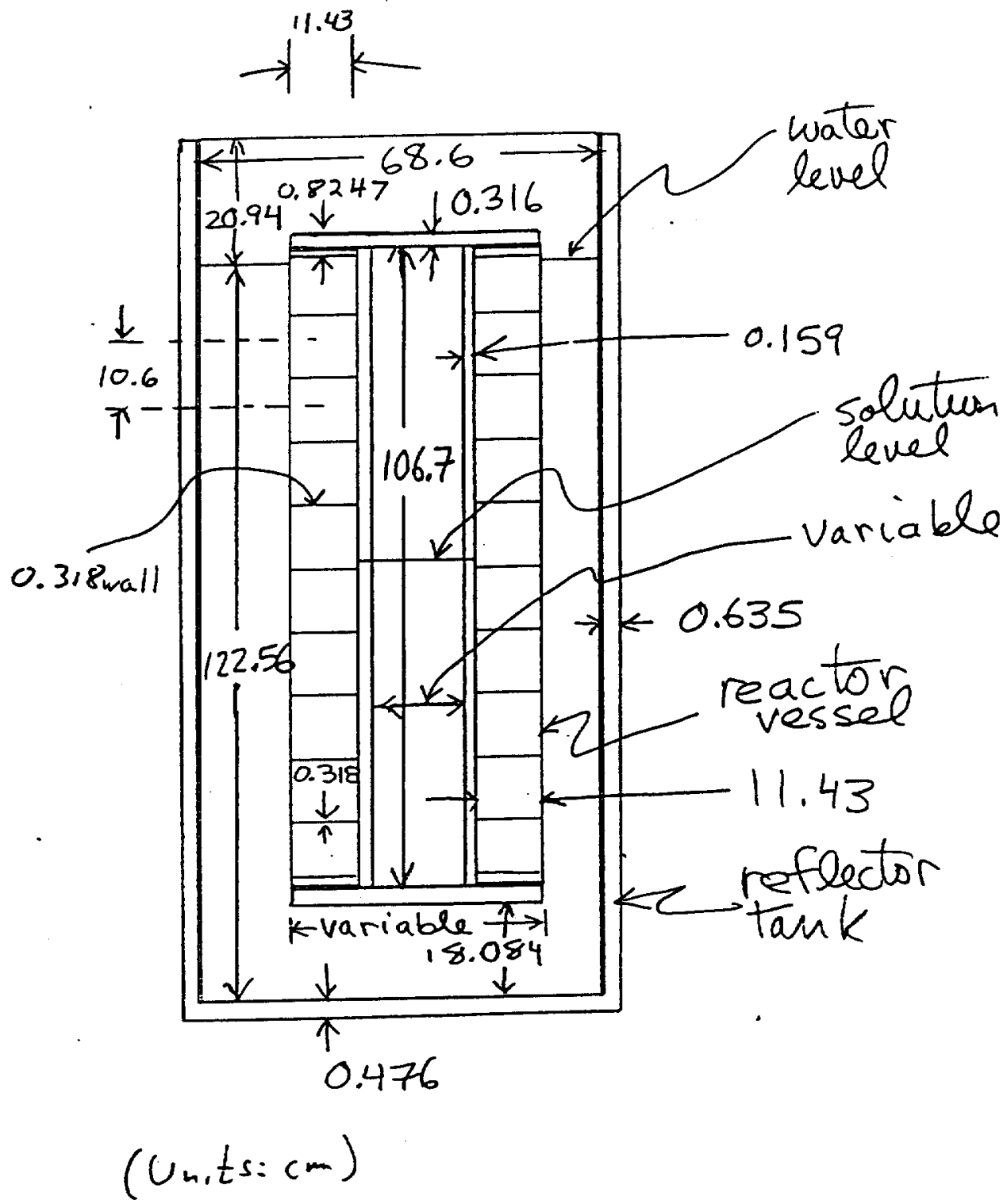

Figure 9. Elevation View of the Benchmark Geometry for Both the Bare and Water-Reflected Experiments, Detailing the Reflector Tank, Reaction Vessel and Reinforcing Grid. 


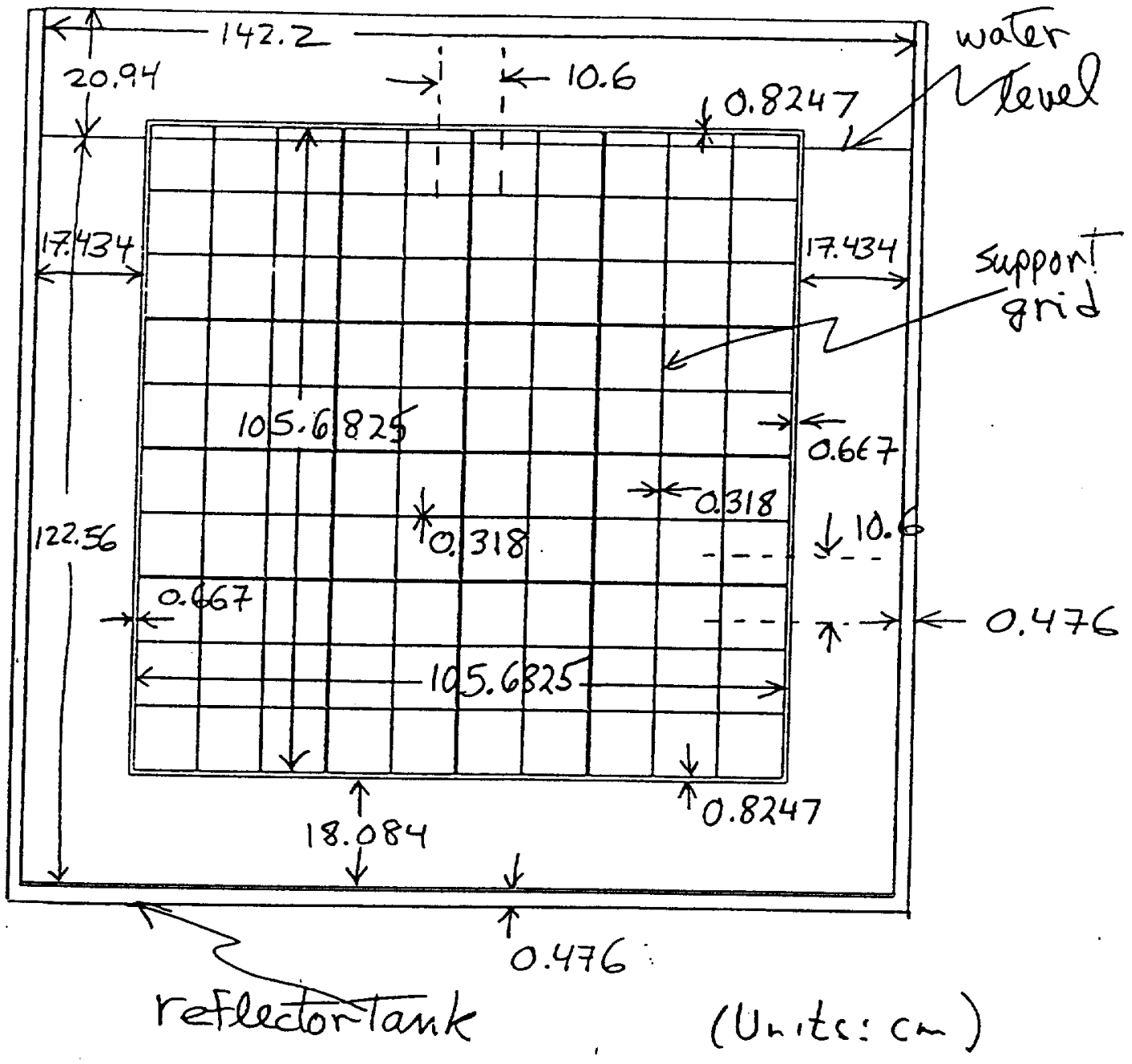

Figure 10. Elevation View of the Benchmark Geometry for Both the Bare and Water-Reflected Experiments, Detailing the Reflector Tank, and Reinforcing Grid of the Reaction Vessel. 
MIX-SOL-THERM-005

\section{Sensitivity Studies:}

\section{Corner Rounding}

An unresolved issue both in the PNL and Smolen's reports was the effect, if any, of the rounded corners of the experimental slab vessel. Each of the four corners of the steel bellows is rounded on a $14.4 \mathrm{~cm}$ radius. The missing volume represents $1.6 \%$ of the total volume with square corners. Sensitivity studies were performed to investigate this issue. Two simple geometries were created with just a bare volume of fuel in both round-cornered cuboid and square-cornered cuboid configurations with the same dimensions as the slab tank, as shown in Figure 11. Each configuration was used in a MCNP calculation for both water-reflected and bare environments. The calculated differences in reactivity, shown in Table 14 , were very small; the water-reflected cases were almost identical.

MCNP / KENO Model

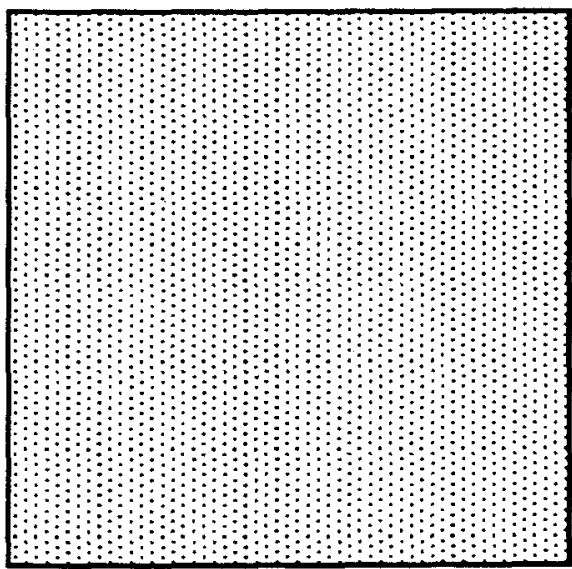

$106.7 \mathrm{~cm}$

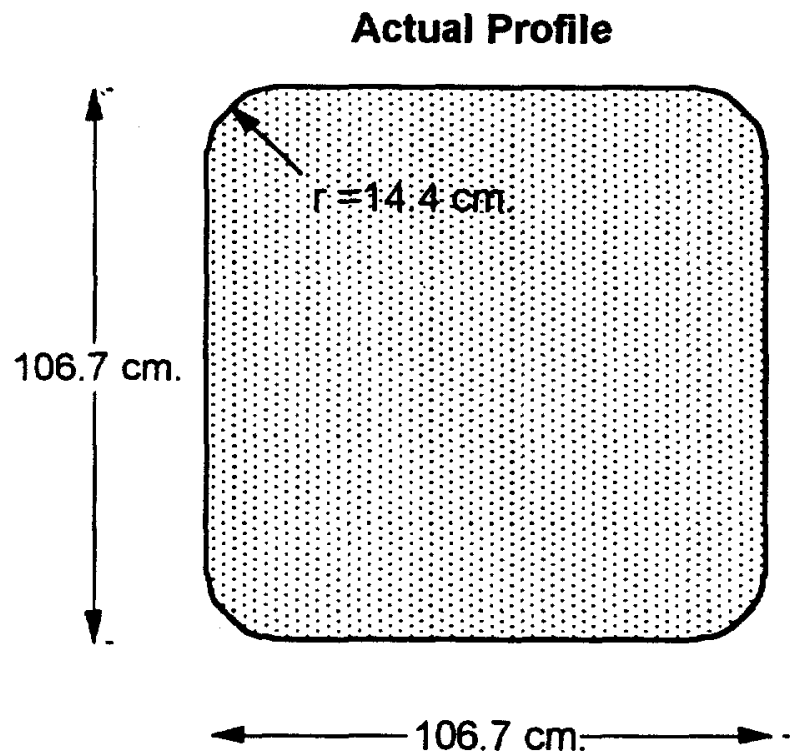

$106.7 \mathrm{~cm}$

Figure 11. Slab Tank Corner Rounding

Table 14. Changes in $\mathrm{k}_{\mathrm{eff}}$ Due to Corner Rounding

\begin{tabular}{||l|c|l|}
\hline Reflector Type & $\Delta \mathrm{k}_{\text {eff }}$ & $\sigma \Delta \mathrm{k}_{\text {eff }}$ \\
\hline \hline Water Reflected & 0.00008 & \pm 0.00056 \\
\hline Bare & 0.00072 & \pm 0.00056 \\
\hline
\end{tabular}




\section{Beillows to Planar Surface Transformation}

The edges of the experimental vessel consisted of a flexible bellows that could expand and contract to effect a variable-width slab tank. Modeling the non-orthogonal pleats of the bellows are beyond the capability of many modeling codes. Thus an appropriate approximation was sought using a flat planar surface at the midpoint of the pleats. Since there is as much volume above and below the midpoints of the pleats, the volume of the solution is conserved.

The thickness of the equivalent plane side plate is not apparent. The actual pleats are fabricated from $0.079 \mathrm{~cm}$ stainless steel. Since they are folded several times it is intuitively obvious that the effective thickness is larger than $0.079 \mathrm{~cm}$. To resolve this issue an exact MCNP model (see Appendix B) of the pleated bellows was constructed and the results of the $\mathrm{k}_{\text {eff }}$ calculations were compared to a flat plate simulation. A sensitivity study was performed in units of $0.079 \mathrm{~cm}$ to determine the thickness of the plate that most closely matched the exact calculation. The results are presented in Table 15.

Table 15. Changes in $k_{\text {eff }}$ Due to Plate Thickness (in units of $0.079 \mathrm{~cm}$ )

\begin{tabular}{||c|c|c||}
\hline Thickness Multiplier & $\Delta \mathrm{k}_{\text {eff }}$ & $\sigma \Delta \mathrm{k}_{\text {eff }}$ \\
\hline \hline $1 \times 0.079$ & 0.00082 & \pm 0.00118 \\
\hline $2 \times 0.079$ & 0.00077 & \pm 0.00117 \\
\hline $3 \times 0.079$ & 0.00106 & \pm 0.00118 \\
\hline $4 \times 0.079$ & 0.00028 & \pm 0.00114 \\
\hline $5 \times 0.079$ & 0.00038 & \pm 0.00120 \\
\hline $6 \times 0.079$ & 0.00078 & \pm 0.00114 \\
\hline $8 \times 0.079$ & 0.00128 & \pm 0.00115 \\
\hline
\end{tabular}

For all reasonable values of thickness ( 2 to $6 \times .079$ ) the effect on $k_{\text {eff }}$ due to the choice of flat plate approximation is statistically insignificant. We chose a value of 4 which did show a slight minimum in the difference in $\mathrm{k}_{\text {eff }}$ Thus the plate thickness chosen is $4 \times 0.079=0.316 \mathrm{~cm}$. This choice is consistent with conserving the total mass of the pleated assembly for typical configurations.

\section{Containment Hood Modeling}

No detailed information was provided for the geometry of the containment hood other than its perimeter dimensions and the thickness of the Plexiglas and stainless steel plates used in the construction. The hood is outside of the reflector tank and outside of the egg-crate support grid of the slab tank and thus should have small effect on an experiment. Sensitivity studies were run to determine whether the selection of materials made a difference in the $\mathrm{k}_{\text {eff }}$ value. Calculations were run with all Plexiglas, all stainless steel, and a homogenized mixture of both. The results are shown in Table 16. No significant difference was observed. A calculation run with no hood (voided material) did show a slight effect. For the sake of simplicity, stainless steel was chosen for the benchmark model. 
Table 16. Changes in $\mathrm{k}_{\mathrm{eff}}$ Due to Hood Material Other Than 304L Stainless Steel

\begin{tabular}{||c|c|c|}
\hline Hood Material & $\Delta \mathrm{k}_{\text {eff }}$ & $\sigma \Delta \mathrm{k}_{\text {eff }}$ \\
\hline \hline Plexiglas & 0.00007 & \pm 0.00086 \\
\hline Homogenized Plexiglas and SS304L & 0.00009 & \pm 0.00090 \\
\hline Void & 0.00050 & \pm 0.00088 \\
\hline
\end{tabular}

The steel grate catwalk inside the hood was not directly above the reflector tank and was predominantly open space. Therefore, it was not included in the model. Similarly, the top of the hood is sufficiently far enough above the reaction vessel that uncertainties in its height are inconsequential.

\section{Modeling Specification Uncertainties}

The calculational uncertainties due to the three aforementioned benchmark model simplifications $(0.00072,0.00114$, and 0.00090$)$ combine in quadrature to give an additional $\mathrm{k}_{\text {eff }}$ uncertainty of \pm 0.00162 


\section{NEANSCIDOC \\ Volume VI \\ MIX-SOL-THERM-005}

\subsection{Dimensions}

\section{Reaction Vessel}

The benchmark model for the slab tank reaction vessel consists of a stainless steel cuboid with two square sides with inside dimensions of $106.7 \mathrm{~cm}$ in height and depth. These square sides are $0.159 \mathrm{~cm}$ thick. The remaining four flat walls of the cuboid, replacing the bellows assembly, are $0.316 \mathrm{~cm}$ thick. The width of the tank varied from one experiment to another and is listed in Table 13. The square sides of the tank are reinforced by an egg-crate style support grid. The grid has a square pitch spacing of $10.6 \mathrm{~cm}$, a depth of $11.43 \mathrm{~cm}$, and is constructed of $0.3175 \mathrm{~cm}$ stainless steel, except for the four outside plates which are $0.667 \mathrm{~cm}$ thick. The solution thickness and critical heights are listed in Table 17.

Table 17. Slab Thickness and Critical Heights.

\begin{tabular}{|c|c|c|}
\hline Experiment D number & Slab Thickness $(\mathrm{cm})$ & Critical Height $(\mathrm{cm})$ \\
\hline 063 & 19.81 & 54.70 \\
\hline 064 & 13.97 & 80.14 \\
\hline 071 & 13.97 & 47.44 \\
\hline 072 & 12.70 & 67.16 \\
\hline 074 & 18.03 & 70.13 \\
\hline 075 & 19.05 & 85.38 \\
\hline 076 & 13.46 & 74.19 \\
\hline
\end{tabular}

\section{Reflector Tank}

The cuboidal reaction vessel is located inside a cuboidal 304L stainless steel tank. The inside dimensions of the tank are $68.6 \mathrm{~cm}$ in the north-south direction, $142.2 \mathrm{~cm}$ in the east-west direction and $143.5 \mathrm{~cm}$ high. The north and south sides are $0.635 \mathrm{~cm}$ thick; the other two sides and the bottom are $0.476 \mathrm{~cm}$ thick. The outside bottom of the reaction vessel is $18.084 \mathrm{~cm}$ above the inside bottom of the reflector tank and has spaces of $17.434 \mathrm{~cm}$ between the plates replacing the bellows and the east and west sides of the reflector tank. The north-south spacing of the vessel within the reflector tank is variable depending on the particular experiment. Spacings are listed in Table 13. The bottom of the reflector tank is $100.6 \mathrm{~cm}$ above the concrete floor.

For the water-reflected experiments, the reflector tank contains water with a depth of $122.56 \mathrm{~cm}$.

Containment Hood (pertains to bare experiments only)

The reaction vessel and reflector tank system are additionally enclosed in a cuboidal containment hood composed of $0.635-\mathrm{cm}$-thick stainless steel plate. The east-west extent of the hood is $278.522 \mathrm{~cm}$; the north-south extent of the hood is $243.84 \mathrm{~cm}$. The north-west corner of the hood is located $183 \mathrm{~cm}$ from the north wall and $152 \mathrm{~cm}$ from the west wall. Within the hood the broad faces of the reflector tank are 
situated $34.3 \mathrm{~cm}$ from the south hood wall and $138.4 \mathrm{~cm}$ from the north hood wall. The narrow faces of the reflector tank are situated $24.6 \mathrm{~cm}$ from the west hood wall and $109.5 \mathrm{~cm}$ from the east hood wall. The hood extends from the floor to $100 \mathrm{~cm}$ below the ceiling.

Room (pertains to bare experiments only)

The solution system is located in a room which is 10.67 meters square and has a ceiling height of 6.4 meters. Three side walls are composed of 1.52 -meters-thick concrete; the south wall is 0.91 meters thick. The concrete ceiling and floor are each 0.61 meters thick. 


\subsection{Material Data}

By definition a molar solution is a gram molecular weight dissolved in enough water to make 1 liter of solution. The density of the free acid in $\mathrm{g} / \mathrm{cm}^{3}$ is obtained by multiplying the measured molarity by the molecular weight of the acid and dividing by 1000 .

In this analysis, the concentrations of $\mathrm{Pu}$ and $\mathrm{U}$ are measured quantities. To obtain the densities for $\mathrm{Pu}\left(\mathrm{NO}_{3}\right)_{4}$ and $\mathrm{UO}_{2}\left(\mathrm{NO}_{3}\right)_{2}$, the $\mathrm{Pu}$ and $\mathrm{U}$ concentrations are multiplied by the ratio of the molecular weight of the nitrate to the atomic weight of the metal.

In a similar way the measured contaminants, assumed to be in solution as nitrates, are scaled by the ratio of the molecular weights of their nitrates to their atomic weights. The form of the nitrate for each impurity can depend on the molarity of the acid solution. That information was not available for most of the impurity nitrates; in those cases the stable nitrate from the list in the "Handbook of Chemistry and Physics" was assumed. The forms used for this report were $\mathrm{Al}\left(\mathrm{NO}_{3}\right)_{3}, \mathrm{~B}\left(\mathrm{NO}_{3}\right)_{3}, \mathrm{Ba}\left(\mathrm{NO}_{3}\right)_{2}$, $\mathrm{Ca}\left(\mathrm{NO}_{3}\right)_{2}, \mathrm{Cd}\left(\mathrm{NO}_{3}\right)_{2}, \mathrm{Ce}\left(\mathrm{NO}_{3}\right)_{3}, \mathrm{Cr}\left(\mathrm{NO}_{3}\right)_{3}, \mathrm{Cu}\left(\mathrm{NO}_{3}\right)_{2}, \mathrm{Dy}\left(\mathrm{NO}_{3}\right)_{3}, \mathrm{Fe}\left(\mathrm{NO}_{3}\right)_{2}, \mathrm{Gd}\left(\mathrm{NO}_{3}\right)_{3}, \mathrm{~K}\left(\mathrm{NO}_{3}\right)_{1}$, $\mathrm{La}\left(\mathrm{NO}_{3}\right)_{3}, \mathrm{Li}\left(\mathrm{NO}_{3}\right)_{1}, \mathrm{Mg}\left(\mathrm{NO}_{3}\right)_{2}, \mathrm{Mn}\left(\mathrm{NO}_{3}\right)_{2}, \mathrm{Mo}\left(\mathrm{NO}_{3}\right)_{3}, \mathrm{Na}\left(\mathrm{NO}_{3}\right)_{1}, \mathrm{Nd}\left(\mathrm{NO}_{3}\right)_{3}, \mathrm{Ni}\left(\mathrm{NO}_{3}\right)_{2}, \mathrm{Rh}\left(\mathrm{NO}_{3}\right)_{3}$, $\mathrm{Ru}\left(\mathrm{NO}_{3}\right)_{3}, \mathrm{Si}\left(\mathrm{NO}_{3}\right)_{4}, \mathrm{Sr}\left(\mathrm{NO}_{3}\right)_{2}, \mathrm{Ti}\left(\mathrm{NO}_{3}\right)_{3}, \mathrm{Zn}\left(\mathrm{NO}_{3}\right)_{2}, \mathrm{Zr}\left(\mathrm{NO}_{3}\right)_{4}$. Concentrations were determined from the values given in Table 6 . Errors resulting from using the wrong nitrate form for an impurity will be very small since the impurity concentrations are, in general, also relatively small. In fact including all impurities by assuming they have the form (Metal Ion) $\left(\mathrm{NO}_{3}\right)_{2}$ gives a difference in $\mathrm{k}_{\text {eff }}$ of about 0.002 .

The density of water in a solution is obtained by adjusting the measured solution density, $\rho_{\text {solution, }}$ of the solution for acid and nitrates:

$$
\rho_{\text {water }}=\rho_{\text {solution }}-\rho_{\text {acid }}-\rho_{\mathrm{Pu}\left(\mathrm{NO}_{3}\right)_{4}}-\rho_{\mathrm{UO}}\left(\mathrm{NO}_{3}\right)_{2}-\rho^{241} \mathrm{AmO}_{2}\left(\mathrm{NO}_{3}\right)_{2}-\rho_{\text {contaminants }}
$$

The concentration of hydrogen, oxygen and nitrogen can then be determined by adding the known concentrations of the appropriate components in the water, acid $\left(\mathrm{HNO}_{3}\right)$, and all nitrates. Several of the solution impurity concentrations were large enough $\left.{ }^{241} \mathrm{Am}, \mathrm{Fe}\right)$ or were strong enough neutron absorbers $\left({ }^{10} \mathrm{~B}, \mathrm{Cd}\right)$ to be included explicitly in the benchmark model. (The concentration-timesabsorption cutoff value used was arbitrary.) The strong neutron absorbers $\mathrm{Gd}$ and ${ }^{6} \mathrm{Li}$ were also included for completeness.

${ }^{a}$ R.C. Weast, et al., pages B-68 through B-146, Handbook of Chemistry and Physics; 70th Edition, CRC Press. Inc. (1989) 


\subsubsection{Solution.}

The number densities of each solution for all the slab tank experiments are given in Tables 18-24. The number densities for the solution explicitly includes ${ }^{241} \mathrm{Am}$ and the neutron absorbers, boron, cadmium, iron, gadolinium, and lithium, in the contaminants. The isotopic abundance for ${ }^{10} \mathrm{~B}$ is chosen to be $19.9 \%$ and that for ${ }^{6} \mathrm{Li}$ is chosen to be $7.5 \%^{\mathrm{a}}$. The density of the nitrates of all the contaminants listed in Table 6 lowers the density of the water in the solution and contributes some extra nitrogen and oxygen. The hydrogen, nitrogen, and oxygen contributed from all sources, including that due to all contaminants, is included in Tables 18-24.

Table 18. Solution Atom Densities for Experiment 063.

\begin{tabular}{||l|l|}
\hline Isotope/Element & $\begin{array}{l}\text { Atom Density } \\
{\left[(\mathrm{b}-\mathrm{cm})^{-1}\right]}\end{array}$ \\
\hline \hline $\mathrm{H}$ & $6.3508 \times 10^{-02}$ \\
\hline $\mathrm{N}$ & $1.1117 \times 10^{-03}$ \\
\hline $\mathrm{O}$ & $3.5225 \times 10^{-02}$ \\
\hline $238 \mathrm{Pu}$ & $3.0123 \times 10^{-08}$ \\
\hline $239 \mathrm{Pu}$ & $9.4249 \times 10^{-05}$ \\
\hline $240 \mathrm{Pu}$ & $8.5597 \times 10^{-06}$ \\
\hline $241 \mathrm{Pu}$ & $4.6159 \times 10^{-07}$ \\
\hline $242 \mathrm{Pu}$ & $9.5001 \times 10^{-08}$ \\
\hline $234 \mathrm{U}$ & $1.1328 \times 10^{-08}$ \\
\hline $235 \mathrm{U}$ & $9.0878 \times 10^{-07}$ \\
\hline $236 \mathrm{U}$ & $3.6903 \times 10^{-08}$ \\
\hline $238 \mathrm{U}$ & $1.5815 \times 10^{-04}$ \\
\hline $241 \mathrm{Am}$ & $5.3199 \times 10^{-07}$ \\
\hline $10 \mathrm{~B}$ & $2.2301 \times 10^{-08}$ \\
\hline $\mathrm{Cd}$ & $1.2538 \times 10^{-08}$ \\
\hline $\mathrm{Fe}$ & $1.2995 \times 10^{-06}$ \\
\hline $\mathrm{Gd}$ & $1.7297 \times 10^{-09}$ \\
\hline${ }^{6} \mathrm{Li}$ & $8.0152 \times 10^{-10}$ \\
\hline
\end{tabular}

${ }^{4}$ R.C. Weast, et al., page B-228, Handbook of Chemistry and Physics; 70th Edition, CRC Press, Inc. (1989) 
MIX-SOL-THERM-005

Table 19. Solution Atom Densities for Experiment 064.

\begin{tabular}{||l|l|}
\hline Isotope/Element & $\begin{array}{l}\text { Atom Density } \\
{\left[(\mathrm{b}-\mathrm{cm})^{-1}\right]}\end{array}$ \\
\hline \hline $\mathrm{H}$ & $6.3520 \times 10^{-02}$ \\
\hline $\mathrm{N}$ & $1.1228 \times 10^{-03}$ \\
\hline $\mathrm{O}$ & $3.5266 \times 10^{-02}$ \\
\hline $238 \mathrm{Pu}$ & $3.0739 \times 10^{-08}$ \\
\hline $239 \mathrm{Pu}$ & $9.6178 \times 10^{-05}$ \\
\hline $240 \mathrm{Pu}$ & $8.7348 \times 10^{-06}$ \\
\hline $241 \mathrm{Pu}$ & $4.7104 \times 10^{-07}$ \\
\hline $242 \mathrm{Pu}$ & $9.6945 \times 10^{-08}$ \\
\hline $234 \mathrm{U}$ & $1.1412 \times 10^{-08}$ \\
\hline $235 \mathrm{U}$ & $9.1557 \times 10^{-07}$ \\
\hline $236 \mathrm{U}$ & $3.7179 \times 10^{-08}$ \\
\hline $238 \mathrm{U}$ & $1.5933 \times 10^{-04}$ \\
\hline $241 \mathrm{Am}$ & $5.4324 \times 10^{-07}$ \\
\hline $10 \mathrm{~B}$ & $2.2758 \times 10^{-08}$ \\
\hline $\mathrm{Cd}$ & $1.2795 \times 10^{-08}$ \\
\hline $\mathrm{Fe}$ & $1.3261 \times 10^{-06}$ \\
\hline $\mathrm{Gd}$ & $1.7650 \times 10^{-09}$ \\
\hline $6 \mathrm{Li}$ & $8.1792 \times 10^{-10}$ \\
\hline
\end{tabular}


MLX-SOL-THERM-005

Table 20. Solution Atom Densities for Experiment 071

\begin{tabular}{||l|l|}
\hline Isotope/Element & $\begin{array}{l}\text { Atom Density } \\
{\left[(\mathrm{b}-\mathrm{cm})^{-1}\right]}\end{array}$ \\
\hline \hline $\mathrm{H}$ & $5.8360 \times 10^{-02}$ \\
\hline $\mathrm{N}$ & $2.7318 \times 10^{-03}$ \\
\hline $\mathrm{O}$ & $3.7946 \times 10^{-02}$ \\
\hline $238 \mathrm{Pu}$ & $8.7207 \times 10^{-08}$ \\
\hline $239 \mathrm{Pu}$ & $2.7285 \times 10^{-04}$ \\
\hline $240 \mathrm{Pu}$ & $2.4781 \times 10^{-05}$ \\
\hline $241 \mathrm{Pu}$ & $1.3363 \times 10^{-06}$ \\
\hline $242 \mathrm{Pu}$ & $2.7503 \times 10^{-07}$ \\
\hline $234 \mathrm{U}$ & $3.1247 \times 10^{-08}$ \\
\hline $235 \mathrm{U}$ & $2.5068 \times 10^{-06}$ \\
\hline $236 \mathrm{U}$ & $1.0180 \times 10^{-07}$ \\
\hline $238 \mathrm{U}$ & $4.3625 \times 10^{-04}$ \\
\hline $241 \mathrm{Am}$ & $1.5466 \times 10^{-06}$ \\
\hline $10 \mathrm{~B}$ & $6.4563 \times 10^{-08}$ \\
\hline $\mathrm{Cd}$ & $3.6298 \times 10^{-08}$ \\
\hline $\mathrm{Fe}$ & $3.7621 \times 10^{-06}$ \\
\hline $\mathrm{Gd}$ & $5.0074 \times 10^{-09}$ \\
\hline $6 \mathrm{Li}$ & $2.3204 \times 10^{-09}$ \\
\hline
\end{tabular}


Volume VI

MIX-SOL-THERM-005

Table 21. Solution Atom Densities for Experiment 072

\begin{tabular}{||l|l||}
\hline Isotope/Element & $\begin{array}{l}\text { Atom Density } \\
{\left[(\mathrm{b}-\mathrm{cm})^{-1}\right]}\end{array}$ \\
\hline \hline $\mathrm{H}$ & $5.8360 \times 10^{-02}$ \\
\hline $\mathrm{N}$ & $2.7318 \times 10^{-03}$ \\
\hline $\mathrm{O}$ & $3.7946 \times 10^{-02}$ \\
\hline $238 \mathrm{Pu}$ & $8.7207 \times 10^{-08}$ \\
\hline $239 \mathrm{Pu}$ & $2.7285 \times 10^{-04}$ \\
\hline $240 \mathrm{Pu}$ & $2.4781 \times 10^{-05}$ \\
\hline $241 \mathrm{Pu}$ & $1.3363 \times 10^{-06}$ \\
\hline $242 \mathrm{Pu}$ & $2.7503 \times 10^{-07}$ \\
\hline $234 \mathrm{U}$ & $3.1247 \times 10^{-08}$ \\
\hline $235 \mathrm{U}$ & $2.5068 \times 10^{-06}$ \\
\hline $236 \mathrm{U}$ & $1.0180 \times 10^{-07}$ \\
\hline $238 \mathrm{U}$ & $4.3625 \times 10^{-04}$ \\
\hline $241 \mathrm{Am}$ & $1.5468 \times 10^{-06}$ \\
\hline $10 \mathrm{~B}$ & $6.4563 \times 10^{-08}$ \\
\hline $\mathrm{Cd}$ & $3.6298 \times 10^{-08}$ \\
\hline $\mathrm{Fe}$ & $3.7621 \times 10^{-06}$ \\
\hline $\mathrm{Gd}$ & $5.0074 \times 10^{-09}$ \\
\hline $6 \mathrm{Li}$ & $2.3204 \times 10^{-09}$ \\
\hline
\end{tabular}


MIX-SOL-THERM-005

Table 22. Solution Atom Densities for Experiment 074

\begin{tabular}{||l|l|}
\hline Isotope/Element & $\begin{array}{l}\text { Atom Density } \\
{\left[(\mathrm{b}-\mathrm{cm})^{-1}\right]}\end{array}$ \\
\hline \hline $\mathrm{H}$ & $5.8269 \times 10^{-02}$ \\
\hline $\mathrm{N}$ & $2.7423 \times 10^{-03}$ \\
\hline $\mathrm{O}$ & $3.7932 \times 10^{-02}$ \\
\hline $238 \mathrm{Pu}$ & $8.7332 \times 10^{-08}$ \\
\hline $239 \mathrm{Pu}$ & $2.7325 \times 10^{-04}$ \\
\hline $240 \mathrm{Pu}$ & $2.4816 \times 10^{-05}$ \\
\hline $241 \mathrm{Pu}$ & $1.3382 \times 10^{-06}$ \\
\hline $242 \mathrm{Pu}$ & $2.7542 \times 10^{-07}$ \\
\hline $234 \mathrm{U}$ & $3.1342 \times 10^{-08}$ \\
\hline $235 \mathrm{U}$ & $2.5145 \times 10^{-06}$ \\
\hline $236 \mathrm{U}$ & $1.0211 \times 10^{-07}$ \\
\hline $238 \mathrm{U}$ & $4.3759 \times 10^{-04}$ \\
\hline $241 \mathrm{Am}$ & $1.5497 \times 10^{-06}$ \\
\hline $10 \mathrm{~B}$ & $6.4655 \times 10^{-08}$ \\
\hline $\mathrm{Cd}$ & $3.6350 \times 10^{-08}$ \\
\hline $\mathrm{Fe}$ & $3.7674 \times 10^{-06}$ \\
\hline $\mathrm{Gd}$ & $5.0146 \times 10^{-09}$ \\
\hline $6 \mathrm{Li}$ & $2.3237 \times 10^{-09}$ \\
\hline \hline
\end{tabular}


MIX-SOL-THERM-005

Table 23. Solution Atom Densities for Experiment 075

\begin{tabular}{||l|l|}
\hline Isotope/Element & $\begin{array}{l}\text { Atom Density } \\
{\left[(\mathrm{b}-\mathrm{cm})^{-1}\right]}\end{array}$ \\
\hline \hline $\mathrm{H}$ & $5.4050 \times 10^{-02}$ \\
\hline $\mathrm{N}$ & $3.8698 \times 10^{-03}$ \\
\hline $\mathrm{O}$ & $3.9595 \times 10^{-02}$ \\
\hline $238 \mathrm{Pu}$ & $1.2675 \times 10^{-07}$ \\
\hline $239 \mathrm{Pu}$ & $3.9658 \times 10^{-04}$ \\
\hline $240 \mathrm{Pu}$ & $3.6017 \times 10^{-05}$ \\
\hline $241 \mathrm{Pu}$ & $1.9423 \times 10^{-06}$ \\
\hline $242 \mathrm{Pu}$ & $3.9974 \times 10^{-07}$ \\
\hline $234 \mathrm{U}$ & $4.7336 \times 10^{-08}$ \\
\hline $235 \mathrm{U}$ & $3.7977 \times 10^{-06}$ \\
\hline $236 \mathrm{U}$ & $1.5421 \times 10^{-07}$ \\
\hline $238 \mathrm{U}$ & $6.6090 \times 10^{-04}$ \\
\hline $241 \mathrm{Am}$ & $2.2581 \times 10^{-06}$ \\
\hline $10 \mathrm{~B}$ & $9.3838 \times 10^{-08}$ \\
\hline $\mathrm{Cd}$ & $5.2757 \times 10^{-08}$ \\
\hline $\mathrm{Fe}$ & $5.4679 \times 10^{-06}$ \\
\hline $\mathrm{Gd}$ & $7.2780 \times 10^{-09}$ \\
\hline $6 \mathrm{Li}$ & $3.3726 \times 10^{-09}$ \\
\hline
\end{tabular}


MIX-SOL-THERM-005

Table 24. Solution Atom Densities for Experiment 076

\begin{tabular}{||l|l|}
\hline Isotope/Element & $\begin{array}{l}\text { Atom Density } \\
{\left[(\mathrm{b}-\mathrm{cm})^{-1}\right]}\end{array}$ \\
\hline \hline $\mathrm{H}$ & $5.4021 \times 10^{-02}$ \\
\hline $\mathrm{N}$ & $3.8695 \times 10^{-03}$ \\
\hline $\mathrm{O}$ & $3.9581 \times 10^{-02}$ \\
\hline $238 \mathrm{Pu}$ & $1.2668 \times 10^{-07}$ \\
\hline $239 \mathrm{Pu}$ & $3.9637 \times 10^{-04}$ \\
\hline $240 \mathrm{Pu}$ & $3.5998 \times 10^{-05}$ \\
\hline $241 \mathrm{Pu}$ & $1.9413 \times 10^{-06}$ \\
\hline $242 \mathrm{Pu}$ & $3.9953 \times 10^{-07}$ \\
\hline $234 \mathrm{U}$ & $4.7360 \times 10^{-08}$ \\
\hline $235 \mathrm{U}$ & $3.7996 \times 10^{-06}$ \\
\hline $236 \mathrm{U}$ & $1.5429 \times 10^{-07}$ \\
\hline $238 \mathrm{U}$ & $6.6122 \times 10^{-04}$ \\
\hline $241 \mathrm{Am}$ & $2.2572 \times 10^{-06}$ \\
\hline $10 \mathrm{~B}$ & $9.3789 \times 10^{-08}$ \\
\hline $\mathrm{Cd}$ & $5.2729 \times 10^{-08}$ \\
\hline $\mathrm{Fe}$ & $5.4651 \times 10^{-06}$ \\
\hline $\mathrm{Gd}$ & $7.2742 \times 10^{-09}$ \\
\hline $6 \mathrm{Li}$ & $3.3708 \times 10^{-09}$ \\
\hline
\end{tabular}




\subsubsection{Water}

The published water temperatures are listed in Table 25 below. The water density and hydrogen and oxygen number densities for the water reflector are also given in the table.

Table 25. Temperature, Density, and Atom Number Densities for Water Reflector.

\begin{tabular}{||c|c|c|c|c||}
\hline $\begin{array}{c}\text { Experiment } \\
\text { Number }\end{array}$ & $\begin{array}{c}\text { Temperature } \\
{\left[{ }^{\circ} \mathrm{C}\right]}\end{array}$ & $\begin{array}{c}\text { Density } \\
{[\mathrm{g} / \mathrm{ml}]}\end{array}$ & $\begin{array}{c}\text { Hydrogen } \\
\text { Atom Density } \\
{\left[(\mathrm{b}-\mathrm{cm})^{-1}\right]}\end{array}$ & $\begin{array}{c}\text { Oxygen } \\
\text { Atom Density } \\
{\left[(\mathrm{b}-\mathrm{cm})^{-1}\right]}\end{array}$ \\
\hline \hline 063 & (b) & & & \\
\hline 064 & 17.2 & 0.99876 & $6.6773 \times 10^{-2}$ & $3.3387 \times 10^{-2}$ \\
\hline 071 & 22.1 & 0.99775 & $6.6705 \times 10^{-2}$ & $3.3353 \times 10^{-2}$ \\
\hline 072 & 22.7 & 0.99760 & $6.6695 \times 10^{-2}$ & $3.3348 \times 10^{-2}$ \\
\hline 074 & (b) & & & \\
\hline 075 & (b) & & & \\
\hline 076 & 21.7 & 0.99784 & $6.6711 \times 10^{-2}$ & $3.3356 \times 10^{-2}$ \\
\hline
\end{tabular}

(a) Interpolations of Table 1-36, Handbook of Tables for Applied Engineering Science; page 67, R.E. Bolz Editor, The Chemical Rubber Publishing Company. (1970)

(b) Water reflector was not used

\subsubsection{Stainless Steel}

The density for stainless steel $304 \mathrm{~L}$ is given in Table 7. Possible atomic weight percents for stainless steel $304 \mathrm{~L}$ are also given in Table 7 . Since the atomic weight percents are given as maximums or as ranges there is a large variety of atomic number densities possible. In order to select a specific set of values that might be representative of the composition of stainless steel $304 \mathrm{~L}$ as used in nuclear criticality calculations, the atomic weight percents for stainless steel $304 \mathrm{~L}$ were chosen from previously accepted standard handbook data. The element weight percents the atomic number densities are given in Table 26.

Table 26. Number densities for stainless steel 304L.

\begin{tabular}{||c|c|c||}
\hline Element & Wt.\% $^{(\mathrm{a})}$ & $\begin{array}{c}\text { Atom Density } \\
\left(\left[\mathrm{b}-\mathrm{cm}^{-1}\right)\right.\end{array}$ \\
\hline \hline $\mathrm{Fe}$ & 70.97 & $6.1376 \times 10^{-2}$ \\
\hline $\mathrm{Cr}$ & 19.00 & $1.7648 \times 10^{-2}$ \\
\hline $\mathrm{Ni}$ & 10.00 & $8.2292 \times 10^{-3}$ \\
\hline $\mathrm{C}$ & 0.03 & $1.2063 \times 10^{-4}$ \\
\hline
\end{tabular}

(a) R. H. Perry and C. H. Chilton. page 23-29, Chemical Engineers 'Handbook; 5th Edition, McGraw-Hill Book Co. (1973) 
MIX-SOL-THERM-00S

\subsubsection{Concrete}

The corresponding number densities using the atomic weight fractions from Table 8 for concrete are given in Table 27. These atom densities are used for room floor, ceiling, and walls.

Table 27. Composition of Concrete Used for Room Floor, Ceiling, and Walls.

\begin{tabular}{|c|c|}
\hline Element & $\begin{array}{l}\text { Atom Density } \\
\text { atom/[b-cm] })\end{array}$ \\
\hline $\mathrm{O}$ & $4.5525 \times 10^{-2}$ \\
\hline $\mathrm{Si}$ & $1.1541 \times 10^{-2}$ \\
\hline $\mathrm{Ca}$ & $4.2012 \times 10^{-3}$ \\
\hline $\mathrm{Al}$ & $2.4910 \times 10^{-3}$ \\
\hline $\mathrm{Fe}$ & $8.4670 \times 10^{-4}$ \\
\hline $\mathrm{Na}$ & $8.7278 \times 10^{-4}$ \\
\hline $\mathrm{H}$ & $1.4617 \times 10^{-2}$ \\
\hline $\mathrm{Mg}$ & $5.3112 \times 10^{-4}$ \\
\hline $\mathrm{K}$ & $2.5839 \times 10^{-4}$ \\
\hline $\mathrm{S}$ & $1.6628 \times 10^{-4}$ \\
\hline $\mathrm{Ti}$ & $9.6702 \times 10^{-5}$ \\
\hline
\end{tabular}




\subsection{Temperature Data}

No data exists for the temperature of the fissile solution during the actual experiments. The estimated temperature range was from about $17^{\circ} \mathrm{C}$ to $30^{\circ} \mathrm{C}$. Since the systems were never taken to full critical, it is assumed that little fission heating took place. Thus room temperature cross-sections should be adequate. Following Smolen, et. al. (Reference 2), the fissile solution temperature is taken to be $23{ }^{\circ} \mathrm{C}$ for all experiments. The temperature of the water reflector varied several degrees throughout the set of experiments. Table 28 shows the variation of the measured reflector temperatures for the four waterreflected experiments. The water temperature of the reflector in the water-reflected experiments was taken as the value shown in Table 28.

Table 28. Variation of Reflector Temperatures.

\begin{tabular}{|c|c|}
\hline $\begin{array}{c}\text { Experiment } \\
\text { ID number }\end{array}$ & $\begin{array}{c}\text { Reflector } \\
\text { Temperature }\end{array}{ }^{\circ} \mathrm{C}$ \\
\hline 064 & 17.2 \\
\hline 071 & 22.1 \\
\hline 072 & 22.7 \\
\hline 076 & 21.7 \\
\hline
\end{tabular}

\subsection{Experimental and Benchmark $k_{e f f}$}

All experiments were extrapolated to criticality by the inverse multiplication method, thus the experimental and benchmark $k_{\text {eff }}$ are 1.000 .

The uncertainty in the benchmark $k_{\text {eff }}$ for the bare and water-reflected experiments is estimated by taking the square root of the sum of the squares of the values for the uncertainties listed in Tables 9,10 , and 11 in Section 2.1 combined with the $\Delta \mathrm{k}_{\text {eff }}$ of 0.00162 due to the modeling simplifications. These combined uncertainties yield an uncertainty in the benchmark $\mathrm{k}_{\text {eff }}$ for both the bare and water-reflected experiments of \pm 0.0030 or \pm 0.0031 . Therefore, the benchmark-model $k_{\text {eff }}$ is $1.000 \pm 0.0031$. 
MIX-SOL-THERM-005

\subsection{RESULTS OF SAMPLE CALCULATIONS}

All calculated $\mathrm{k}_{\text {eff }}$ values and standard deviations are reported in Table 29

Table 29. Calculated results.

\begin{tabular}{||c|c|c|c|}
\hline $\begin{array}{c}\text { Experiment } \\
\text { Number }\end{array}$ & $\begin{array}{c}\mathrm{k}_{\text {eff }} \pm \sigma \\
\text { KENO } \\
(16 \text { gp Hansen Roach) }\end{array}$ & $\begin{array}{c}\mathrm{k}_{\text {eff }} \pm \sigma \\
\text { KENO } \\
(27 \mathrm{gp} \text { ENDF/B-IV) }\end{array}$ & $\begin{array}{c}\mathrm{k}_{\text {eff }} \pm \sigma \\
\text { MCNP } \\
(\text { ENDF/B-V) }\end{array}$ \\
\hline \hline 063 & $0.9991 \pm 0.0004$ & $1.0029 \pm 0.0004$ & $1.0015 \pm 0.0008$ \\
\hline 064 & $1.0048 \pm 0.0015$ & $1.0053 \pm 0.0015$ & $1.0034 \pm 0.0007$ \\
\hline 071 & $1.0109 \pm 0.0014$ & $1.0102 \pm 0.0015$ & $1.0019 \pm 0.0008$ \\
\hline 072 & $1.0121 \pm 0.0015$ & $1.0068 \pm 0.0016$ & $1.0000 \pm 0.0008$ \\
\hline 074 & $0.9997 \pm 0.0004$ & $0.9979 \pm 0.0004$ & $0.9934 \pm 0.0009$ \\
\hline 075 & $1.0058 \pm 0.0004$ & $0.9972 \pm 0.0004$ & $0.9902 \pm 0.0008$ \\
\hline 076 & $1.0160 \pm 0.0015$ & $1.0039 \pm 0.0016$ & $0.9990 \pm 0.0008$ \\
\hline
\end{tabular}

Three of the KENO 16-group Hansen Roach calculations and one of the 27-group calculations are more than one percent high with the remainder lying in the region between plus and minus one percent of 1.0000. The MCNP with ENDF/B-V cross sections and the other KENO 27-group results with ENDF/B-iV cross sections all lie in the region between plus and minus one percent of 1.0000 . 
MIX-SOL-THERM-005

\subsection{REFERENCES}

1. R. C. Lloyd, Criticality Experiments with Mixed Plutonium and Uranium Nitrate Solution at a Plutonium Fraction of 0.4 in Slab and Cylindrical Geometry, PNL-6327 Battelle Pacific Northwest Laboratories, Richland, Washington, April 1988.

2. G. R. Smolen, R.C. Lloyd, and H. Funabashi, Criticality Data and Validation Studies of PlutoniumUranium Nitrate Solutions in Cylindrical and Slab Geometry, Nuclear Technology, 107: pp. 304-325, 1994

3. E. D. Clayton, Neutron Source Multiplication Method, in Proceedings Workshop on Subcriticality Reactivity Measurements, (G. A. Whan Ed.), University of New Mexico, Albuquerque, New Mexico, August 1985.

4. R. C. Lloyd, Criticality Experiments with Mixed Plutonium and Uranium Nitrate Solution at a Plutonium Fraction of 0.5 in Slab and Cylindrical Geometry, PNL-5768 Battelle Pacific Northwest Laboratories, Richland, Washington, December 1986.

5. G. R. Smolen, R.C. Lloyd, and H. Funabashi, Criticality Data and Validation Studies of PlutoniumUranium Nitrate Solutions in Anmular Geometry, Nuclear Technology, 107: pp. 326-339, 1994 


\section{APPENDIX A: TYPICAL INPUT LISTINGS}

\section{A.1 KENO V.a Input Listings}

\section{Hansen-Roach Cross Sections}

For the bare experiments, KENO V.a with 16-energy-group Hansen-Roach cross sections was run using 4800 active generations with 1000 neutrons per generation, resulting in 4,800,000 neutron histories. For the water reflected experiments, 300 active generations with 1000 neutrons per generation were run, resulting in 300,000 neutron histories. Nine generations were skipped before averaging for all calculations. Phosphorous cross sections are not available for 16-energy-group Hansen-Roach and so do not appear in carbon steel material. The gadolinium and lithium cross sections were also not included for the fissile solution.

The $\sigma_{\mathrm{p}}$ value for each experiment was calculated using the Hopper-Reiner method ${ }^{\mathrm{a}}$. The actual $\sigma_{\mathrm{p}}$ used is to linearly apportion the cross sections between the two closest available Hansen-Roach library values.

\section{7-Group ENDF/B-IV Cross Sections}

For the bare experiments, KENO V.a with the SCALE-4 27-energy-group cross sections was run using 4800 active generations with 1000 neutrons per generation, resulting in 4,800,000 neutron histories. For the water reflected experiments, 300 active generations with 1000 neutrons per generation were run, resulting in 300,000 neutron histories. Nine generations were skipped before averaging for all calculations.

In the calculations the thickness of the plates making up the egg-crate grids was entered as $0.3174 \mathrm{~cm}$ due to significant-figure rounding. The specified benchmark value is $0.3175 \mathrm{~cm}$. This small discrepancy is not expected to affect $k_{\text {eff. }}$

\footnotetext{
${ }^{a}$ C. M. Hopper and J-P Renier. Expanded and tpplied Sixteen-Neutron-Energv-Group Cross-Section Library, Transactions American Nuclear Society. 61, 186 (June 1990).
} 


\section{Sample KENO V.a Input Listing (Hansen-Roach Cross Sections)}

\section{Bare Experiments}

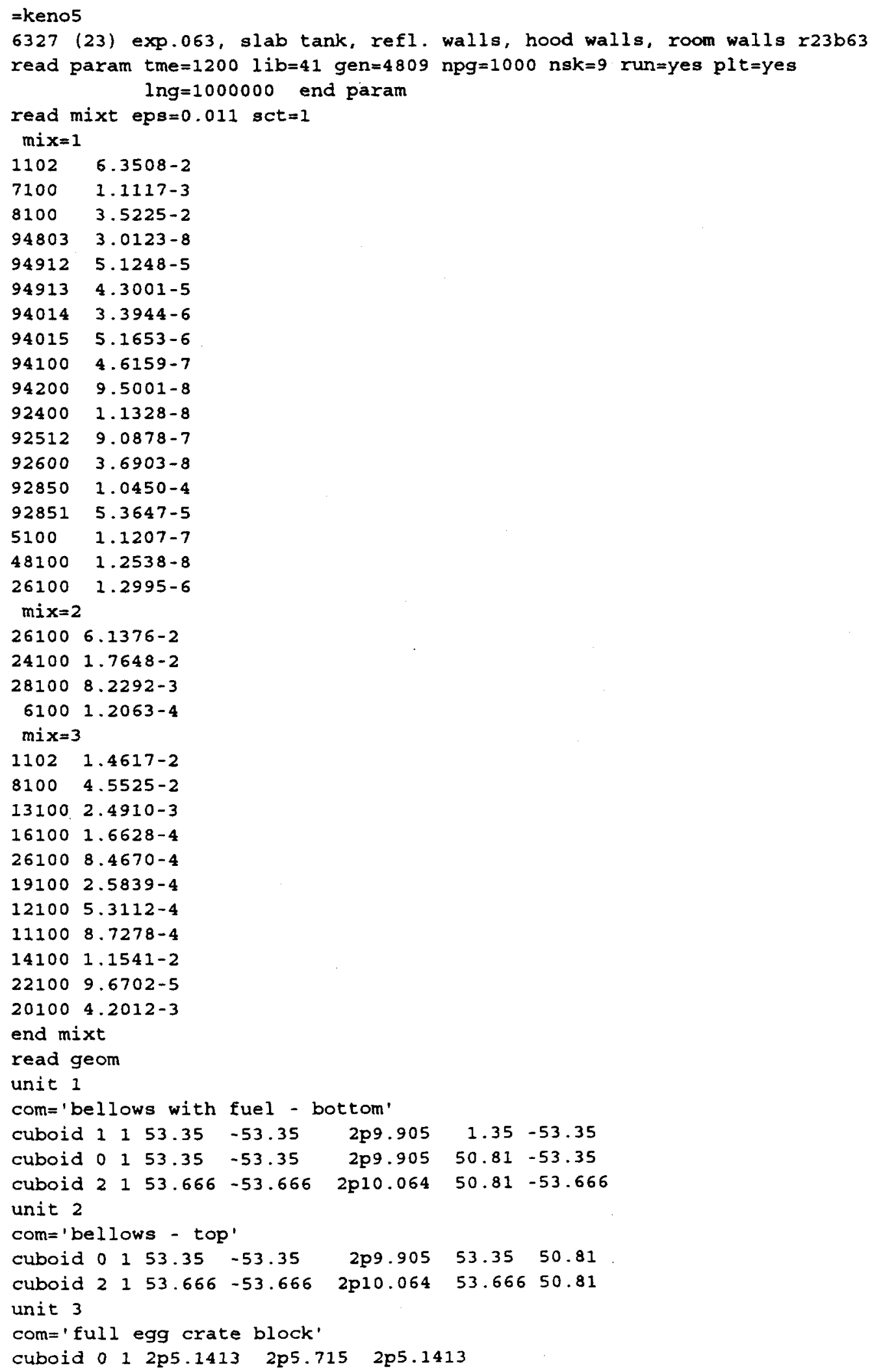




\section{MIX-SOL-THERM-005}

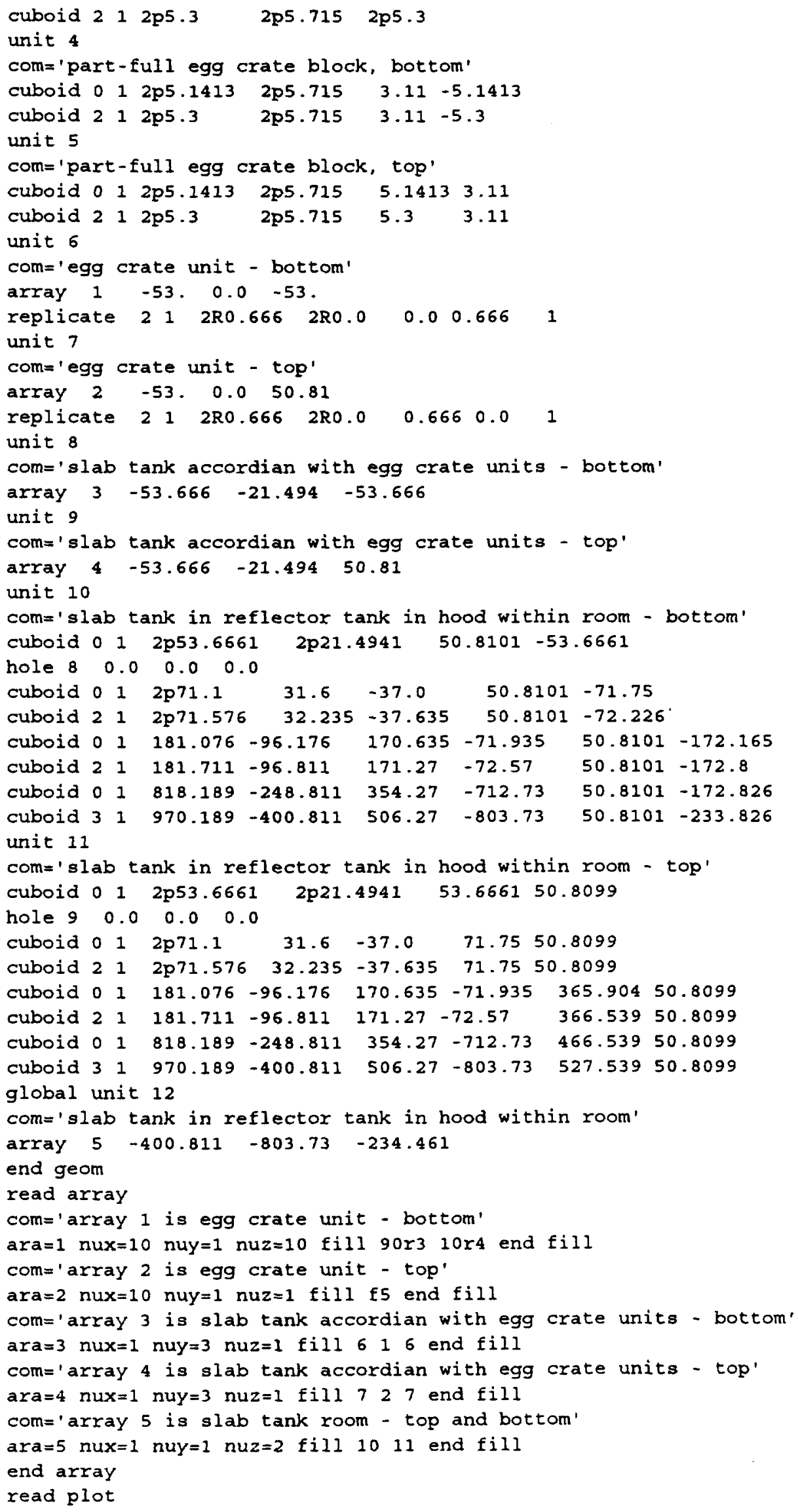




\section{MLX-SOL-THERM-005}

$t t l=' x-y$ plane through the slab tank at $z=0$.' $x u l=-55 . y u l=55.2 u l=0 . x l r=55 . y l r=-55.21 r=0$. uax $=1$. vdn=-1. nax $=74$ nch=' . fscw' plt=yes end t $l=' x-z$ plane through the bellows wall at $y=-10$.' $x u l=-55 . y u l=-10 . z u l=55 . x l r=55 . y l r=-10.21 r=-55$. uax $=1$. wdn $=-1$. nax $=74 \mathrm{nch}={ }^{\prime} . \mathrm{fscw}^{\prime} \mathrm{plt}=\mathrm{yes}$ end t $l=' x-z$ plane through the bellows wall at $y=10 . '$ $x u l=-55 . y u l=10.2 u l=55 . x l r=55 . y 1 r=10.21 r=-55$. uax $=1$. wan $=-1$. nax $=74$ nch='. fscw' $p l t=y e s$ end tt $l=' x-z$ plane through the egg-crate block at $y=-20$.' $^{\prime}$ $x u l=-6 . y u l=-20 . z u l=6 . x I r=6 . y l r=-20 . z l r=-6$. uax $=1$. wan $=-1$. nax $=74$ nch='. fscw' plt=yes end t $l=' x-z$ plane through the egg-crate block at $y=20$.' xul $=-6$. yul=20. $z u l=6 . x l y=6 . y l r=20 . z l r=-6$. uax $=1$. $w d n=-1$. nax $=74 \mathrm{nch}=$ '.fscw' plt=yes end t $l=' x-z$ plane through the egg-crate block at $y=-20 . '$

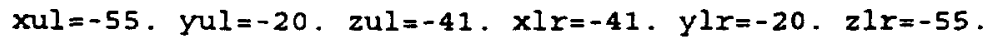
uax $=1$. wdn=-1. nax $=74 \mathrm{nch}=\mathrm{I}^{\prime} . \mathrm{fscw}$ ' plt=yes end $t t l=' x-z$ plane through the egg-cxate block at $y=20$.' $x u l=41 . y u l=20 . z u l=55 . x l r=55 . y l r=20 . z l r=41$. uax $=1$. wdn=-1. nax $=74$ nch='. fscw' plt=yes end $t t l=' x-z$ plane through the egg-crate at $y=-20 . '$ $x u l=-55 . y u l=-20 . z u l=55 . x l r=55 . y l r=-20 . \quad z l r=-55$. uax $=1$. $w d n=-1 . \operatorname{nax}=74 \mathrm{nch}={ }^{\prime} . \mathrm{fscw}^{\prime} \mathrm{plt}=$ yes end $t t l=' x-z$ plane through the egg-crate at $y=20$.' $x u l=-55 . y u l=20 . \quad z u l=55 . x l r=55 . y l r=20 . z l r=-55$. uax $=1$. $w d n=-1$. nax $=74$ nch='. fscw' $p l t=y e s$ end tt $l=' y-z$ plane through the slab tank at $x=0$ ' $x u l=0 . y u l=-35 . \quad z u l=61.7 x l x=0 . y l r=35 . \quad z l r=-61.7$

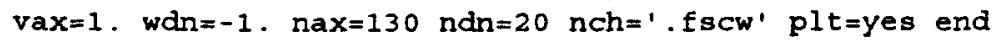
end plot

end data

end 


\section{MIX-SOL-THERM-005}

\section{Water Reflected Experiments}

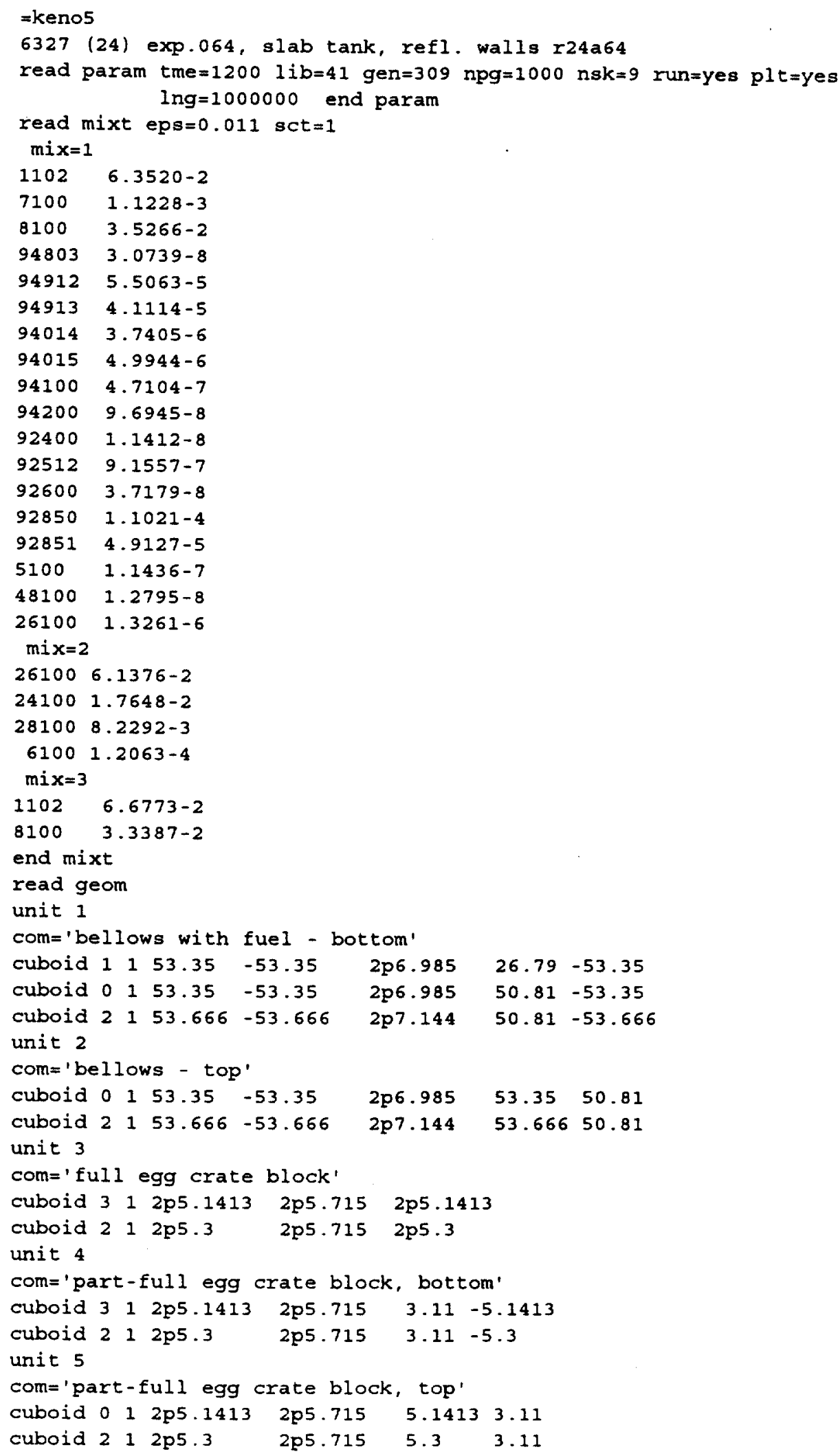


NEA/NSC/DOC

Volume VI

MIX-SOL-THERM-005

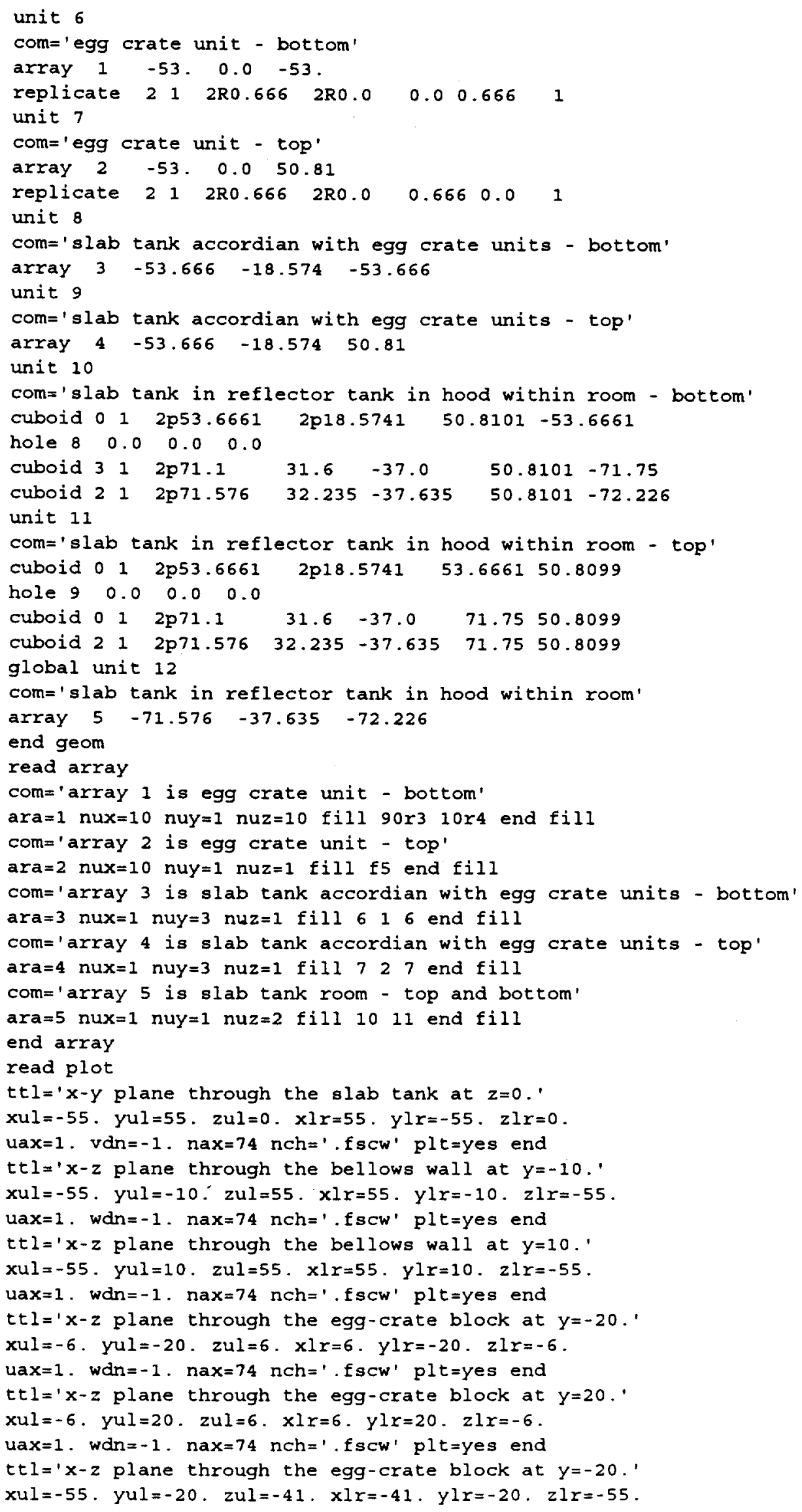

Page 47 
NEANSC/DOC

Volume VI

\section{MLX-SOL-THERM-005}

uax=1. $w d n=-1$. nax $=74$ nch='. fscw' plt=yes end

tt $1=$ ' $x-z$ plane through the egg-crate block at $y=20$.'

$x u l=41$. yul=20. zul=55. $x l r=55 . y l r=20 . z l r=41$.

uax=1. $w d n=-1$. nax $=74$ nch='. fscw' $p 1 t=$ yes end

$t t l=' x-z$ plane through the egg-crate at $y=-20 . '$

$x u l=-55 . y u l=-20 . z u l=55 . x l r=55 . y l r=-20 . z l r=-55$.

uax $=1$. wan $=-1$. nax $=74$ nch='. fscw' plt=yes end

$t t l=' x-z$ plane through the egg-crate at $y=20 . '$

$x u l=-55 . y u l=20 . \quad z u l=55 . x l r=55 . y l r=20.2 l r=-55$.

uax $=1$. $w d n=-1$. nax=74 nch='. fscw' plt=yes end

$t t l=' y-z$ plane through the slab tank at $x=0$ '

$x u l=0 . y u l=-35 . z u l=61.7 \quad x l r=0 . y l r=35 . \quad z l r=-61.7$

$\operatorname{vax}=1$. $\operatorname{wdn}=-1$. $\operatorname{nax}=130 \mathrm{ndn}=20 \mathrm{nch}=1$. fscw' plt=yes end

end plot

end data

end 
MIX-SOL-THERM-005

\section{Sample KENO V.a Input Listing (27-energy-group SCALE-4)}

\section{Bare Experiments}

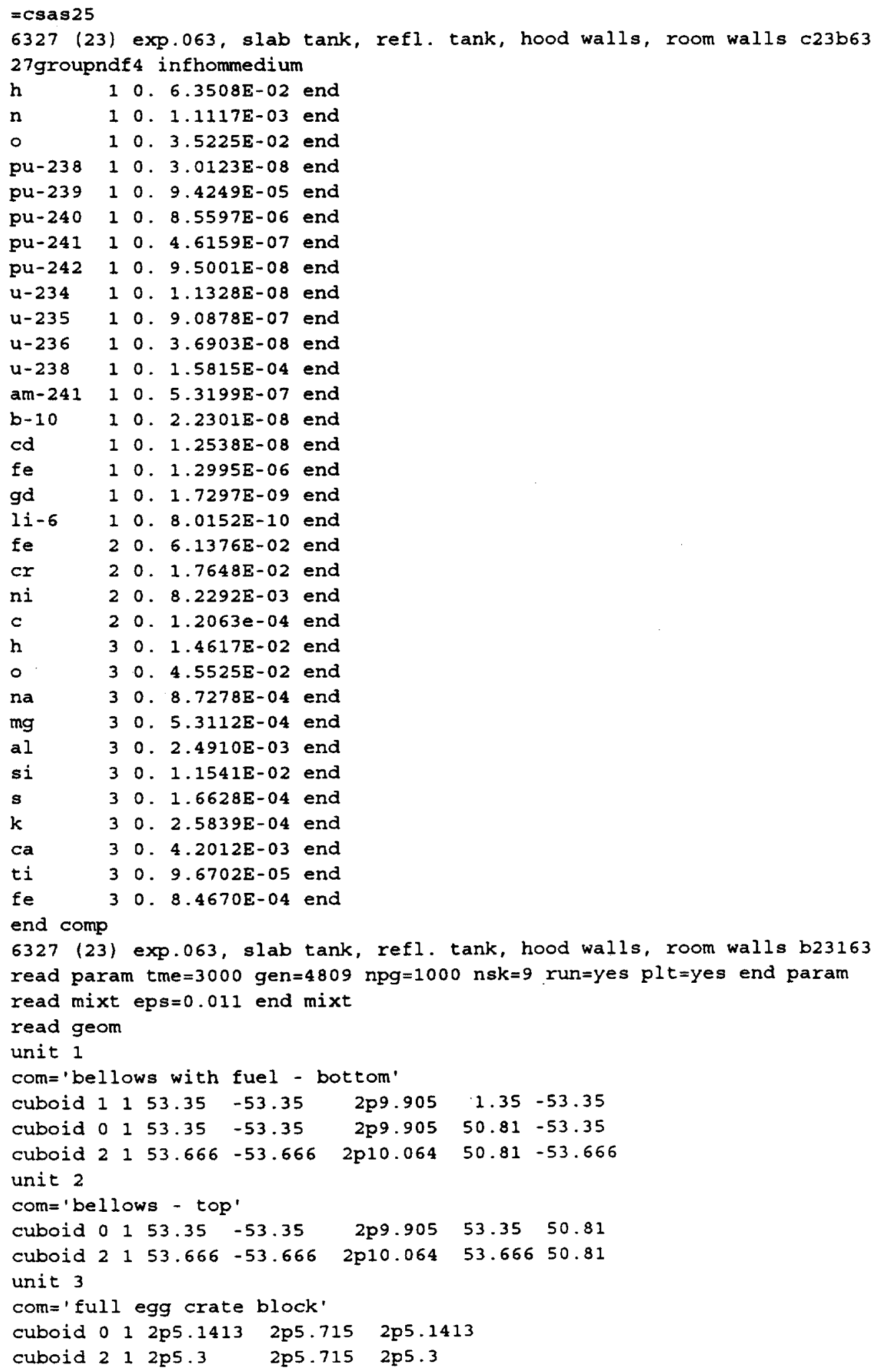




\section{MIX-SOL-THERM-005}

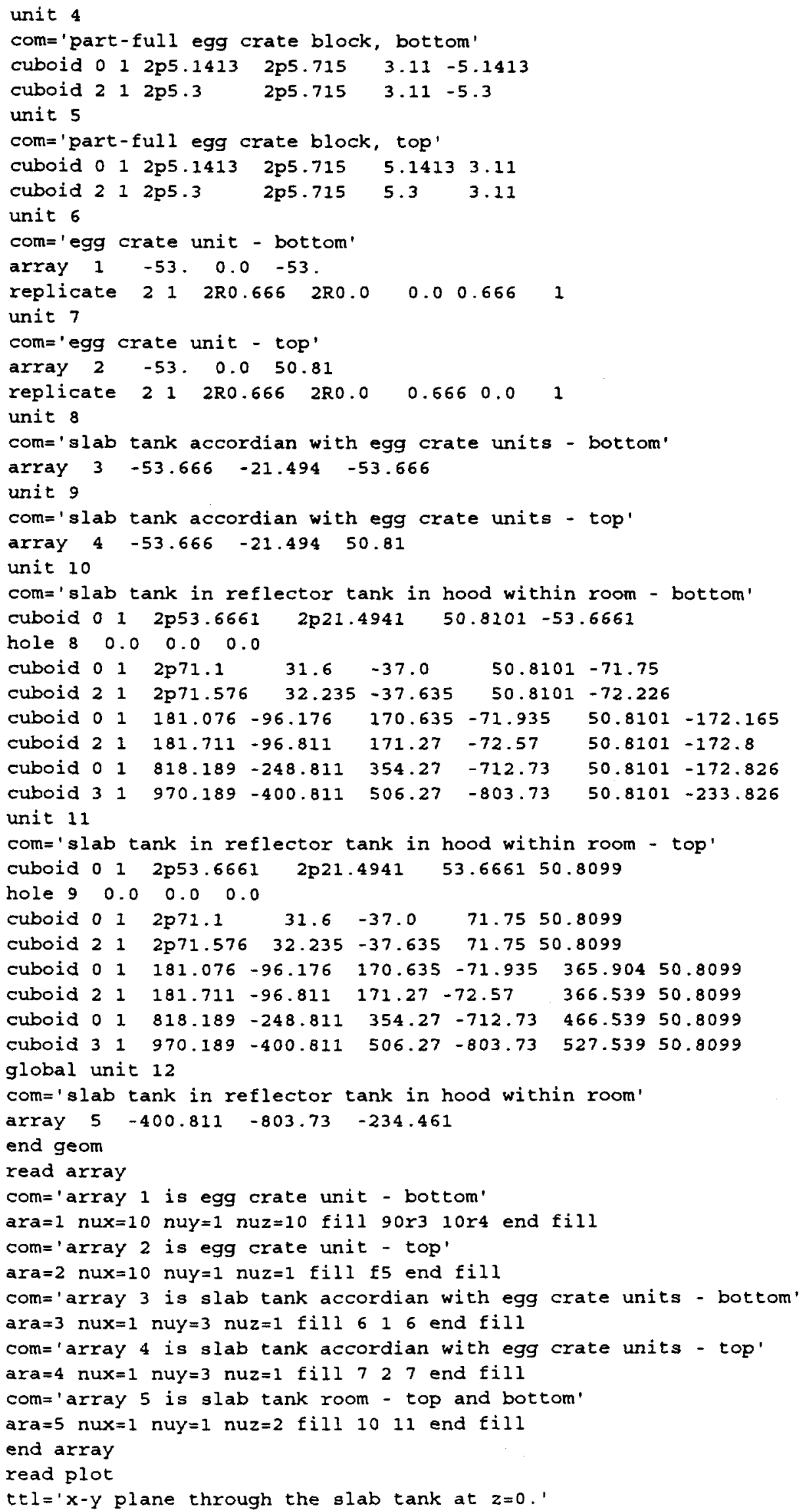




\section{MIX-SOL-THERM-005}

$x u l=-55 . \quad y u l=55 . \quad z u l=0 . x l r=55 . \quad y l r=-55 . \quad z l r=0$. uax $=1$. vdn=-1. nax $=74$ nch='. fscw' $p l t=y e s$ end $t t l=' x-z$ plane through the bellows wall at $y=-10 . '$ $x u l=-55 . y u l=-10 . \quad z u l=55 . x l r=55 . y l r=-10 . z l r=-55$. uax $=1$. wdn=-1. nax $=74$ nch='. fscw' plt=yes end t $l=' x-z$ plane through the bellows wall at $y=10$.' $x u l=-55 . y u l=10 . \quad z u l=55 . x l r=55 . y l r=10 . z l x=-55$. uax $=1$. wdn $=-1$. nax $=74 \mathrm{nch}={ }^{\prime}$. fscw' $\mathrm{plt}=$ yes end t $l=' x-z$ plane through the egg-crate block at $y=-20$.' $x u l=-6 . y u l=-20 . \quad z u l=6 . x l r=6 . y l r=-20.21 r=-6$. $u a x=1$. wdn $=-1$. nax $=74 \mathrm{nch}={ }^{\prime}$. Escw' plt=yes end tt $l=' x-z$ plane through the egg-crate block at $y=20$.' $x u l=-6 . y u l=20.2 u l=6 . x l r=6 . y l r=20 . z l r=-6$. uax $=1$. wdn $=-1$. nax $=74$ nch $=$ '. fscw' plt=yes end $t t l=' x-z$ plane through the egg-crate block at $y=-20 . '$ $x u l=-55 . y u l=-20 . z u l=-41 . x l r=-41 . y l r=-20 . \quad z l r=-55$. uax $=1$. wdn=-1. nax=74 nch='. fscw' plt=yes end ttl='x-z plane through the egg-crate block at $y=20$.' $x u l=41 . y u l=20 . z u l=55 . x l r=55 . \quad y l x=20 . z l r=41$. uax $=1$. wdn=-1. nax $=74$ nch $=$ '. fscw' plt=yes end $t t l=1 x-z$ plane through the egg-crate at $y=-20 .^{\prime}$ $x u l=-55 . y u l=-20, z u l=55 . x 1 r=55 . y l r=-20, z l r=-55$. uax $=1$. wdn $=-1$. nax $=74 \mathrm{nch}={ }^{\prime}$. fscw' plt=yes end $t t 1=' x-z$ plane through the egg-crate at $y=20$.' $x u l=-55 . y u l=20 . \quad z u l=55 . x 1 r=55 . \quad y l r=20 . \quad z l r=-55$. uax $=1$. wan=-1. nax $=74$ nch='. fscw' plt=yes end ttl='y-z plane through the slab tank at $x=0$ ' xul $=0 . y u l=-35 . \quad z u l=61.7 \quad x 1 r=0 . y 1 r=35 . \quad z l r=-61.7$ $\operatorname{vax}=1$. wdn $=-1$. nax=130 ndn=20 nch='.fscw' plt=yes end end plot

end data end 
NEANSC/DOC

Volume VI

MIX-SOL-THERM-005

\section{Water Reflected Experiments}

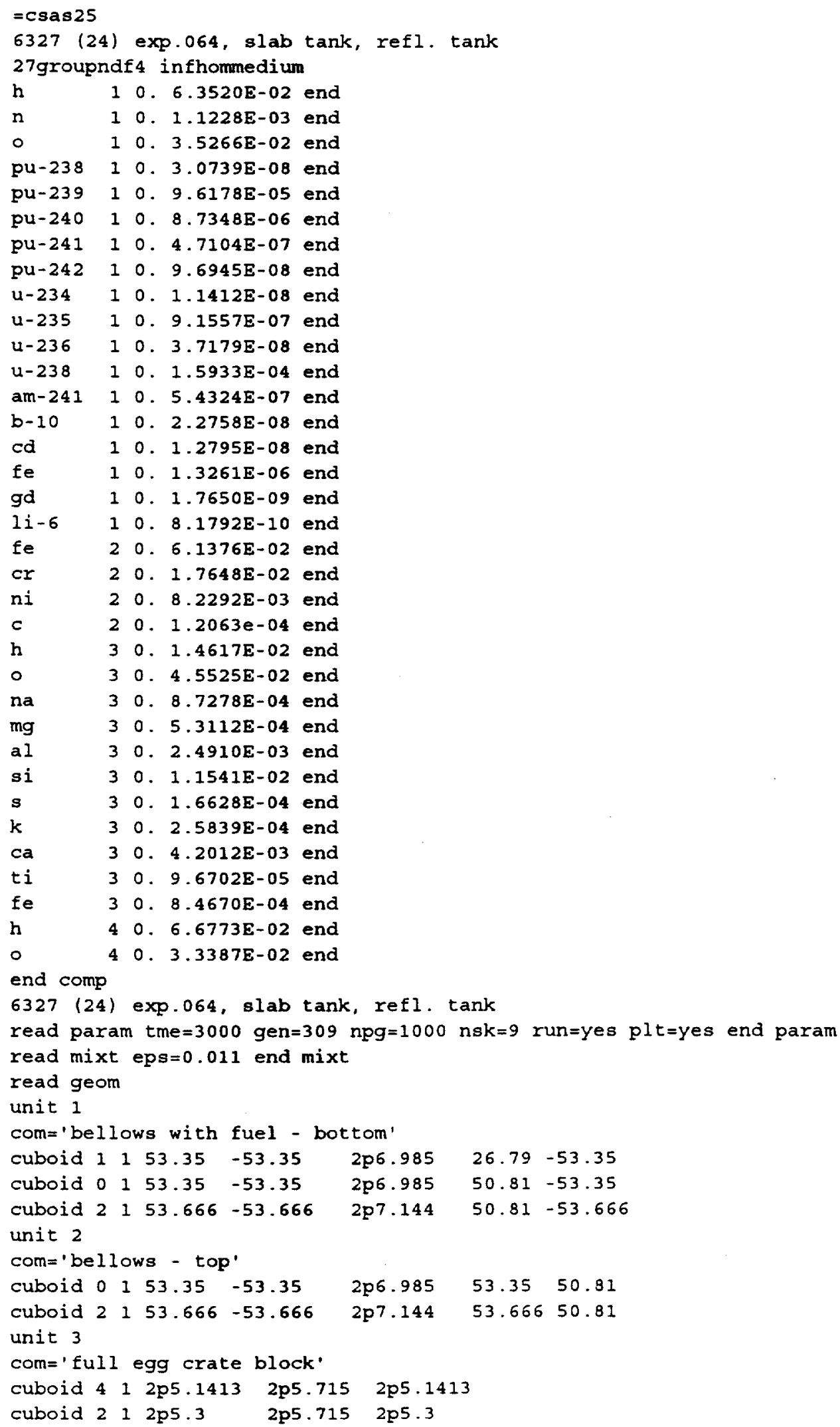




\section{MIX-SOL-THERM-005}

unit 4

com='part-full egg crate block, bottom'

$\begin{array}{lllllll}\text { cuboid } 4 & 1 & 2 \mathrm{p} 5.1413 & 2 \mathrm{p} 5.715 & 3.11 & -5.1413 \\ \text { cuboid } 2 & 1 & 2 \mathrm{p} 5.3 & 2 \mathrm{p} 5.715 & 3.11 & -5.3\end{array}$

unit 5

com='part-full egg crate block, top'

$\begin{array}{llllll}\text { cuboid } 0 & 1 & 2 p 5.1413 & 2 p 5.715 & 5.1413 & 3.11 \\ \text { cuboid } 2 & 1 & 2 p 5.3 & 2 p 5.715 & 5.3 & 3.11\end{array}$

unit 6

com='egg crate unit - bottom'

array $1 \quad-53$. $0.0 \quad-53$.

replicate $2 \begin{array}{lllllll}2 & 1 & 2 R 0.666 & 2 R 0.0 & 0.0 & 0.666 & 1\end{array}$

unit 7

com='egg crate unit - top'

$\begin{array}{lllll}\text { array } 2 & -53.0 .0 & 50.81\end{array}$

replicate $\begin{array}{lllllll}2 & 1 & 2 \mathrm{R} 0.666 & 2 \mathrm{RO} 0.0 & 0.666 & 0.0 & 1\end{array}$

unit 8

com='slab tank accordian with egg crate units - bottom'

$\begin{array}{lllll}\text { array } & 3 & -53.666 & -18.574 & -53.666\end{array}$

unit 9

com='slab tank accordian with egg crate units - top'

$\begin{array}{lllll}\text { array } 4 & -53.666 & -18.574 & 50.81\end{array}$

unit 10

com='slab tank in reflector tank in hood within room - bottom'

$\begin{array}{lllllll}\text { cuboid } 0 & 1 & 2 p 53.6661 & 2 p 18.5741 & 50.8101 & -53.6661\end{array}$

hole $8 \quad 0.0 \quad 0.0 \quad 0.0$

$\begin{array}{lllllll}\text { cuboid } 4 & 1 & 2 \mathrm{p} 71.1 & 31.6 & -37.0 & 50.8101 & -71.75\end{array}$

$\begin{array}{llllllll}\text { cuboid } 2 & 1 & 2 \mathrm{p} 71.576 & 32.235 & -37.635 & 50.8101 & -72.226\end{array}$

unit 11

com='slab tank in reflector tank in hood within room - top'

cuboid $0102 p 53.6661 \quad 2 p 18.5741 \quad 53.666150 .8099$

hole $90.0 \quad 0.0 \quad 0.0$

$\begin{array}{lllllll}\text { cuboid } 0 & 1 & 2 p 71.1 & 31.6 & -37.0 & 71.75 & 50.8099\end{array}$

$\begin{array}{lllllll}\text { cuboid } 2 & 1 & 2 p 71.576 & 32.235 & -37.635 & 71.75 & 50.8099\end{array}$

global unit 12

com='slab tank in reflector tank in hood within room'

$\begin{array}{llll}\text { array } 5 & -71.576 & -37.635 & -72.226\end{array}$

end geom

read array

com='array 1 is egg crate unit - bottom'

ara=1 nux=10 nuy=1 nuz=10 fill $90 \times 3$ 10r4 end fill

com='array 2 is egg crate unit - top'

ara=2 nux=10 nuy=1 nuz=1 fill f5 end fill

com='array 3 is slab tank accordian with egg crate units - bottom'

ara=3 nux=1 nuy=3 nuz=1 fill $6 \quad 1 \quad 6$ end fill

com='array 4 is slab tank accordian with egg crate units - top'

ara=4 nux=1 nuy=3 nuz=1 fill 727 end fill

com='array 5 is slab tank room - top and bottom'

ara=5 nux=1 nuy=1 nuz=2 fill 1011 end fill

end array

read plot

tt $l=$ ' $x-y$ plane through the slab tank at $z=0$.'

$x u l=-55 . y u l=55 . \quad z u l=0 . x 1 r=55 . y 1 r=-55 . \quad z l r=0$.

uax $=1$. vdn=-1. nax $=74 \mathrm{nch}={ }^{\prime}$. fscw' plt=yes end

$t t l=' x-z$ plane through the bellows wall at $y=-10 . '$

xul $=-55 . y u l=-10 . \quad z u l=55 . x l r=55 . y l r=-10 . z l r=-55$.

uax $=1$. wdn=-1. nax $=74$ nch='. fscw' plt=yes end

$t t l=' x-z$ plane through the bellows wall at $y=10 . '$

$x u l=-55 . y u l=10 . z u l=55, x l r=55 . y l r=10 . z l r=-55$.

uax $=1$. wdn $=-1$. $\operatorname{nax}=74 \mathrm{nch}={ }^{\prime}$. fscw' $\mathrm{plt}=$ yes end 
MIX-SOL-THERM-005

$t t l=' x-z$ plane through the egg-crate block at $y=-20$.' $x u l=-6$. yul $=-20$. zul $=6 . x l r=6 . y l r=-20 . z l r=-6$. uax $=1$. $w d n=-1$. nax $=74$ nch $='$. fscw' $p l t=y e s$ end $t t l=\prime x-z$ plane through the egg-crate block at $y=20$.' $x u l=-6 . y u l=20 . \quad z u l=6 . x l r=6 . y l r=20 . z 1 r=-6$. uax $=1$. wan $=-1$. nax $=74$ nch ${ }^{\prime}$. fsch' $p l t=y e s$ end tt $l=' x-z$ plane through the egg-crate block at $y=-20$.' $\mathrm{xul}=-55$. yul $=-20 . \quad z u l=-41 . x \mathrm{l} r=-41 . y \operatorname{lr}=-20 . \quad z l r=-55$. uax $=1$. wdn=-1. nax $=74 \mathrm{nch}={ }^{\prime}$. fscw' $p l t=y e s$ end $t t l=' x-z$ plane through the egg-crate block at $y=20$.' $x u l=41 . y u l=20$. zul $=55 . x I r=55$. ylr $=20 . z \operatorname{lr}=41$. uax $=1$. $w d n=-1$. nax $=74$ nch $=$ '. fscw' $p l t=y e s$ end tt $1=$ ' $x-z$ plane through the egg-crate at $y=-20 . '$ $x u l=-55 . y u l=-20 . z u l=55 . x l y=55 . y l r=-20 . \quad z l r=-55$. uax $=1$. wdn=-1. nax $=74 \mathrm{nch}={ }^{\prime}$. Escw' $p l t=y e s$ end tt $1=' x-z$ plane through the egg-crate at $y=20$.' $x u l=-55 . y u l=20 . \quad z u l=55 . x l r=55 . y l r=20 . z l r=-55$. uax $=1$. wdn=-1. nax $=74$ nch='.fscw' plt=yes end $t t l=' y-z$ plane through the slab tank at $x=0$ ' $x u l=0 . y u l=-35 . \quad z u l=61.7 \quad x l r=0 . y l r=35 . z l r=-61.7$ $\operatorname{vax}=1$. $\operatorname{wdn}=-1$. $\operatorname{nax}=130 \mathrm{ndn}=20 \mathrm{nch}=$ '. fscw' plt=yes end end plot end data end 
MIX-SOL-THERM-005

\section{A.2 MCNP Input Listings}

MCNP version 4a was run with the ENDF/B-V cross section library for all materials except for natural gadolinium for which the cross sections were extracted from the ENDL-85 library. MCNP was run for 440 generations of 3000 neutrons per generation. Forty generations were skipped before averaging, so the results are an average of $1,200,000$ neutron histories.

Because of number rounding of the individual cells, and the increase in exterior dimensions necessitated by the model simplification process, an additional $0.5087 \mathrm{~cm}$ of stainless steel is added to the top and bottom, and east and west perimeter of the egg-crate assembly to match the exterior surfaces of the slab tank. 


\section{Sample MCNP Input Listing (ENDF/B-V cross section library)}

MCNP4a was run using 440 generations with 3000 neutrons per generation. Forty generations were skipped before averaging, so the results are an average of $1,200,000$ neutron histories.

\section{Bare Experiments}

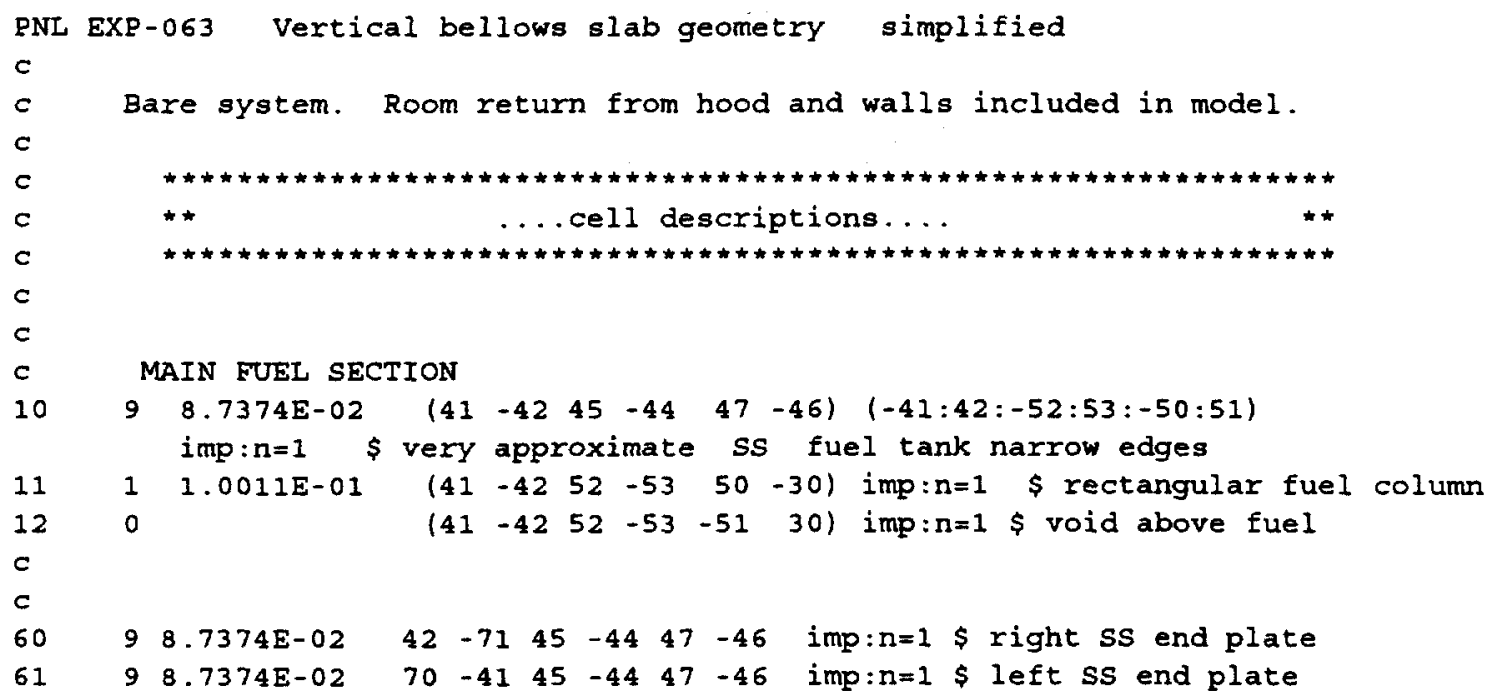

SQUARE LATTICE STAINLESS STEEL SUPPORT GRID

$09.7374 E-02 \quad(-500: 502: 504:-506: 76:-71)$

$\left(\begin{array}{lllll}47-46-44 & 45-76 & 71\end{array}\right)$ imp: $n=1$ s steel walls of right grid holding box

$7198.7374 \mathrm{E}-02 \quad(-500: 502: 504:-506:-75: 70)$

$\left(\begin{array}{lllll}47-46 & -44 & 45 & -70 & 75\end{array}\right)$ imp:n=1 $\$$ steel walls of left grid holding box

c

$100 \quad 0500-502-504506-7671$ fill=5 imp:n=1 \$inner right holding box to be filled

$200 \quad 0 \quad 500-502-504506-7075$ fill=5 imp:n=1 \$inner left holding box to be filled

$c$

$c$

c

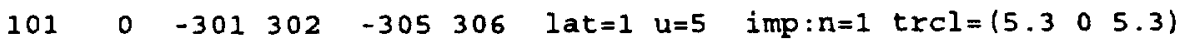

fill $=-5: 4-5: 40: 0 \quad 20$ 89r 30 9r $\$$ repeated unit cell with upper layer partly

filled

1020

103

$\begin{array}{llll}-401 & 402 & -405406\end{array}$

$8.7374 E-02$

(401:-402:405:-406)

$\mathrm{u}=20$ imp $: \mathrm{n}=1$

$\$$ innermost unit cell

cell

104

1050

106

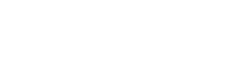

$(-401402 \quad-405406) \quad 304 \quad u=30$

$(-401 \quad 402 \quad-405 \quad 406) \quad-304 \quad u=30$

imp: $n=1$

$\$$ unbounded outside of unit

cell

8. $7374 E-02$

(401:-402:405:-406)

imp : $n=1$

$\$$ void innermost unit cell

imp: $n=1$. \$ innermost unit cell

$c$

c

c

C

$900 \quad(1-75: 76:-47: 46:-45: 44)$ 
NEA/NSC/DOC

Volume VI

\section{MIX-SOL-THERM-005}

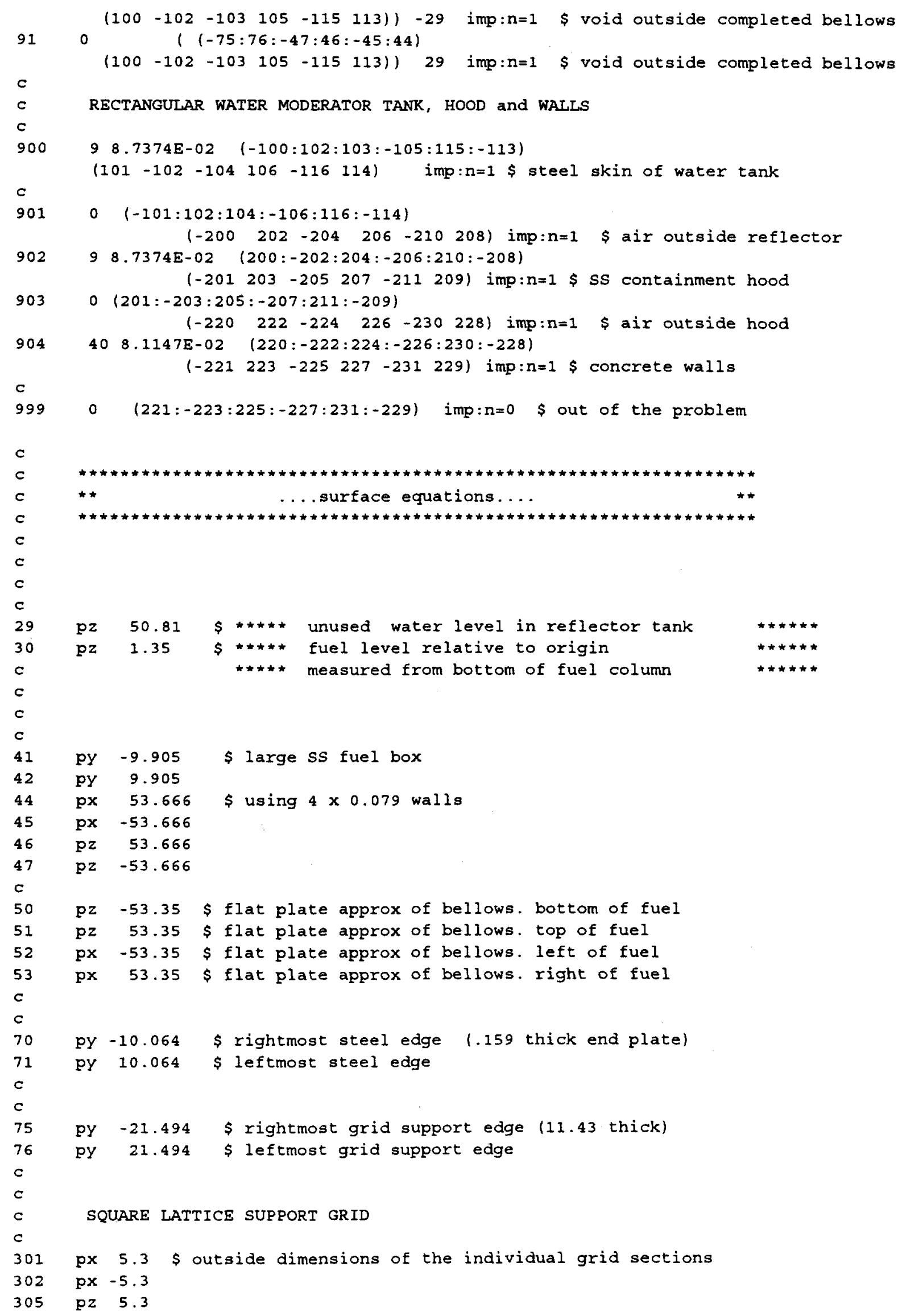


MIX-SOL-THERM-005

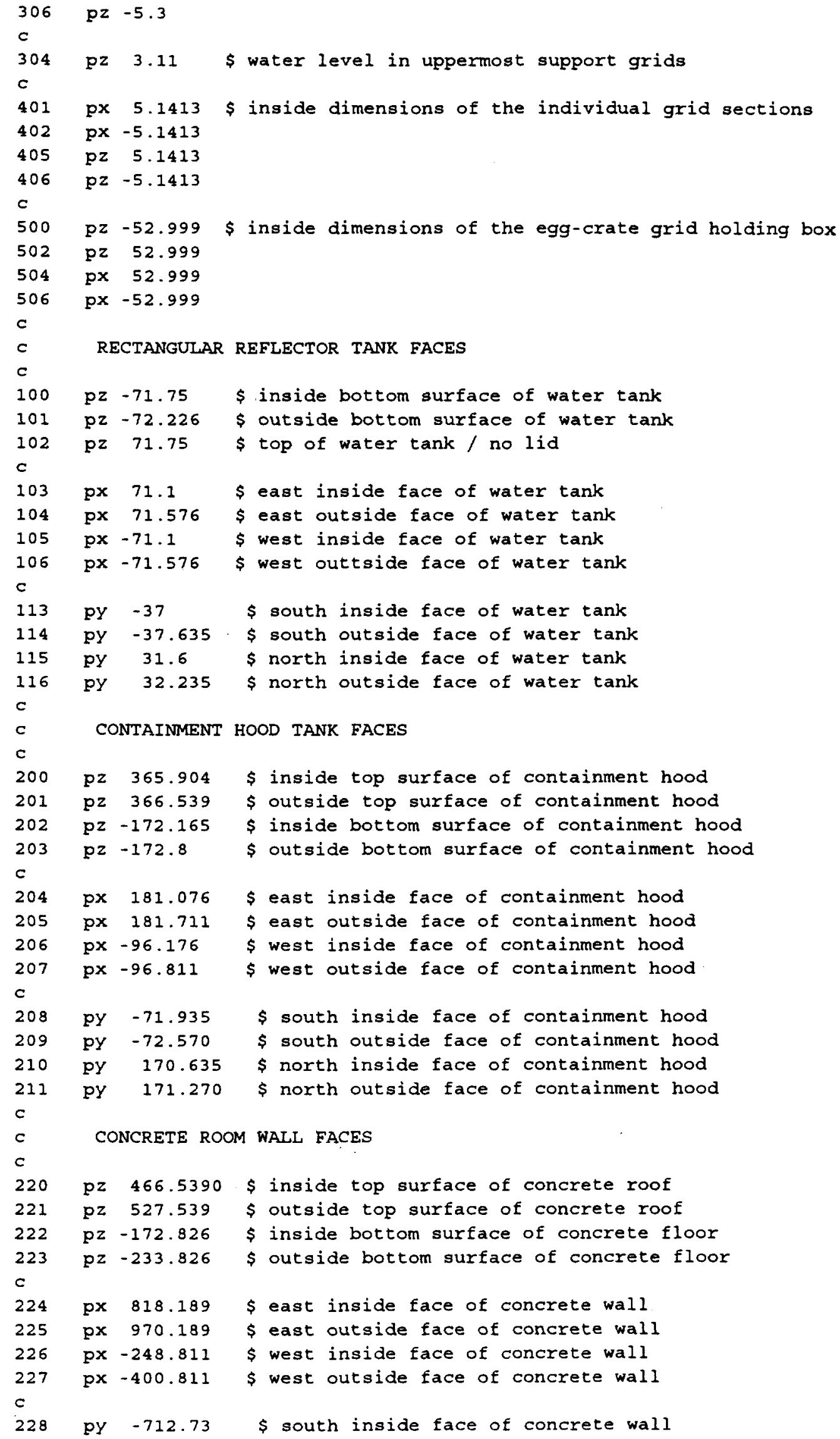

\section{c CONCRETE ROOM WALL FACES}

$\$$ inside top surface of concrete roof

$\$$ outside top surface of concrete roof

$\$$ inside bottom surface of concrete floor

$\$$ outside bottom surface of concrete floor

$\$$ east inside face of concrete wall

$\$$ east outside face of concrete wall

$\$$ west inside face of concrete wall

$\$$ west outside face of concrete wall 
NEANSC/DOC

Volume VI

\section{MIX-SOL-THERM-005}

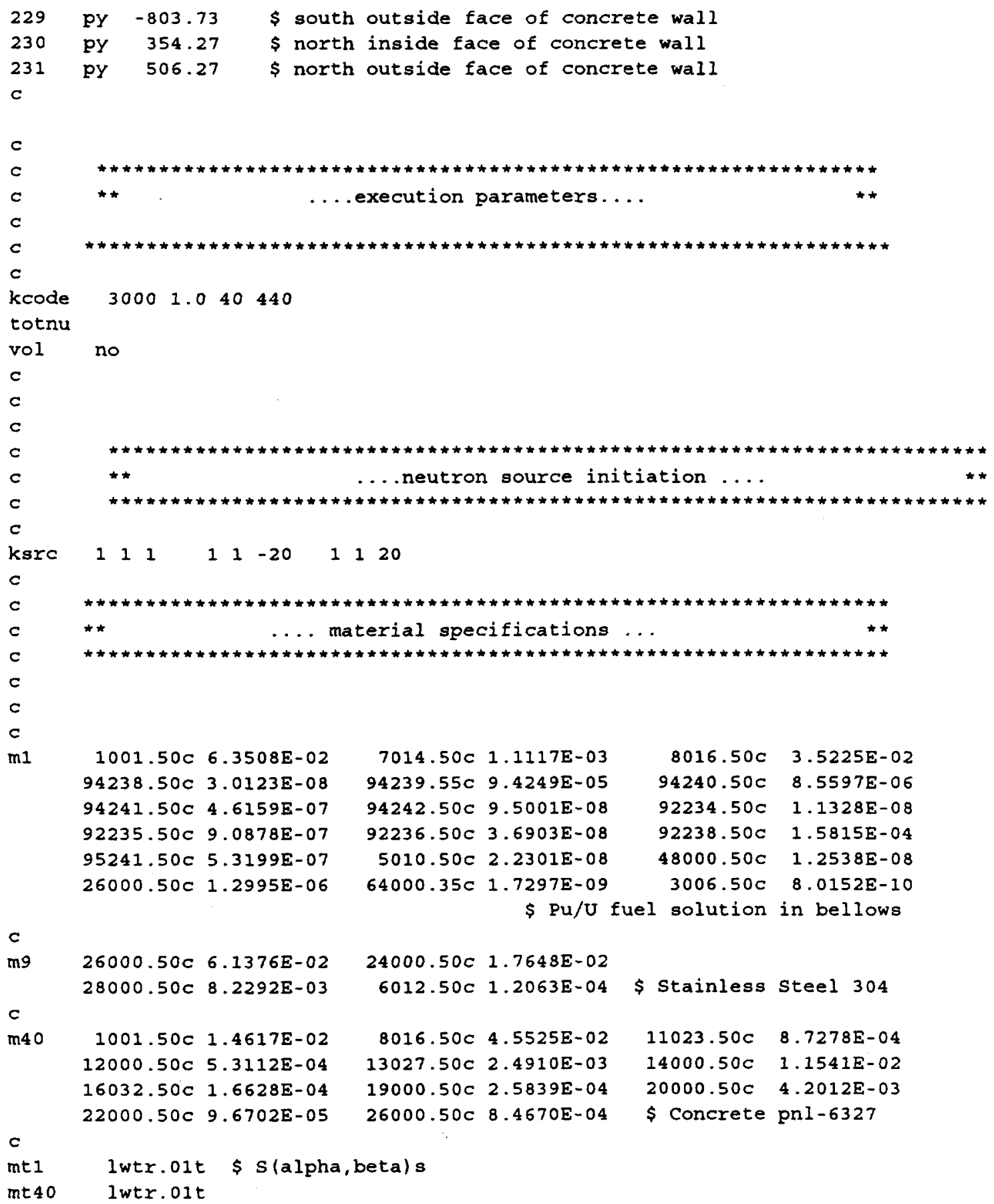


NEANSC/DOC

Volume VI

MIX-SOL-THERM-00S

\section{Water Reflected Experiments}

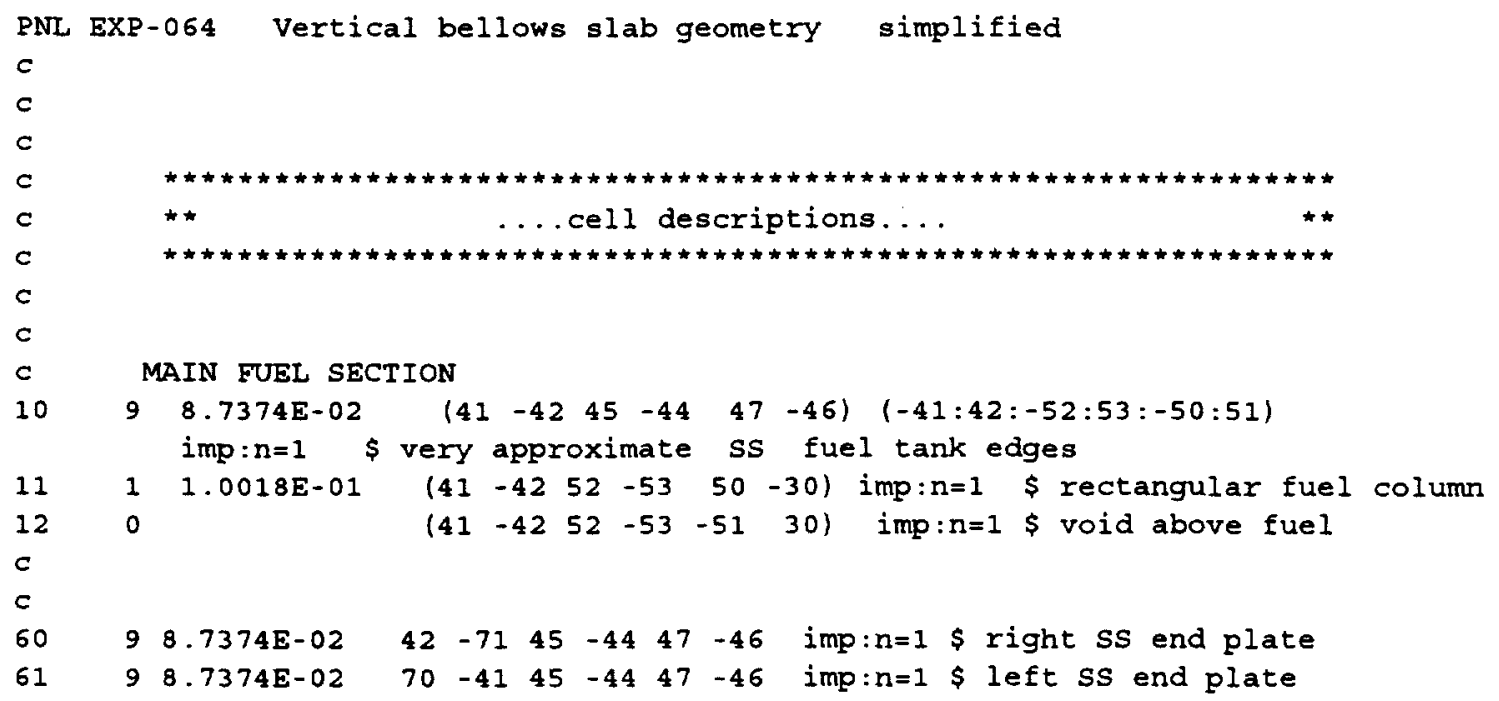

SQUARE LATTICE STAINLESS STEEL SUPPORT GRID 
NEANSC/DOC

Volume VI

\section{MIX-SOL-THERM-005}

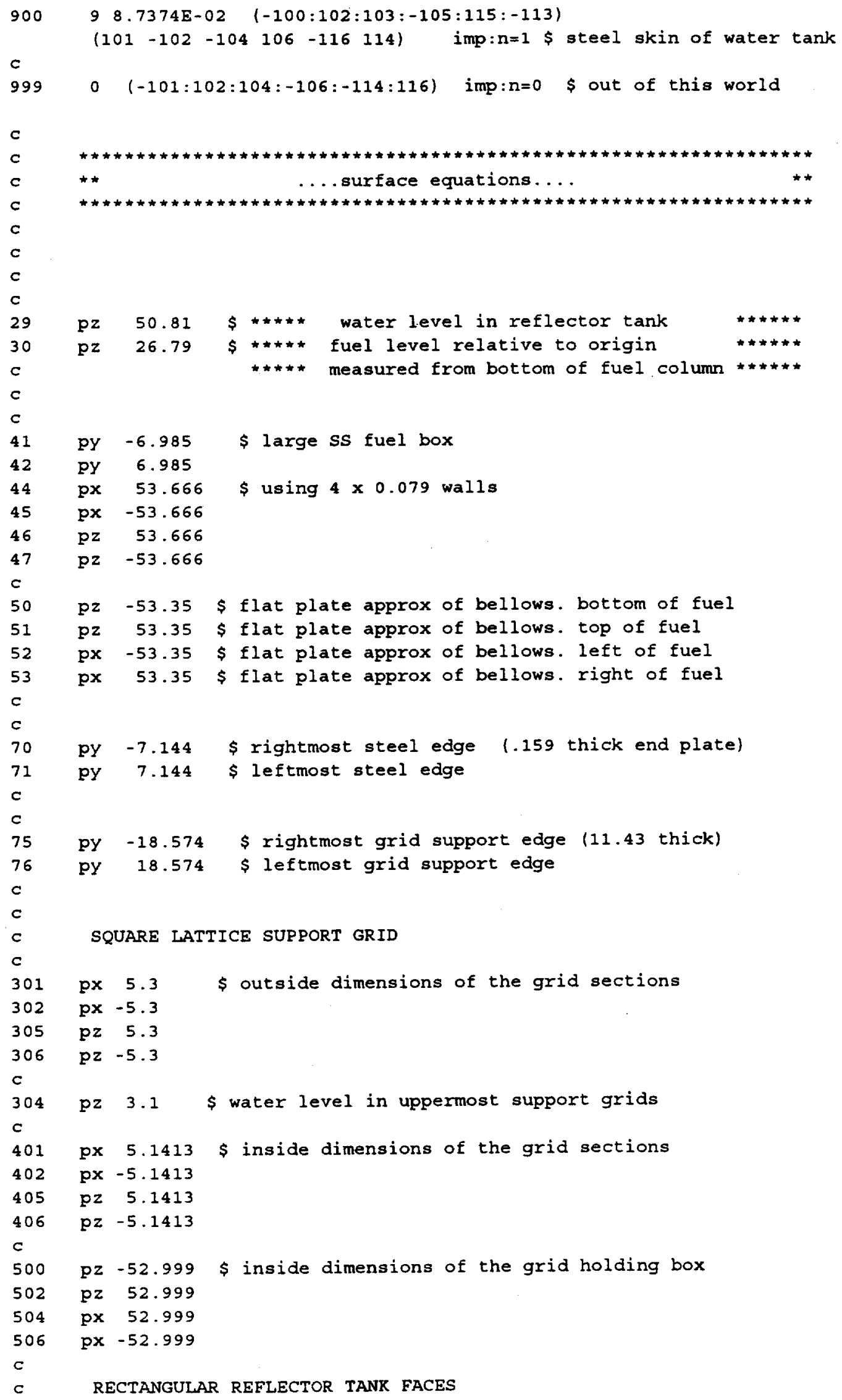




\section{NEANNSC/DOC}

Volume VI

\section{MIX-SOL-THERM-005}

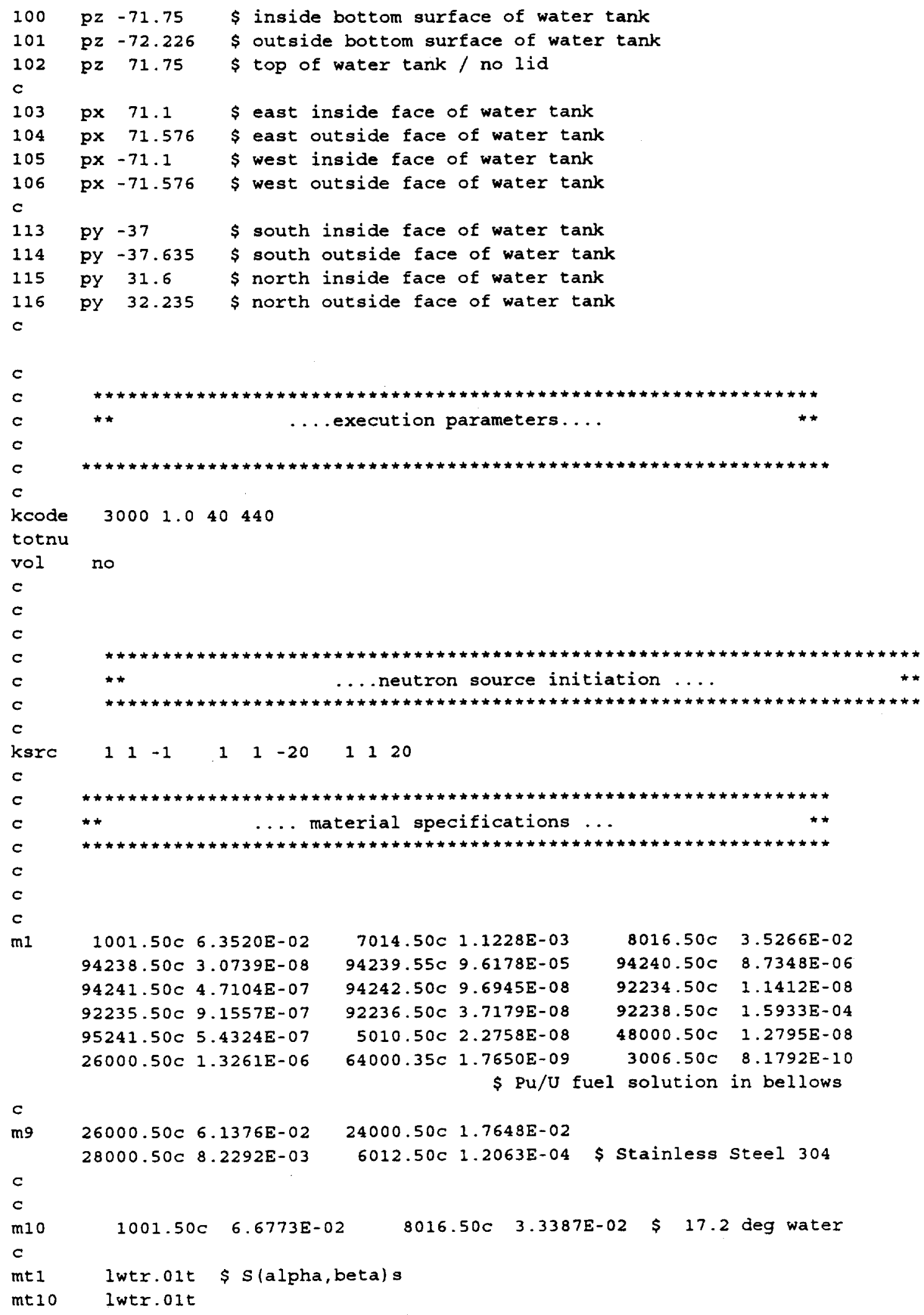




\section{APPENDIX B: DETAILED MODEL}

This detailed model was constructed to verify the adequacy of the simplified benchmark model and for use in the sensitivity study to determine the appropriate thickness of the flat plates that would replace the pleats.

MCNP4a was run using 440 generations with 3000 neutrons per generation. Forty generations were skipped before averaging, so the results are an average of $1,200,000$ neutron histories.

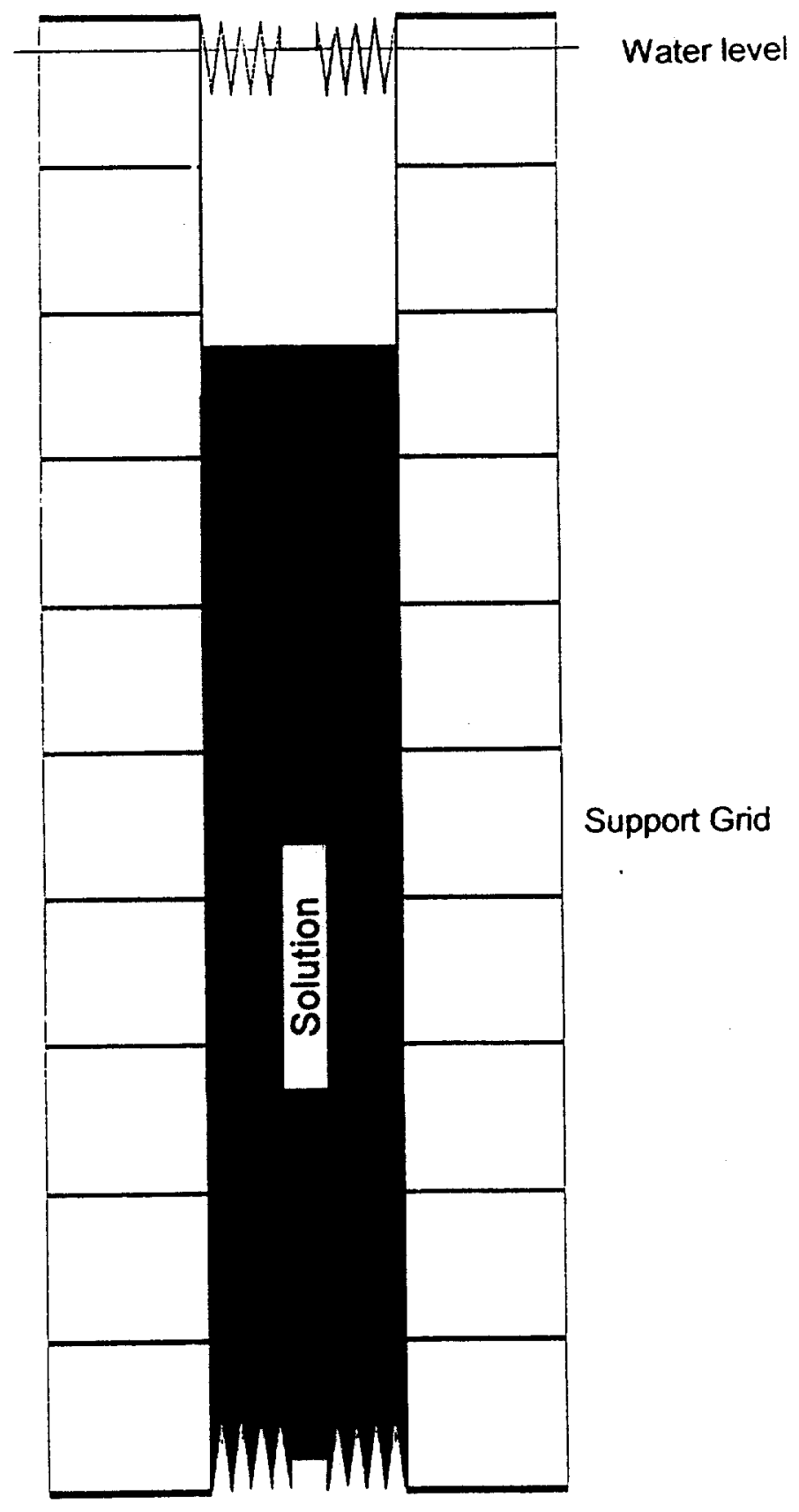

Figure 12. Detailed Model of the Reaction Vessel with Pleated Bellows Assembly 


\section{MCNP Input listing of Detailed Model}

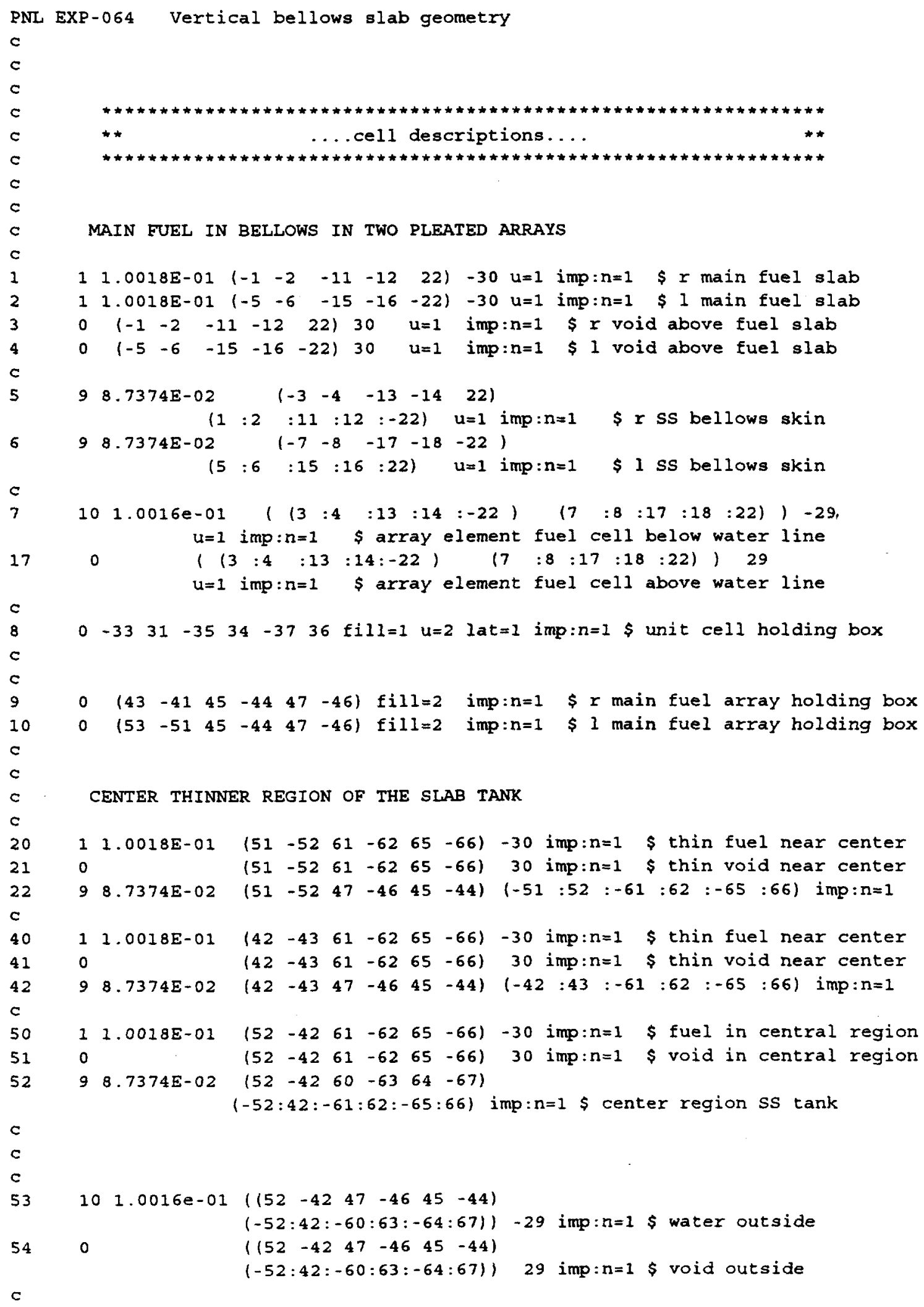

\section{MAIN FUEL IN BELLOWS IN TWO PLEATED ARRAYS}

$11.0018 \mathrm{E}-01 \quad(-1-2 \quad-11-12 \quad 22)-30 \mathrm{u}=1$ imp: $\mathrm{n}=1$ \$ $\mathrm{r}$ main fuel slab

$11.0018 E-01(-5-6 \quad-15-16-22)-30 u=1$ imp: $n=1$ \$ 1 main fuel slab

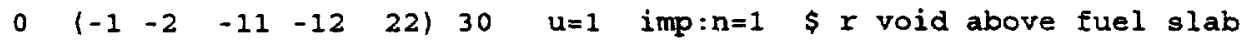

$0 \quad\left(\begin{array}{llllll}-5 & -6 & -15 & -16 & -22\end{array}\right) \quad 30 \quad u=1 \quad i m p: n=1 \quad \$ 1$ void above fuel slab

$98.7374 \mathrm{E}-02 \quad\left(\begin{array}{lllll}-3 & -4 & -13 & -14 & 22\end{array}\right)$

$(1: 2: 11: 12:-22) \quad u=1$ imp: $n=1 \quad \$ r$ ss bellows skin

$98.7374 E-02 \quad(-7-8 \quad-17-18-22)$

$(5: 6: 15: 16: 22) \quad u=1$ imp: $n=1 \quad$ \& 1 sS bellows skin

$101.0016 \mathrm{e}-01(13: 4: 13: 14:-22)(7: 8: 17: 18: 22) \quad(29$, $u=1$ imp: $n=1$ a array element fuel cell below water line

0 $((3: 4: 13: 14:-22) \quad(7: 8: 17: 18: 22)) \quad 29$ $\mathrm{u}=1$ imp:n=1 \$array element fuel cell above water line

$0-33 \quad 31-3534-3736$ fill=1 $u=2$ lat=1 imp:n=1 \$ unit cell holding box

$0 \quad\left(\begin{array}{llllll}43 & -41 & 45 & -44 & 47 & -46\end{array}\right) \quad f i l l=2 \quad i m p: n=1 \quad \$ \quad r$ main fuel array holding box $0 \quad\left(\begin{array}{llllll}53 & -51 & 45 & -44 & 47 & -46\end{array}\right)$ fill=2 imp:n=1 $\$ 1$ main fuel array holding box

CENTER THINNER REGION OF THE SLAB TANK 


\section{NEANNSC/DOC}

Volume VI

\section{MIX-SOL-THERM-005}

$\begin{array}{llllllllll}60 & 9 & 8.7374 E-02 & 41 & -70 & 45 & -44 & 47 & -46 & \text { imp:n=1 } \$ \text { right ss end plate } \\ 61 & 9 & 8.7374 E-02 & 71 & -53 & 45 & -44 & 47 & -46 & \text { imp:n=1 } \$ \text { left ss end plate }\end{array}$

c

70

71

100

200

c

$c$

$1010-301302-305306 \quad l a t=1 \quad u=5 \quad i m p: n=1 \quad t r c l=\left(\begin{array}{llllll}5.3 & 0 & 5.3\end{array}\right)$

fill $=-5: 4 \quad-5: 4$ 0:0 $2089 \mathrm{r} 30$ 9r $\$$ repeated unit cell with upper layer partly

filled

$102 \quad 101.0016 e-01 \quad-401402 \quad-405 \quad 406$

$10398.7374 \mathrm{E}-02 \quad(401:-402: 405:-406)$

$(47-46)(1-500: 502: 504:-506: 75:-70)$

SQUARE LATTICE STAINLESS STEEL SUPPORT GRID

$9 \quad 8.7374 E-02 \quad(-500: 502: 504:-506: 75:-70)$

74E-02 (-500:502:504:-506:-76:71)

$(47-46-4445-7176)$ imp: $n=1$ s steel walls of left grid holding box

cell

$1040 \quad(-401402 \quad-405406) \quad 304 \quad u=30 \quad i m p: n=1$

$105101.0016 e-01 \quad(-401402 \quad-405406)-304 u=30 \quad i m p: n=1$

$10698.7374 \mathrm{E}-02 \quad(401:-402: 405:-406) \quad u=30 \quad i m p: n=1$

cel1

c

$c$

c

c

$90 \quad 101.0016 \mathrm{e}-01 \quad(1-76: 75:-47: 46:-45: 44)$

$(100-102-103105-113$ 115)) -29 imp:n=1 \$ water outside completed bellows

$910 \quad(\{-76: 75:-47: 46:-45: 44)$

$(100-102-103105-113115)) \quad 29$ imp:n=1 $\$$ void outside completed bellows

c RECTANGULAR WATER MODERATOR TANK

$c$

$90098.7374 \mathrm{E}-02 \quad(-100: 102: 103:-105: 113:-115)$

$(101-102-104106-114$ 116) imp:n=1 $\$$ steel skin of water tank

c

$9990(-101: 102: 104:-106: 114:-116)$ imp:n=0 $\$$ out of this world

c

c

c

c

c

c

c

of bellows

SPECIFY ONE PLEAT OF THE BELLOWS TO BE REPEATED

$2 \quad \mathrm{p} \quad-52.7654 \quad 0 \quad-52.7654 \quad-52.7654 \quad .6944 \quad-47.6744 \quad 52.7654 \quad 0 \quad-52.7654 \quad \$ \quad r \quad$ wedge

bottom of bellows

c

3

SS

.... surface equations....

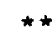

$\star \star$

$\$$ unbounded outside of unit

$\$$ void innermost unit cell

$\$$ innermost unit cell

\$ unbounded outside of unit 
NEA/NSC/DOC

Volume VI

MIX-SOL-THERM-005

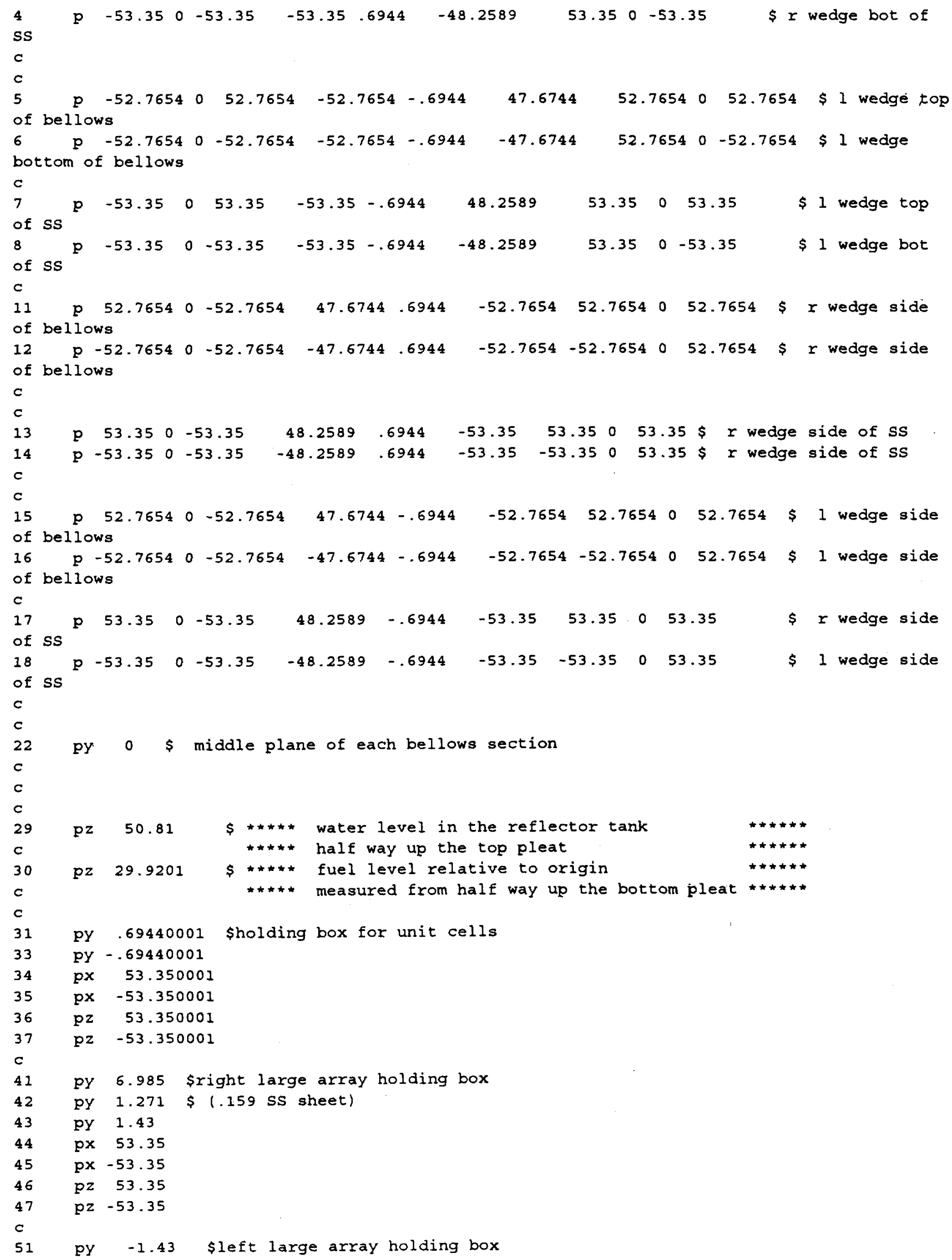

Page 66 


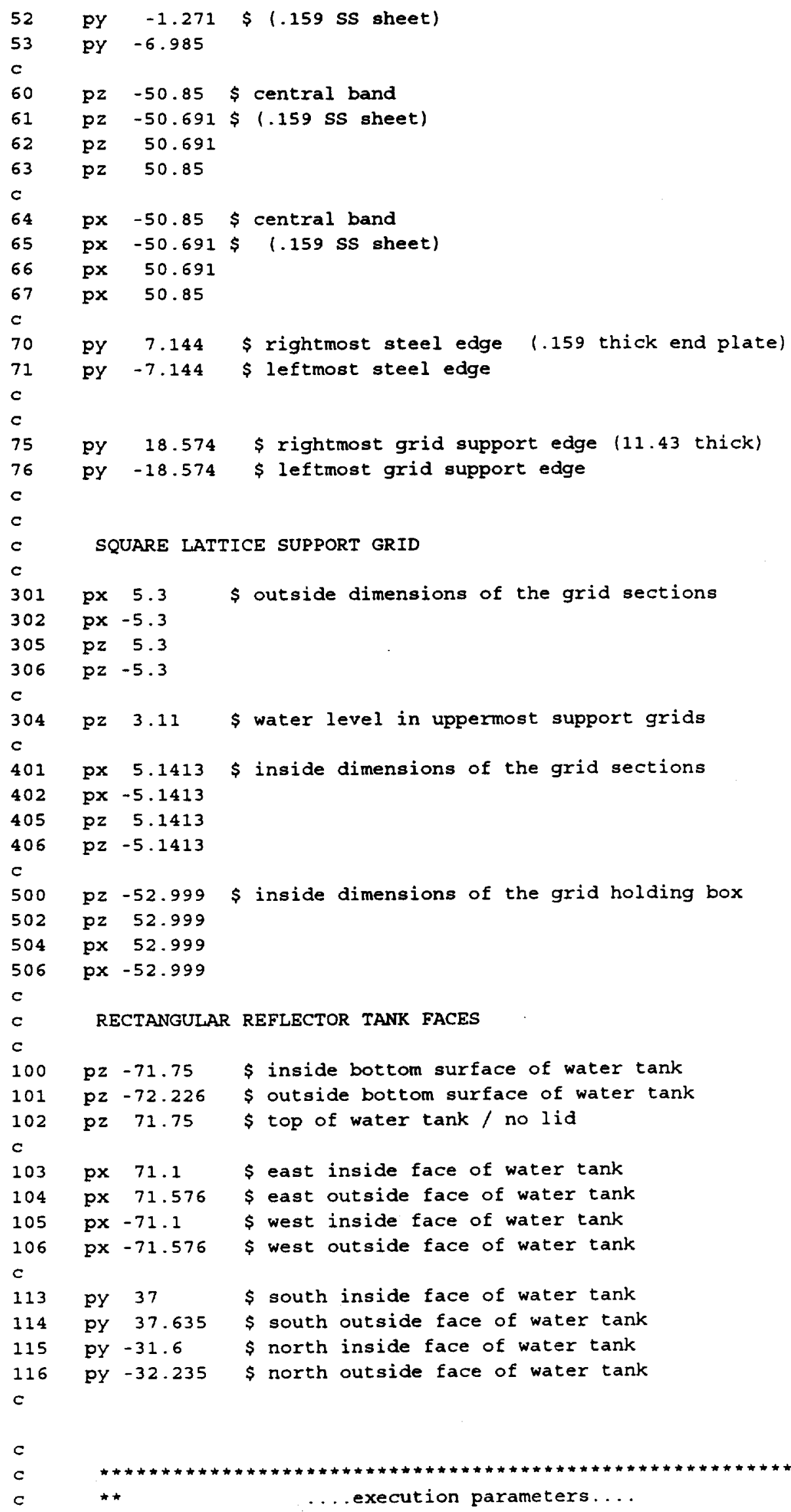


NEA/NSC/DOC

Volume VI

MLX-SOL-THERM-005

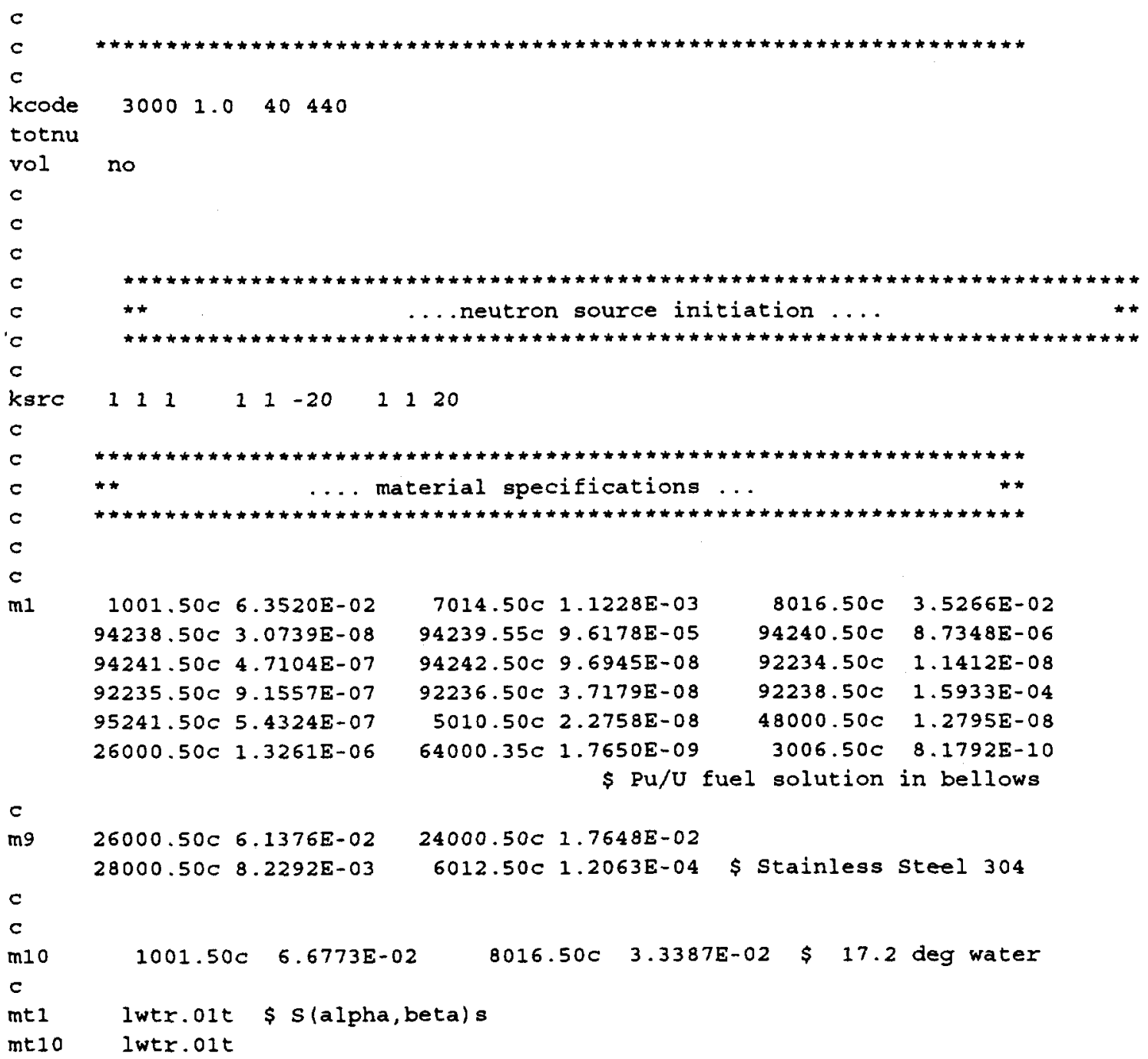




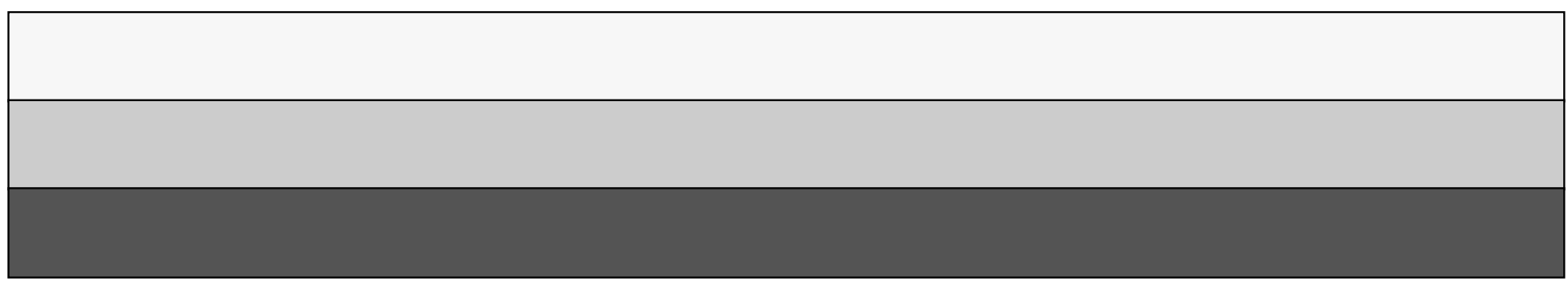

